\title{
WestVirginiaUniversity
}

THE RESEARCH REPOSITORY @ WVU

Graduate Theses, Dissertations, and Problem Reports

2011

\section{Improving Student Coaches' Learning through Teaching Reflective Techniques}

Wesley R. Meeteer II

West Virginia University

Follow this and additional works at: https://researchrepository.wvu.edu/etd

\section{Recommended Citation}

Meeteer, Wesley R. II, "Improving Student Coaches' Learning through Teaching Reflective Techniques" (2011). Graduate Theses, Dissertations, and Problem Reports. 3372.

https://researchrepository.wvu.edu/etd/3372

This Dissertation is protected by copyright and/or related rights. It has been brought to you by the The Research Repository @ WVU with permission from the rights-holder(s). You are free to use this Dissertation in any way that is permitted by the copyright and related rights legislation that applies to your use. For other uses you must obtain permission from the rights-holder(s) directly, unless additional rights are indicated by a Creative Commons license in the record and/ or on the work itself. This Dissertation has been accepted for inclusion in WVU Graduate Theses, Dissertations, and Problem Reports collection by an authorized administrator of The Research Repository @ WVU.

For more information, please contact researchrepository@mail.wvu.edu. 
Improving Student Coaches’ Learning through

Teaching Reflective Techniques

Wesley R. Meeteer II

Dissertation submitted to the

College of Physical Activity and Sport Sciences

at West Virginia University

in partial fulfillment

of the requirements for the degree of

Doctor of Philosophy

in

Kinesiology

with an emphasis

in

Physical Education Teacher Education

Kristen Dieffenbach, Ph.D., Co-chair

Robert Wiegand, Ed.D., Co-chair

Andrew Hawkins, Ph.D.

Sean Bulger, Ed.D.

Richard Walls, Ph.D.

Department of Coaching and Teaching Studies

Morgantown, West Virginia

2011

Keywords: Reflection; Athletic Coaching Education; Journal Writing

Copyright 2011 Wesley R. Meeteer II 


\section{ABSTRACT \\ Improving Student Coaches' Learning through Teaching Reflective Techniques}

\section{Wesley R. Meeteer II}

The purpose of this research was to examine how teaching reflective concepts and directing reflective writing would influence student coaches' (SC) level of reflective writing in a one semester coaching internship course. A Multiple baseline format was used to implement the intervention. The intervention used five reflective ideas to try and enhance the level of SCs' reflective abilities including; (a) teaching the SCs a reflective cycle, b) introducing SCs to high levels of quality reflective writing, (c) allowing SCs to assess the level of reflection their personal journals, (d) having SCs write reflective statements within the five reflective levels of the scale, and (e) providing SCs with constructive feedback on their journals. The results suggested that the intervention had no substantial influence on SCs level of reflective writing. Further research is needed to examine the time and practice SCs need in coaching education programs to improve their reflective abilities and how SCs' role frames influence their beliefs and effort given toward reflective practice. 


\section{DEDICATIONS}

This dissertation is dedicated to my mother and father;

Wes and Alice Meeteer

Their love, support, and guidance have helped me to become the person I am today and will continue to inspire me wherever life takes me. 


\section{ACKNOWLEDGEMENTS}

I would like to take this time to express my sincere appreciation to all of those people who assisted me throughout my time at West Virginia University. I may not have succeeded through this journey without each and every one of you. I acknowledge my co-chair Dr. Kristen Dieffenbach, who has made too many contributions to count toward my success in my career, the doctoral program and the dissertation process. Without her mentoring, endless amount of time, constant feedback, encouragement, and guidance I would not be here today. I wish to extend my gratitude toward my committee members Dr. Robert Wiegand, Dr. Andrew Hawkins, Dr. Sean Bulger, and Dr. Richard Walls for their helpful feedback and guidance throughout the dissertation process and my time in the program. Dr. Hawkins, thank you for your insightful suggestions that helped me navigate through the methods and results of my dissertation. Dr. Walls, thank you for helping me fix the technical mistakes in my writing. Dr. Bulger, thank you for your guidance in my research endeavors and job hunting process. Dr. Wiegand, thank you for serving as my chair and keeping the doctoral process real.

Special acknowledgements go to Dr. Ryan Flett, Dr. Valerie Wayda, and Dr. Lynn Housner. Dr. Flett, thank you for your time, helpful comments and participating as a third reviewer for my dissertation. Dr. Valerie Wayda, thank you for always being available to solve any problem that I have encountered as a teacher, student and researcher. Dr. Lynn Housner, thank you for your help and support throughout the program.

A special acknowledgement go to my friends and fellow PETE doctoral students, Will Davis, Camille Ramsey, Han Chen, James Wyant, Josh Nelson, Marcus Kinney, Kiel Illg, and Kasey DiGiacinto. Every one of you helped to me to complete this journey through your friendships, support, and comradery. Anytime I had a question or needed help I could count on each of you. Without out all of you I would not have completed this process and defiantly would not have had as much enjoyment along the ride.

I would also like to acknowledge my family and especially sisters Kara and Kami for always being supportive of me in every decision I have ever made or task that I have ever accomplished. Last but defiantly not least I would like the thank Jennifer Dempsey for all of her late night last minute writing critiques and her continuous love and support through the entire doctoral process. 


\section{TABLE OF CONTENTS}

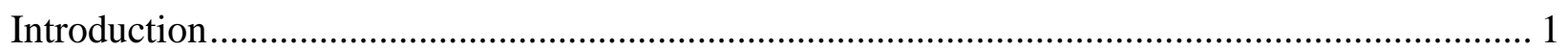

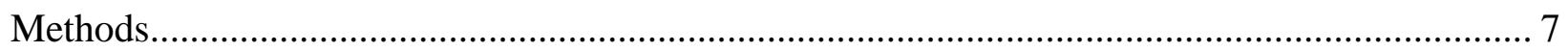

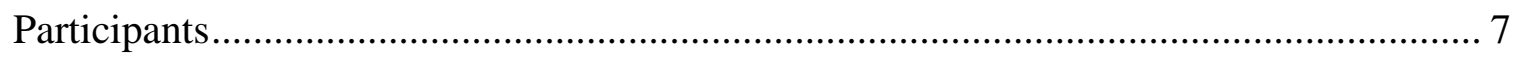

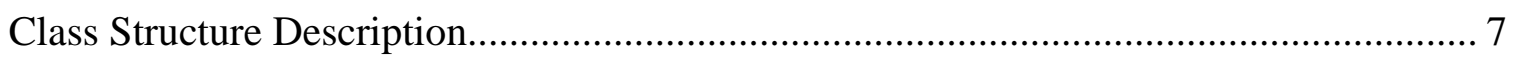

Reflective Journal Assignment ................................................................................ 9

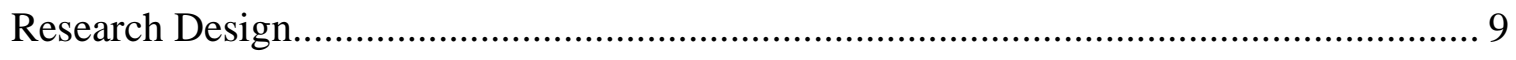

Implementation of the Multiple Baseline Design ............................................................ 10

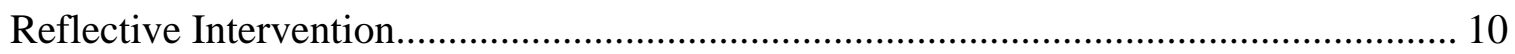

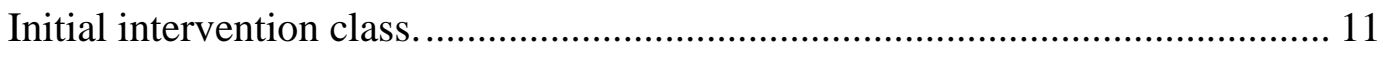

Post intervention follow-up............................................................................ 12

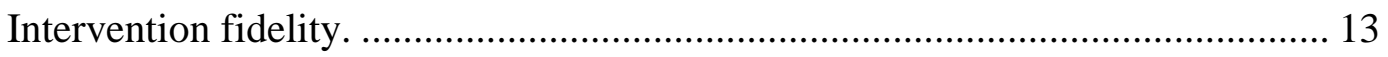

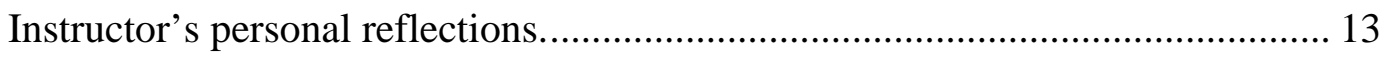

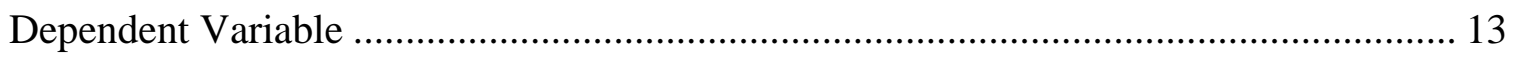

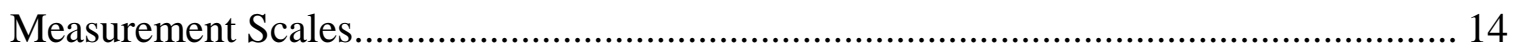

Five-Point Level of Reflection Scale.................................................................. 14

Revised Five-Point Level of Reflection Scale..................................................... 14

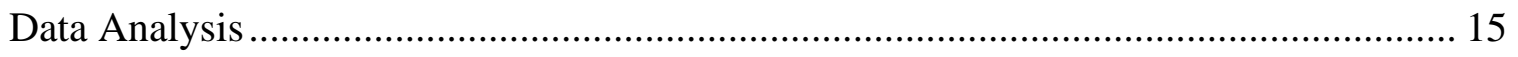

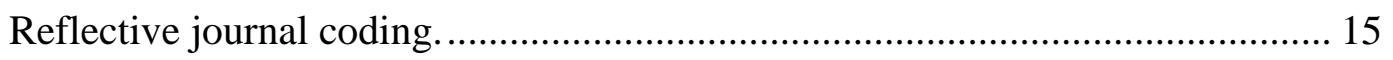




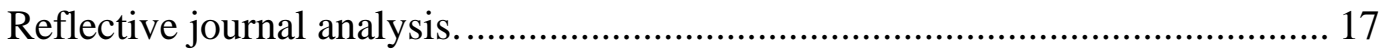

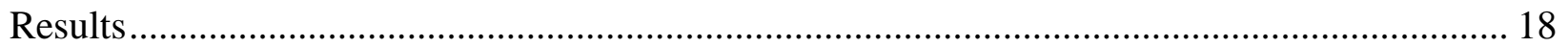

Inter-Rater Reliability Scores ........................................................................... 18

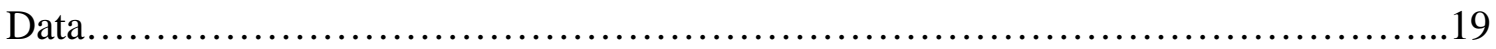

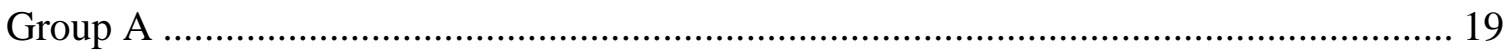

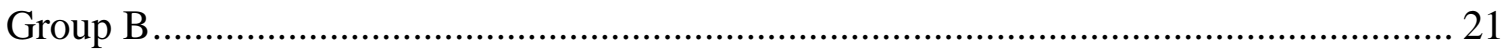

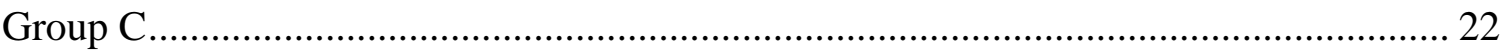

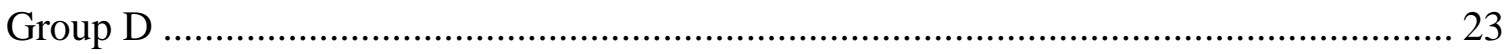

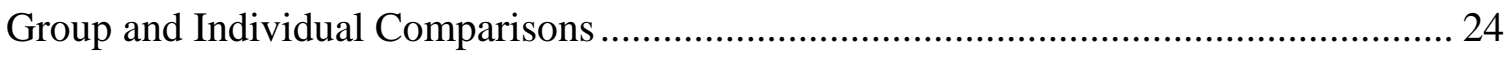

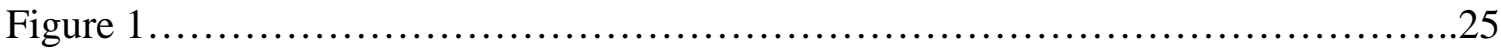

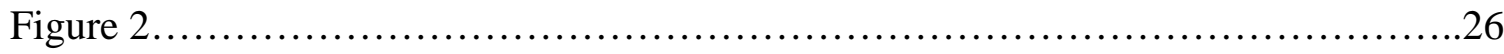

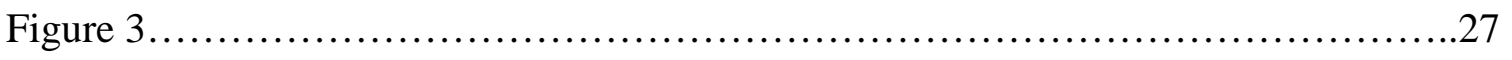

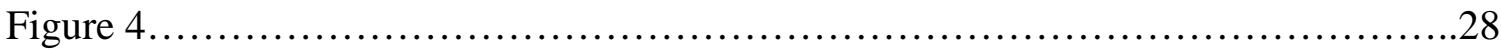

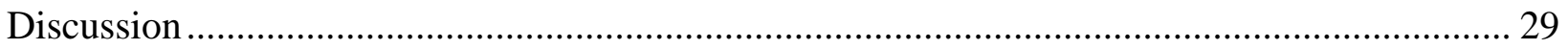

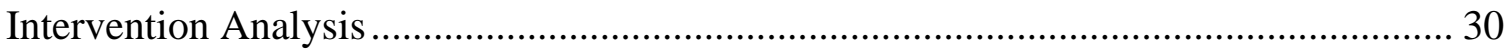

Student coaches’ previous experience with reflective concepts. ....................... 30

Student coaches’ beliefs about reflective practice. ........................................ 31

Student coaches accountability................................................................ 34 
Instructor's post intervention reflections. ....................................................... 36

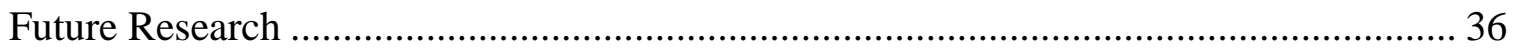

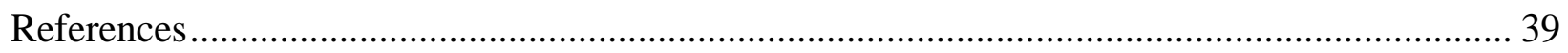

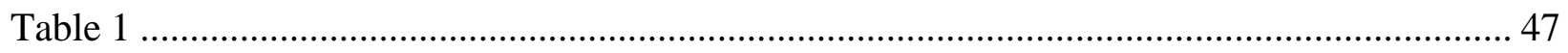

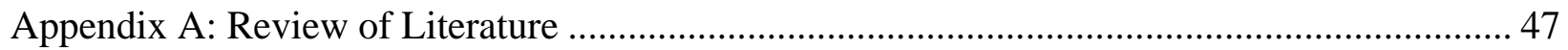

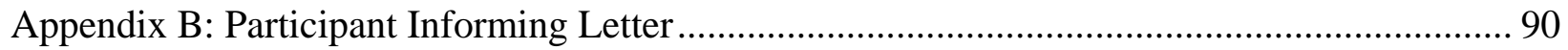

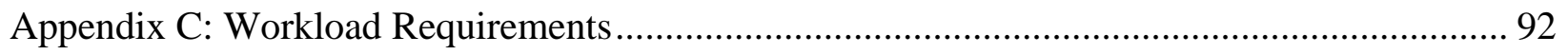

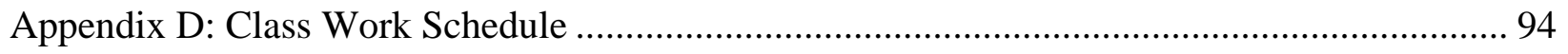

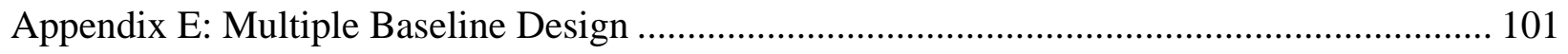

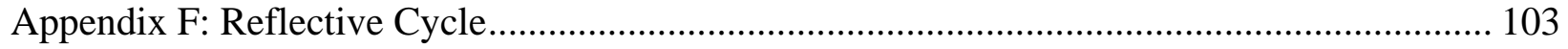

Appendix G: High Level of Reflective Writing ............................................................... 105

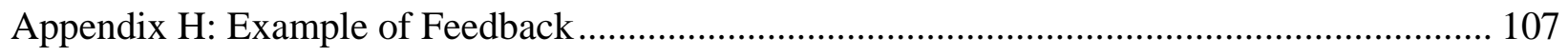

Appendix I: Five-Point Level of Reflection Scales ........................................................ 109

Appendix J: Examples of Coding and Inter-rater Reliability Score ..................................... 114

Appendix K: Figures 5-37 Group and Individuals’Aggregated Data .................................... 117 


\section{Introduction}

Coaching education has been recognized as an important component in the development and knowledge acquisition of sports coaches (Woodman, 1993). Although Woodman (1993) suggested that coaching education is an important part of coaches' development, the current theoretical methods used to educate coaches have been questioned (Cushion, 2001; Jones, 2000; Lyle, 2007). Problems in current formal academic Coaching Education Programs (CEP) exist because they do not help coaches develop cognitive abilities that allow them to, as Lyle (2002) stated, "move beyond existing practice, to innovate, to experiment, to adapt, to reflect, and to build underpinning knowledge and skills for the requirements of higher level coaching” (p. 280). Although CEP graduates may leave with a wide range of scientific sports knowledge, their behaviors and abilities may not improve because of the manner in which the information was taught to them (Saury \& Durand, 1998).

CEPs have typically been designed to teach coaches the content knowledge needed to improve the performance of the athletes and the teams that they coach (Luikkonen, Laasko, \& Telama, 1996). Although this information is extremely important, it is only part of the learning process. McDonald and Tinning (1995) suggested that student coaches (SC) leave with incomplete knowledge. Turner and Martinek (1995) suggested that SCs obtain a decontextualized view of the coaching process, whereas coaches only learn content knowledge as single subjects and not as combined entities necessary to becoming an effective coach. Coaches must not be taught only the content but also how to effectively connect the knowledge so it can be implemented in the practical coaching setting. A CEP's curriculum that focuses only on content knowledge and teaches the content as separate entities produces problems because 
coaches are not given sufficient opportunities to practice implementing the knowledge and fail to learn how to effectively integrate the knowledge into their coaching practice.

The current problems within CEPs have set the table for change. Over the past two decades coaching researchers have placed the coaching education process and the changes that need to be made under a microscope. After seeing the multitude of variables involved in coaching, researchers asked, "how can a single coaching education program realistically prepare coaches for so many contexts and a myriad of contextual factors” (Cushion, Armour, \& Jones, 2003, p. 221)?

Because of the complex nature of coaching, some have suggested taking a holistic approach to coaching education (Jones \& Turner, 2006; Potrac, Brewer, Jones, Armour, \& Hoff, 2000). The holistic approach allows SCs to examine the intricacies of the coaching process while connecting content knowledge and its application. One concept involved in the holistic approach is developing a coach’s cognitive abilities, which some researchers suggest is critical to becoming an expert coach (Abraham \& Collins, 1998; Côte, Salamela, Trudel, Baria, \& Russell, 1995).

Although cognitive abilities encompass many areas, reflection is one cognitive ability considered to be important in a coach’s knowledge development (Côte et al., 1995; Côte \& Gilbert, 2009), in CEP (Knowles, Gilbourne, Borrie, \& Neville, 2001; Knowles, Tyler, Gilbourne, \& Eubank, 2006) and in becoming and being an expert (Schempp, McCullick, \& Mason, 2006). A strong correlation exists between learning from experience and reflection (Boud \& Fales, 1983; Lueng \& Kimber, 2003). Because reflection is deemed so critical to coaches' learning, the United Kingdom's national governing bodies have suggested that all CEP 
classes should be centered on teaching and developing reflective skills (Knowles, Borrie, \& Telfer, 2005).

Although the research suggests that reflection is important, how can it be utilized and taught to future coaches? Knowles et al. (2005) stated that “coaching education should focus on developing the coach's capacity to learn from, and understand, his or her own experiences” (p. 1713). In other words, coaching programs should focus on teaching SCs how to reflect in a purposeful manor so they can improve their abilities to learn from their experiences. Schempp, McCullick, and Mason (2006) suggested that coaching expertise is gained through combining years of experience with purposeful improvement efforts such as the use of reflective practices.

Coaching literature sheds light on the need for coaches to reflect purposefully (Knowles et al., 2005; Schempp et al., 2006), but what is purposeful reflection? Purposeful reflection is the process in which coaches describe and interpret experiences and think of ways to improve. Purposeful reflection helps coaches understand what they do and why they do it (Cassidy, Jones, \& Potrac, 2004). Purposeful reflection is an intellectual process where individuals develop a new understanding through the examination of experiences (Knowles, et al., 2005). Purposeful reflection has also been described as a cognitive activity practitioners use to make links or bridge gaps in professional knowledge and practice (Boud, Keogh, \& Walker, 1985; Nelson \& Cushion, 2006; Saylor, 1990; Stevens \& Cooper, 2009). Without purposeful reflection coaches are "stuck in experience" or "in danger" of failing to gain new insight, understanding, and or knowledge of their practice (Cushion et al., 2003; Stevens \& Cooper, 2009).

Although it is evident that reflection is a critical component in coaching development, only a few studies have examined the ways in which reflective practices are taught to coaches 
(Knowles et al., 2001; Knowles et al., 2005; Nelson \& Cushion, 2006). Knowles et al., (2005) examined the reflective practices taught by six award winning CEPs in the United Kingdom, and not one of the six programs had a structured process to directly teach or nurture reflective skills. Nelson and Cushion (2006) suggested that a coach’s education should be based on practical coaching experience and making SCs reflect upon their experiences.

Because there is little research on teaching and developing reflective abilities within coaching education, it is critical to look to other fields that have established methods for teaching reflective practice. The teaching and development of reflective practice to enhance learning has been used within several fields, including education (e.g., Bain, Ballantyne, Packer, \& Mills, 1999; Hume, 2009; Osterman \& Kottkamp, 1993), nursing (e.g., Craft, 2005; Ghaye \& Lillyman, 2000), educational psychology (Lueng \& Kimber, 2003), sports psychology (Anderson, Knowles, \& Gilbourne, 2004), and CEPs (Knowles et al., 2001; Nelson \& Cushion, 2006). These fields have established a vast amount of information that can be used as guides to help teach and develop coaches’ reflective abilities in CEPs.

One type of reflective practice used within multiple academic programs is reflective journal writing (e.g., Bain et al., 1999; Bain, Mills, Ballantyne, \& Packer, 2002; Hume, 2009; Knowles et al., 2001). Reflective journaling is described as "a learning exercise in which students express in writing their understanding of, reflection on, response to or analysis of an event, experience or concept” (Ballantyne \& Packer, 1995a, p. 1). Galvin (2006) describes reflective journals further by suggesting that the journals bring structure to the reflective process. It is important to guide students’ journaling because the writing process can be difficult for students to learn (Johns, 1994; Stevens, \& Cooper, 2009). 
Several other researchers have suggested methods to improve students' journal writing. One suggestion to help improve journal writing was using feedback (Bain et al., 1999; Bain et al., 2002; Stevens \& Cooper, 2009). Teachers can provide feedback to help students solve problems and answer questions while also encouraging students to think with more depth, analyze their thoughts and action, and explore different courses of action (Bain et al., 2002). Providing examples of high quality reflections has also been used to help improve journal writing (Hume, 2009; Moon , 1999a). Another method used to enhance the quality of students' reflective journaling is requiring students to assess the reflective levels of their own journals using a reflective scale (Bain et al., 2002).

Educators must attempt to improve SCs' reflective skills, and many suggestions have been made on how to make these improvements. However, how can something so subjective be measured for improvement? Measuring the level of reflective thought or understanding is one way several researchers have measured reflective skills (e.g., Biggs \& Collis, 1982; Mezirow, 1981; Powell, 1989; Bain et al., 1999). The hierarchical levels used by Mezirow (1981) or Bain et al., (1999) represent levels of thought from basic, low-level descriptive thought to high levels of transformative or reconstructive thought. Higher levels of reflective thinking in the aforementioned research represent an ability to think more critically and with more depth while also showing a better understanding of the content of discussion.

Several reasons exist for examining the level of reflective writing as a means to assess SCs' growth. Maas (1991) suggested that the student with the highest levels of writing develop ideas while writing. Bain and colleagues (2002) suggested when students develop ideas as they write the journal changes from just a record of events into an influential learning tool. Students who write at higher levels of reflection, show their ability for transformational learning, which is 
described as critically examining personal assumptions (Kegan, 1994). Moon, (1999b) argues that high reflective quality is critical in ensuring learners progress. Students that write at higher levels of reflection are more likely developing ideas during the writing process, turning journal writing into an influential learning tool.

As CEPs strive to effectively improve SCs' current and future professional behaviors, knowledge, and reflective skills, it is essential to continuously evaluate the newly developed teaching process and its subsequent effects on SCs. CEP coordinators and educators must keep in mind the coaching education literature that suggest nurturing coaches' reflective skills (Knowles et al., 2005) and encourage SCs to reflect upon experiences (Knowles et al., 2001; Nelson \& Cushion, 2006; Schempp et al., 2006).

The purpose of this study was to examine how teaching reflective concepts and directing reflective writing would influence the level of reflective writing SCs attained in their weekly journals. It was hypothesized that the SCs would write more high-level reflective statements and less low-level reflective statements after receiving the intervention. The level of reflection was measured using a scale adapted from Bain et al. (1999). Five reflective ideas were used to teach the concepts and enhance the level of SCs' reflections, including (a) teaching the United Kingdom’s National Coaching Foundation Reflective Cycle (Galvin, 2006), (b) introducing SCs to high levels of quality reflective writing, (c) allowing SCs to assess their personal journals, (d) requiring SCs to write reflective statements within the different reflective levels, and (e) providing SCs with constructive feedback related to the reflective cycle and the level of their reflective journals. 


\section{Methods}

\section{Participants}

The participants in this study were SCs enrolled in a one-semester athletic coaching internship course within a land grant university's undergraduate CEP. The university enrollment is about 29,000 students, with approximately 60 SCs in the CEP. This research study was reviewed and approved by West Virginia University’s Internal Review Board. Participation in this study was voluntary. There were no rewards or punishments for participating. Permission was obtained from all SCs to use their journal entries as data for this research. The research initially started with 21 participants. However, over the course of the study four participants were dropped for failing to turn in work or upon request, leaving a total of 17 participants: 5 females and 12 males. A copy of the participant informing letter can be found in Appendix B.

For the purposes of this study the SCs were purposefully assigned to four different groups: A, B, C, and D. Initially there were three groups of five and one group of six. Because four SCs were dropped from the study the groups had three, three, five, and six SCs respectively. The participants were purposefully divided into groups by age, coaching experience, number of internship hours, and gender because each one of these aspects was considered to be a potential confounding variable. Each group had an average age range of 21.4 to 24.8 years, an average coaching experience range of 2.2 to 2.8 years, an average number of internship credits range of 5.6 to 6.2 credits, and one to two females per group.

\section{Class Structure Description}

During the fall 2010 internship class, each enrolled SC was required to complete a professional field experience at their own desired level of sport (i.e., youth, high school, recreational, disability, Special Olympic, or college). There were two sections of the 
professional field experience, and each section allowed the SCs to sign up for one to six internship credit hours. These two sections were combined into one class for the purposes of this study. The combined class was taught by an instructor who obtained a master's degree in education, youth and college coaching experience, and a strong research knowledge of reflective practice. The instructor is also pursuing a doctoral degree in kinesiology with a cognate in coaching education.

Each credit hour of coaching internship required the SCs to complete a total of 15 contact hours of coaching, which included season and practice planning meetings, practices, and games. Thus, a SC enrolled in the coaching internship class for 3 credits needed to complete 45 coaching contact hours with his or her team in addition to the course assignments in order to satisfy the course requirements. All SCs in the study enrolled in three or more credit hours. For the purposes of this study, all SCs completed the same amount of reflective journal entries. The remainder of the SCs' course assignment workload was based on the number of hours in which they enrolled. A copy of the workload requirements can be found in Appendix C.

The class instruction followed a blended format including direct classroom instruction and instruction and assignment submission in an online classroom. SCs participated in three oncampus classes lasting two-and-a-half to three hours. The first on-campus class took place in week one of the semester. In this class all SCs were introduced to the course, discussed the work load requirements, and submitted internship paperwork. The second on campus meeting was the initial intervention class where SCs came to class only in their preselected groups in either week 4, 7, 10, or 13. All SCs were required to attend the third and final on-campus class. In the third class SCs turned in portfolios containing all required work and participated in group conversations to discuss the overall experience. 


\section{Reflective Journal Assignment}

For the purpose of this study SCs wrote 15 reflective journal entries, one per week of the class. The requirements for each journal included being at least 250 typed words, submitting by the required date and relating to his or her current internship experience. The SCs would receive a passing grade on the journals if they met these requirements. The SCs' journal grades were not based on writing journals at higher levels of reflection. The reflective journal assignment gave SCs the freedom to reflect on the experiences that they felt were important. The SCs had little accountability due to the way the reflective journal assignment was designed. Their grades for each journal were reduced only if they did not meet one of the requirements above. The broad freedom and little accountability made the reflective journal assignment more closely resemble the freedom and accountability placed on real world coaches (Knowles et al., 2006).

SCs were encouraged to reflect upon topics related to their experiences in their internships, observation of the head coaches, or anything else related to their coaching improvement during their internship experiences. If the SCs had trouble finding an experience to reflect on, they were encouraged to use the weekly reading topics to stimulate their thinking or use a previous coaching experience. The weekly reading topics related to the eight domains of the National Standards for Sport Coaches (NASPE, 2006). The domains were established by NASPE as the areas in which SCs should show proficiency upon graduation. The weekly topics can be found in the key points section of the weekly class schedule in Appendix D.

\section{Research Design}

A non-concurrent multiple baseline between subject design was utilized to implement the intervention. Multiple baseline designs traditionally wait to implement the intervention until the dependent variable has reached a steady rate of response (Baer, Wolf, \& Risley, 1968; Cooper, 
Heron, \& Heward, 2007). In a non-concurrent design the duration of baselines are identified prior to the study and participants are randomly or purposefully assigned to a baseline (Watson \& Workman, 1981). Because the semester only allowed for 16 weeks to intervene, the baseline stages had to be predetermined.

The use of a multiple baseline design helps to establish whether a change in the level of reflective writing was caused by the intervention through repeating the intervention (Cooper et al., 2007). In this study the intervention was repeated three times. The baseline phase allows the researchers to collect data on the SCs current reflective abilities. The data in the intervention phase is compared to the data in the baseline phase to determine if the intervention had any influence. It was hypothesized that SCs would increase the amount of high level reflective statements, and decrease the amount of low level reflective statements in which they wrote, after receiving the intervention.

\section{Implementation of the Multiple Baseline Design}

The multiple baseline design was implemented in the following fashion. In the first three weeks all groups remained in the baseline stage. In week four, Group A participated in the initial intervention class while the remaining three groups remained at baseline. Groups B, C, and D received the intervention in weeks 7,10 , and 13 respectively. A visual representation of the multiple baseline design is located on Appendix E.

\section{Reflective Intervention}

Five elements were included in the intervention: (1) teaching the United Kingdom's National Coaching Foundation Reflective Cycle (Galvin, 2006) a conceptual model of reflection for guiding reflective thought and writing journal reflections (Appendix F); (2) introducing SCs 
to a previously written high quality reflective journal; (3) requiring SCs to evaluate their own reflective journals; (4) making SCs practice writing reflective statements at the five levels of reflectivity; and (5) giving SCs feedback related to the United Kingdom's National Coaching Foundation Reflective Cycle (Galvin, 2006) and the revised Five-Point Level of Reflection Scale. The study did not examine the effects of each part of the intervention separately, but instead the total influence of the entire intervention on SCs' level of reflective journal writing.

Initial intervention class. In the initial intervention each group was introduced to four of the five concepts of reflective practice. First, Galvin's (2006) reflective model was taught by breaking down the model into its six parts and describing how to use each part as a guide to reflecting. These parts were taught in the order that the United Kingdom's National Coaching Foundation Reflective Cycle (Galvin, 2006) suggested. Secondly, the SCs read a reflective writing piece from Perry (2000) that displayed high levels of reflection and participated in group discussions about this journal. A sample of Perry's (2000) reflective piece can be found in Appendix G.

Assessing personal reflective journals writings was the third concept introduced in the initial intervention class. The SCs were introduced to the revised Five-point Level of Reflection Scale and how it could be used to assess the reflective level of their journals. After learning about the scale and how it was to be utilized, the SCs used the scale to assess one of their own personal baseline reflective journal entries. The instructor helped SCs through this process when questions were asked and also discussed why or why not each SC had assessed their reflective journal correctly. 
The fourth and final task of the initial intervention class was to write reflective statements at the different levels of the revised Five-point Level of Reflection Scale. During this time, the SCs were instructed to use the previous topic from the reflective journal they assessed and to write statements at different reflective levels. After writing their statements the SCs read their statements aloud, and the instructor described why their statement was or was not written at the correct level and how they could make it the correct level. At the conclusion of the initial intervention class the SCs were instructed to use the reflective cycle, scale, and concepts taught in the intervention to guide the remainder of their reflective journal writings.

Post intervention follow-up. In the post intervention the instructor provided feedback to the SCs about their reflective journals. Feedback was the fifth concept of the reflective intervention. The feedback was related to the United Kingdom's National Coaching Foundation Reflective Cycle (Galvin, 2006) and the level of reflection SCs reached in their reflective journal. SCs received feedback on every journal entry they wrote after participating in the initial intervention class. The feedback included four different statements. One statement addressed the SCs' ability to follow the United Kingdom’s National Coaching Foundation Reflective Cycle. Two statements addressed the level of reflective writing that the SCs reached in their journals and how to improve the level which they reached. The fourth statement was positive feedback on something the SCs wrote about in their journals. An example of feedback can be found in Appendix H.

As part of the post intervention the SCs also assessed the journal they wrote two weeks after participating in the initial intervention class. This is an extension of the third concept previously discussed in the initial intervention class. The SCs followed the same format for this process that they used in the initial intervention class and used the same Five-Point Level of 
Reflection Scale. SCs were required to assess only one journal in the post intervention, making a total of two journal assessments over the entire reflective intervention.

Intervention fidelity. For fidelity purposes the instructor used the same powerpoints, reflective examples, reflective scales, reflective cycle, and time frame for each initial intervention class. In addition, each initial intervention was audio recorded to help maintain that the same information which was given by the instructor. In the post intervention the instructor gave the same type and number of feedback statements to each SC on every journal they wrote after completing the initial intervention class. By doing this the instructor was able strengthen the fidelity of the intervention, which is important for assuring that all participants received all parts of the intervention in the same manner (Bellg et al., 2004; Dumas et al., 2001).

Instructor's personal reflections. Throughout the study the instructor kept a personal journal in which he reflected on the implementation of the intervention, the SCs' reactions to the intervention, and the overall process of this study. The instructor wrote a journal entry immediately after each initial-intervention class. In addition, the instructor wrote journal entries at other times throughout the study on events that may have influenced the study or the SCs' abilities to improve their reflective capabilities. These journal writings were used as supplemental information to help interpret and discuss any influence that the intervention had on the SCs' level of reflective writing.

\section{Dependent Variable}

The dependent variable in this study was the frequency in which SCs wrote reflective statements in their journal within the five levels of the revised Five-Point Level of Reflection Scale. Recording the frequencies with which SCs' journal statements fit into the reflective scale 
made it possible to track and determine the change over time in their reflective writing behaviors. An example of a participant's reflective level scoring chart can be found in Table 1.

\section{Measurement Scales}

Five-Point Level of Reflection Scale. The Five-Point Level of Reflection Scale developed by Bain et al. (1999) was chosen to serve as the scale which was to be used to measure the level of reflection the SCs displayed in their journals. The scale had been previously used in Bain et al. (1999) and Bain et al. (2002), two studies measring the level of SCs' reflective journaling in teacher education. This original scale only included 17 criteria divided between the five levels of the scale. The five levels represented higher orders of reflective thinking, including reporting, responding, relating, reasoning, and reconstructing. A copy of the Five-Point Level of Reflection Scale can be found in Appendix I.

Revised Five-Point Level of Reflection Scale. Several changes were made to the original scale. The first change was made because the scale was going to be used in a different context: athletic coaching education instead of teacher education. The words "student teacher" were changed to "student coach". Second, the original scale was modified by removing the negative terminology in Levels 1 and 2. Removing this terminology made it possible for the SCs to reach all reflective levels in the scale in one journal entry, and to assess the SCs' reflective behaviors. Third, the SCs' journal content varied from that of a student teacher. Because the content was different, it was difficult for the researchers to code the SCs' journals consistently using some of criteria and wording in the original scale. For this reason changes were made to the original scale based on the content displayed in the SCs' reflective journals and deductive reasoning of the three researchers. A chart containing the reasoning for and changes to the original scale and the revised Five-point Level of Reflection Scale can be found in Appendix I. 


\section{Data Analysis}

Journal entries were assessed by three researchers trained in qualitative research methods. The researchers developed the revised Five-Point Level of Reflection Scale and sought consensus in coding style through extensive training using the scale. Prior to the start of the study and assessing journals, researchers independently assessed the reflective writing samples from week one using the revised Five-Point Level of Reflection Scale. The researchers compared responses and discussed discrepancies of 21 journals to come to a consensus on how to implement the rating scale consistently. During the study, journal entries were assessed weekly for the first four weeks and bi-weekly from weeks 6 to 15 by the primary researcher. The SCs’ reflective journals were assessed weekly for the first four weeks to help establish a baseline of Group A's level of reflective writing. The journals were assessed bi-weekly after week four because there were enough data points to establish a baseline for the other three groups, and research suggested that assessing the journal entries bi-weekly would help to account for missing data points (Bain et al., 2002). The second and third raters randomly assessed 20\% of the journal entries in each assessment week to help ensure rating reliability.

Reflective journal coding. The research team coded every sentence as a statement, and each statement received a code. Each statement could be coded as (a) one of the 22 different criteria within the revised Five-Point Level of Reflection Scale, (b) not relating to the internship experience, or (c) a repeat of a previous statement. Only statements coded as (a) were counted toward the level of reflectivity that SCs reached in their journals.

When all three researchers were in agreement on how a statement was coded using the 22 criteria within the reflective levels, the coding was upheld. When only two people agreed, the 
majority coding was upheld. When no coding consensus was reached, the primary researcher chose the code that he felt best suited the statement.

In some cases only two researchers coded a statement and the third coded the statement as a repeat of a prior statement or not relating to the internship. When the two researchers who coded the statement agreed, then the coding was upheld. When the two researchers' codes were different, then the primary researcher chose the code that he felt best suited. Most often, when only two of the three coded a statement, it was because the third researcher felt that the statement was a repeat of a previously coded statement.

The researchers felt SCs occasionally wrote some complex compound sentences that contained multiple, distinct statements where each statement warranted its own independent code. The complex, compound sentences could be divided by all three researchers, two researchers, or one researcher. When the sentence was divided into two statements by all three researchers, then the previous coding rules were upheld. When a compound sentence was coded as one statement by one researcher, and broken into two statements by the other two researchers, then two different codes were recorded. One of the codes was based on all three researchers' agreement or disagreement. The second code was based on only two researchers agreeing. If a sentence was broken into two statements by only one researcher, then his or her second coding was ignored. Appendix J depicts the possible coding combinations.

Each individual received a frequency score for each of the five reflective levels within the revised Five-Point Level of Reflection Scale, making a total of five scores per journal. The frequency scores for each of the five Levels were determined by the frequency of coded 
statements a SC had written within each level in a single journal. These five frequency scores per journal are the data that were assessed in this study.

Inter-rater reliability of reflective journal coding. The three researchers established two different inter-rater reliability (IRR) scores, which are important in determining that the results were reliable (Trochim, 2006). The first IRR score was based on the researchers' abilities to consistently code the journals using the 22 criteria within the five Levels of the scale. The second IRR score was based on the researchers' abilities to consistently code the journals using only the five Levels of the scale and not the 22 criteria. Both IRR scores were based on a zeroto-two point scale when all three researchers coded a statement, and a zero-to-one point scale when only two researchers coded a statement. The IRR scoring is described in the following paragraph.

When the second and third researchers agreed with the first researcher on how a statement was coded, the IRR scores were given a two out of two. When only one of the researchers agreed with the primary researcher, the IRR score was awarded a score of one out of two. When no rating consensus was reached, the IRR scores were given zero out of two. When only the first researcher and a second researcher coded a statement and they agreed on the coding, then the IRR score was given a score of one out of one. When the two researchers disagreed, then the IRR score was given zero out of one. The total score obtained was divided by the total possible score to obtain the IRR scores. These rules were upheld for both the first and second IRR scores. Appendix J depicts both IRR scores.

Reflective journal analysis. The reflective journal data were analyzed by examining the groups' and SCs' weekly and phase frequency scores for each of the five Levels within the scale. 
A SCs' weekly frequency scores per reflective level consisted of all scores achieved during the single journal for that particular week. The baseline phase mean frequency scores were derived from all journal scores achieved before receiving the intervention. The intervention phase mean frequency scores consisted of all journal scores achieved after receiving the intervention. All of individuals' and groups' mean frequency scores were visually examined in the graphical representation of the data in a multiple baseline design format using means, trends, and variability. This process helped to determine whether or not the intervention had an influence on the SCs' level of reflective journal writing.

\section{Results}

The results are presented in Figures 1 through 4 on pages 25 through 28. Figures 1 through 4 represent the multiple baseline data of each group's mean frequency of reflective level statements within the first four levels of the scale. Each group's aggregated frequency, mean, and trend data are presented in Figures 5 through 20 in Appendix K. Each individual's data are presented in Figures 21 through 37 in Appendix K.

\section{Inter-Rater Reliability Scores}

The two IRR scores were based on the 32 journals that were coded by all three researchers. The researchers maintained a 76.2\% IRR score when rating the journals based on the 22 criteria within the levels. This score is above the $66.7 \%$ considered to be appropriate by some standards when rating qualitative information (Marques \& McCall, 2005). The researchers maintained an 85\% IRR score based only on the levels and not the criteria within the levels, which is considered appropriate by most standards (McMillan \& Schumacher, 1997). 


\section{Data}

The data showed that SCs wrote statements between only the first and fourth levels of the revised Five-Point Level of Reflection Scale. The fifth level of the scale, the highest level of reflection writing, was removed because only one SC wrote a Level 5 statement over the entire study. No other SC wrote a Level 5 statement. Based on visual inspection of the data, the intervention had no substantial influence on the SCs' level of reflective journal writing. The graphical representation of the data shows that there were no level or trend changes when the intervention was introduced across the multiple baselines. Also none of the groups reached a steady rate of response in any of the reflective levels across the baseline or intervention phases. Figure 1 depicts that the intervention did not influence the mean frequency of Level 1 statements made by three of the groups. Group 2 made the only visible change in the mean frequency of Level 1 statements after receiving the intervention. The intervention did not influence the mean frequencies of Level 2 statements made by three of the groups. Group 1 made the only visible change in Level 2 statements after receiving the intervention. The Level 2 data can be seen in Figure 2. There was no visual change in the mean frequency of Level 3 or Level 4 statements made by any of the groups. These data can be seen in Figures 3 and 4 respectively. Based on the data, the intervention did not influence the SCs' ability to improve their level of reflective journal writing.

\section{Group A}

Group A’s data are represented in Figures 1, 2, 3, and 4. The group and individual participants' aggregated data are represented in figures 5, 9, 13, 17, 21, 22, and 23 in Appendix K. A visual inspection of Group A’s graphs show that a steady rate of response was never achieved. The group had an increase in the mean frequency and trends of Level 2 and 4 
statements across the intervention. Because the variability was high in the weekly mean frequencies, the regression lines that represent the trend were non-significant $p>0.05$. Therefore any increase or decrease in trends cannot be considered to adequately represent the reflective levels reached by the SCs or the development in SCs' reflective abilities. One aspect to highlight about Group A's data was the jump in the mean frequency of Level 2 statements after receiving the intervention stage. It must be noted that Participant 2 from the group was the main cause for this increase.

Participants 2, 3, and 5 were part of Group A, and their data are represented in Figures 21 through 23. None of the participants reached a steady rate of response. Participant 3 decreased the frequency of Level 1 statements by an average of over 4 statements per journal and increased the frequency of Level 2 statements by over seven per journal after receiving the intervention. Participant 5 did increase the mean number of Level 3 statements after receiving the intervention by two statements per journal. Participant 2 did not make any changes that were visibly noticeable in the graphs.

The Level 2 statements written by the participants were either judgment statements or feelings statements about their internship experiences. The Level 3 statements made by the participants ranged across the seven criteria in the level with most statements relating to previous experiences or giving a superficial explanation of an event or experience. Participants' Level 4 statements written after receiving the intervention were statements that analyzed an event or explained their feelings or behaviors. 


\section{Group B}

Group B’s data are represented in Figures 1, 2, 3, and 4. Group B’s data are also represented in Figures 6, 10, 14, 18, 24, 25, and 26 in Appendix K. Group B did not reach a steady state of response in either the baseline or intervention stage. The variability in its data were higher than the variability in Group A's data. The main point that is visibly noticeable in the graphs is the drop in mean frequency of Level 1 statements after receiving the intervention. Group B’s Level 1 statements decreased by over three per journal after receiving the intervention.

Group B included Participants 8, 9, and 10. Participant 10 was the only group member to write a Level 4 statement. Participant 10 reached a high of four Level 4 statements in one journal. Participant 4 also averaged writing more words per journal than either of the other two participants within Group B. Neither Participants 8 nor 9 wrote a Level 4 statement, but they did increase the frequency of Level 2 statements after receiving the intervention and decreased the frequency of Level 1 statements. Participant 9 decreased the frequency of Level 1 statements by an average of almost 6 statements per journal after receiving the intervention. Each participant's Level 3 mean frequencies did not visibly change from baseline to the intervention.

The Level 2 statements made by the participants in Group B were judgment, feeling, or goal statements. The Level 3 statements made by the participants varied from connecting an event with a prior experience, evaluating something as good or bad, and giving a superficial explanation of an event or experience. The majority of Level 3 statements were superficial explanations of events or experiences. 


\section{Group C}

Group C’s data are represented in Figures 1, 2, 3, and 4. Group C’s data are also represented in Figures 7, 11, 15, 19, 27, 28, 29, 30, and 31 in Appendix K. This group did not reach a steady state of response over the baseline or intervention stages. Like the other groups, Group C had a high variability in the mean number of reflective level statements in each level across each week. Group C’s mean frequency in Level 1, 2, and 3 statements stayed relatively the same in the baseline and intervention stages. The only visibly noticeable point in the graphs was the increase in the mean frequency of Level 4 statements after receiving the intervention. However, this increase was small and occurred because Participant 6 wrote most of the Level 4 statements.

Group C had five participants including Participants 6, 11, 12, 14, and 15. Not one of the participants reached a steady rate of response. The variability in the individuals' data was much higher than the mean variability of the group. Participant 6 was the only participant to increase the mean frequency of Level 2 and, more notably, Level 4 statements. Participant 6 increased the mean frequency of Level 2 statements by two statements per journal and Level 4 statements by three per journal after receiving the intervention. As a result Participant 6 was able to decrease the frequency of Level 1 statements by an average of two statements per journal. The other four participants in this group never wrote more than two Level 4 statements per journal. It should be noted that Participant 6 averaged writing the most words per journal out of any of the other participants. Participant 6 was three years older than any other participant.

The Level 2 statements made by the participants focused on judgments, feelings, and goals with judgment statements being the most prevalent. Participants' made Level 3 statements across all seven criteria in the level, but the statements mainly focused on previous experiences 
and superficial explanations. Level 4 statements were made in all criteria, but most comments focused on the exploration or analysis of an experience or the attempt to explain their own feelings or behaviors.

\section{Group D}

Group D’s data are represented in Figures 1, 2, 3, and 4. The groups' data are also represented in Figures 8, 12, 16, 20, 32, 33, 34, 35, 36, and 37 in Appendix K. Group D, like all three other groups, did not reach a steady rate of response across the baseline or intervention stages. The mean frequencies of reflective level statements did not visibly change from the baseline to the intervention stages. Group D averaged the least amount of statements per journal between all four groups.

Group D included Participants 16, 17, 18, 19, 20, and 21. None of the participants reached a steady rate of response over the course of the study. Participant 17 was the only participant to write more than two Level 4 statements in a reflective journal. Participant 17 also failed to turn in the first two journals of the study. Participant 20 was the only other participant to write two Level 4 reflective statements in a reflective journal. Participants 18 and 21 did not write a Level 4 reflective statement over the entire study, and Participant 16 wrote only one Level 4 statement. Participant 16 was the only SC in Group D to reduce the mean number of Level 1 statements in the intervention stage by more than two statements per reflective journal. Participant 16 also increased the number of Level 3 statements by two per journal after receiving the intervention. Participant 19 was the only SC to increase the mean frequency of Level 2 and Level 3 statements after receiving the intervention by more than 2 statements per journal. 
The Level 2 statements written by the participants focused on judgments, goals, and feelings with the majority being judgments. The Level 3 statements made by the participants ranged across the seven criteria but focused mainly on superficial explanations and areas in which the participants felt they performed well or learned something.

\section{Group and Individual Comparisons}

None of the groups or individual participants reached a steady rate of response. The only difference in the groups' data is the increase in the Level 2 statements of Group A and the decrease in Level 1 statements by Group B. Participant 6 was the only participant to show a visual change in the fourth level of reflectivity. The intervention did not influence any other participant to consistently write statements at or above the fourth reflective level. Three participants never wrote a Level 4 statement, and two others wrote only a singular Level 4 statement over the entire study. Only 6 of the 17 participants reached a mean of five or more statements per week at Level 3 in either the baseline or intervention phases. Participants 5, 12, 16, and 20 increased their mean frequency of Level 3 statements above five per week in the intervention stage. Participants 15 and 20 decreased their Level 3 statements below a mean frequency of five after receiving the intervention.

The participants in all groups wrote mainly judgment statements within reflective Level 2. Within reflective Level 3, participant in all groups wrote most statements that connected an event with a previous experience or gave a superficial explanation of why an event happened. The reflective Level 4 statements written by the participants in all groups were focused on analyses of why an event happened or an explanation of their feelings or behaviors. It should be noted that in general those SCs who wrote the most Level 4 statements averaged writing the most words per journal. 


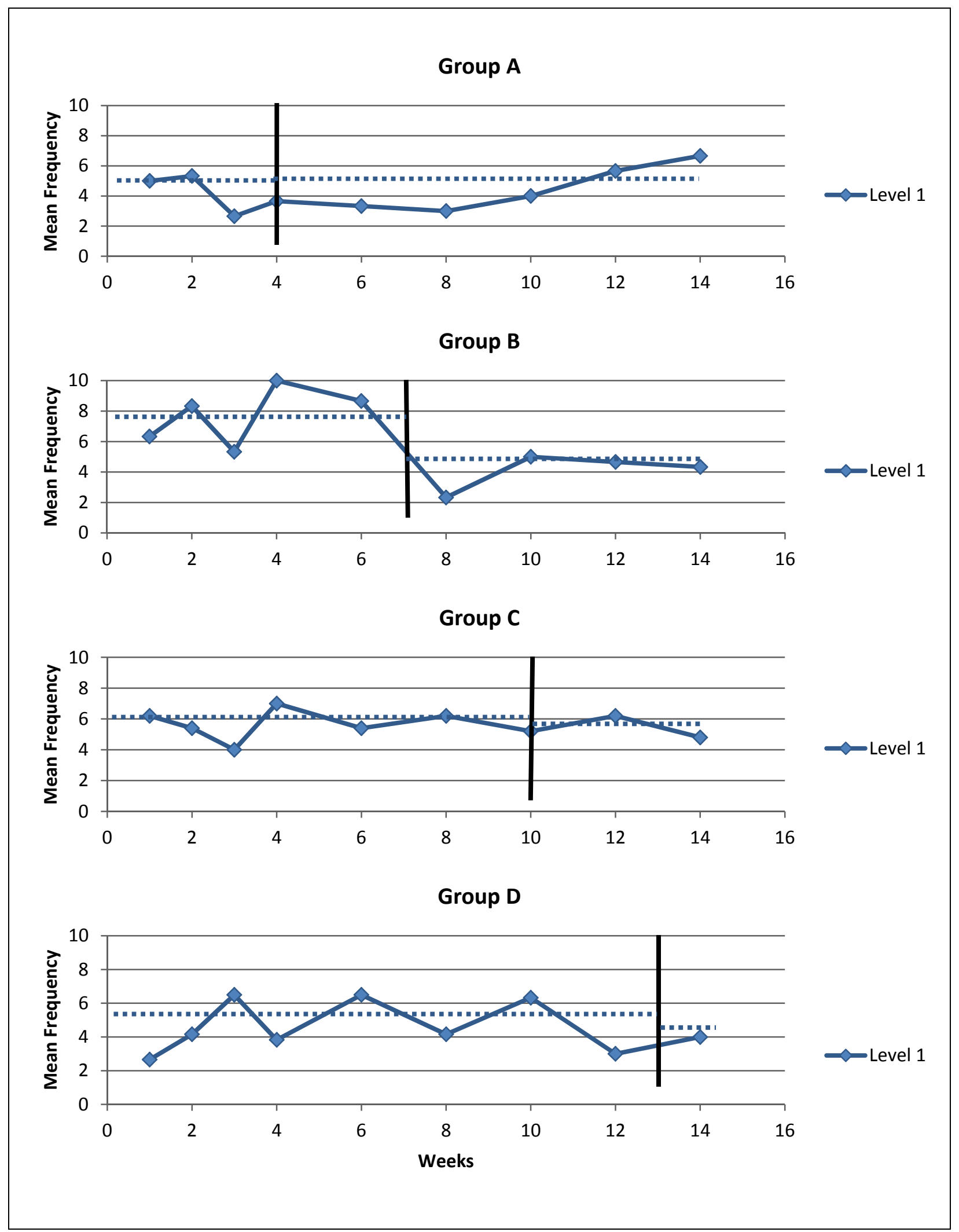

Figure 1. Groups' mean frequency scores of Level 1 responses per week. Mean phase lines were added to show each group's average number of Level 1 responses accumulated in each phase. 


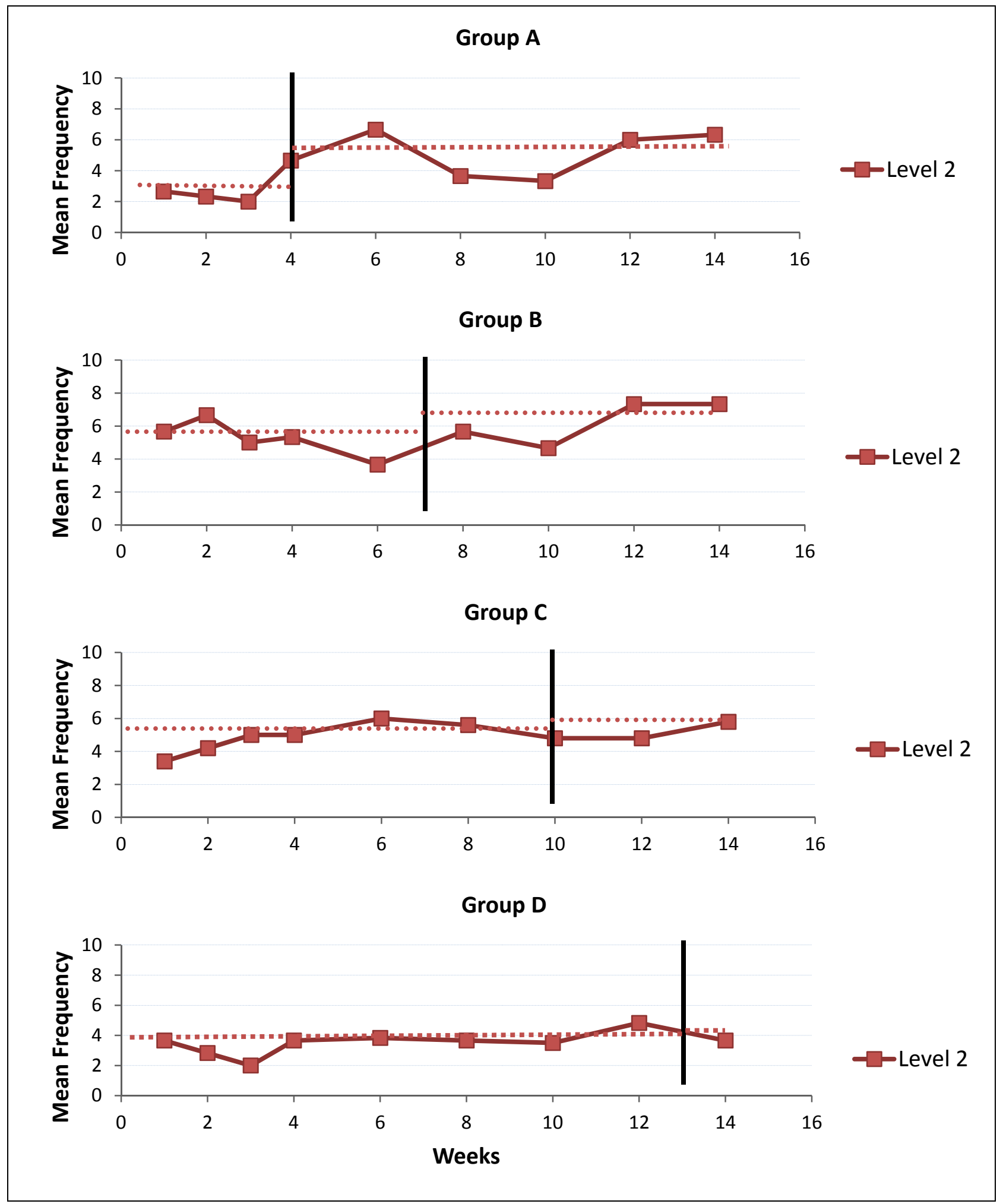

Figure 2. Groups' mean frequency scores of Level 2 responses per week. Mean phase lines were added to show each group's average number of Level 2 responses accumulated in each phase. 


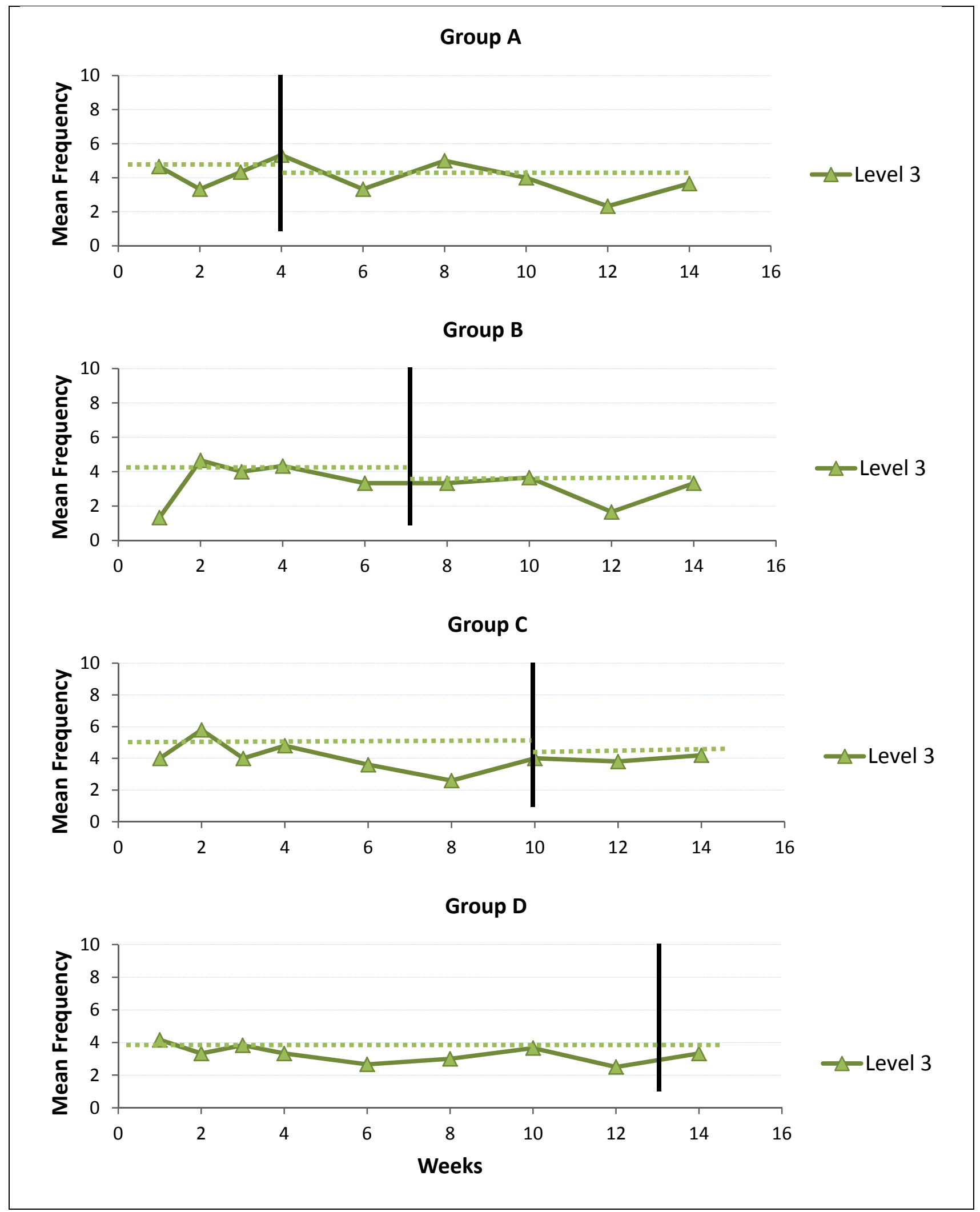

Figure 3. Groups' mean frequency scores of Level 3 responses per week. Mean phase lines were added to show each group's average number of Level 3 responses accumulated in each phase. 


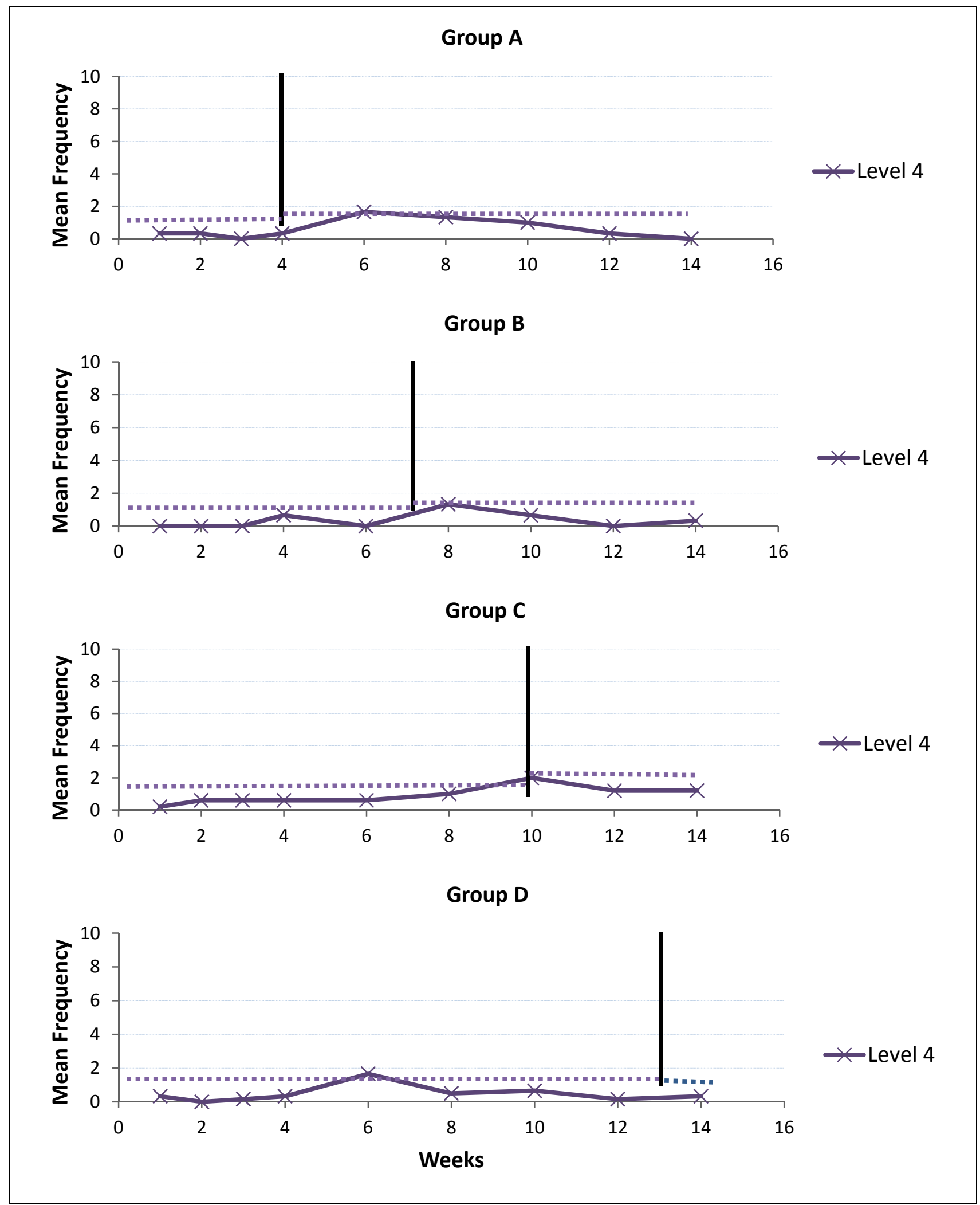

Figure 4. Groups' mean frequency scores of Level 4 responses per week. Mean phase lines were added to show each group's average number of Level 4 responses accumulated in each phase. 


\section{Discussion}

The results of the study indicate that the intervention had little to no influence on the SCs' level of journal writing. The Groups' data showed no positive or negative trends in the level of journal writing after receiving the intervention. Also there were no consistent increases or decrease in the Groups' level of reflection means from the baseline to intervention phase. Other problems existed in the individuals' inability to establish a steady rate of response in the frequency of SCs' reflective level statements. Not establishing a steady rate of response is one of the hindrances of the non-concurrent multiple baseline design (Watson \& Workman, 1981). As a result of the high variability in the individuals’ data, most regression lines were nonsignificant ( $>>0.05)$. Therefore, the regressions lines could not be used to analyze the individuals' data because they did not adequately represent the data's trends. The means of the baseline and intervention phases were the only data that showed the intervention's influence on the individual SCs' level of reflective writing. The mean lines showed that the intervention had no substantial influence on the SCs' level of journal writing.

The first IRR score based on the 22 criteria was 76.2\%, which is above the suggested level of some research standards (Marques \& McCall, 2005), but low compared to other more rigorous standards (McMillan \& Schumacher, 1997). This reduced the ability of the researchers to adequately and reliably say that each statement was the criterion in which it was coded. The lower IRR must be taken into account when making any suggestions related to the criteria. The IRR score based on the researchers' assessment of the reflective levels was significantly higher at 85\%, which meets most standards for reliability (McMillan \& Schumacher, 1997). The researchers can be confident that they were consistently rating the statements within the same levels and that the data presented in the graphs are reliable. 


\section{Intervention Analysis}

All of the techniques and concepts used in this study to teach SCs about reflective practice were based on sound reflective theories (e.g., Dewey, 1993, Gibbs, 1988; Schön, 1983 and 1987) and positive results in previous research (e.g., Bain et al., 1999, Bain et al., 2002, Hume, 2009). Although the techniques used in this intervention did not influence the SCs' level of reflection, a few factors may have caused problems. A few concepts outside of the reflective techniques and concepts could have contributed to the intervention's lack of influence. These concepts include (a) the SCs' previous experience and time reflecting, (b) the SCs' beliefs about reflective practice, and (c) the SCs' accountability.

Student coaches' previous experience with reflective concepts. One factor that was different about this study compared to previous studies on reflective journal writing in a one semester class (e.g., Bain et al., 1999; Bain et al., 2002; Hume, 2009) was the SCs' previous experience with reflective concepts. Participants in the previous reflective studies were able to increase their reflective levels of writing within one semester class, but they all had some type of previous experience learning and practicing reflection throughout their program (e.g., Bain et al., 1999; Bain et al., 2002; Hume, 2009; Knowles et al., 2001). In this study the SCs had not been introduced or taught anything about reflection or reflective concepts within the program prior to the study.

Based on the information, from this study and previous studies (e.g., Bain et al., 2002; Hume, 2009) the SCs may not have had enough time or previous experience with reflective practice to grasp the concept of reflecting at higher levels and the importance of doing so. As Stevens and Cooper (2009) explained, refelctive practice and thinking are complex processes and 
skills. Improving the depth of thought takes time for students to develop and requires students to move through phases or levels of reflective thought (Dewey, 1933).

Because reflective practice is considered a learned skill, the researchers can look at the academic-learning-time concept described by Caldwell, Huitt, and Graeber (1982) and Fisher et al. (1978). The more time SCs spend engaging in and practicing reflective writing at a high level of success, the more likely they are to learn and improve. This concept is supported by Boud and Fales (1983) when they suggested that people are more likely to improve their reflecting capabilities when they spend more time reflecting. In this study it was unknown whether this previous experience would affect the intervention's influence on the SCs' reflective abilities. The SCs previous experience and time practicing reflecting may have contributed to the intervention's lack of influence. Future interventions of this nature should examine how much time and practice are needed for SCs to develop their thinking and reflective capabilites to help them move through the phase of reflective thought as described by Dewey (1933). Future research should examine SCs reflective abilities over the course of a program and not just a single semester class.

Student coaches' beliefs about reflective practice. Some of the essential personal factors that must be present while a person develops and learns a skill are motivation, autonomy, (Race, 2005) and positive role frames (Anderson, 1997). The SCs' motivation and autonomy toward reflective practice could have been reduced or negated because of their role frames. Role frame can be described as a coach's beliefs, attitude, and vision in which they picture the coaching role (Gilbert \& Trudel, 2001; Gilbert \& Trudel, 2005). Many research studies on expert coaches have suggested that education programs and reflective practices were not a significant component in their learning and career path, but playing and coaching experience 
were significant components (Erickson, Côte, \& Frazer-Thomas, 2007; Nash \& Sproule, 2009). Other research suggests that all coaches developed their knowledge by playing and coaching, observing coaches, mentoring, reading books and articles about best practices, and talking with other coaches (Côte et al., 1995; Irwin, Hanton, \& Kerwin, 2004). All of these learning experiences can skew the SCs' role frames with regard to reflective practice because most coaches have never been introduced to or required to practice using reflective theories and concepts.

In this study, SCs' role frames with regard to reflective practice have only been made stronger by not being required to reflect throughout the program. Before receiving the intervention class, many SCs thought of reflective journaling as a way to record their experiences and called it "busy work" instead of thinking of it as an opportunity to analyze and learn from their experiences. In Bain et al. (2002) the students who never reached the reasoning level, which is the fourth level of reflection, thought of reflective journals as records. Almost $70 \%$ of the journals written in this study did not have any reasoning statements. The SCs' role frames may have influenced their ability or motivation to use the reflective journals as a means to learn from their experiences. The only way coaching education can have a meaningful impact on SCs is to understand and find ways to work with the SCs' values and beliefs (Anderson, 1997). The idea of understanding and dealing with SCs' values and beliefs is supported by Jones and Turner, 2006, and Kelly, 2006. Without a positive role frame of reflective practice, engaging SCs intellectually and helping them to develop the ability to think and write at higher reflective levels will be difficult.

The belief SCs have about journals and efforts which they put toward the reflective journal assignment resonates in their comments and the number of words they wrote per journal. 
First, when the SCs were asked in the intervention class and the final class of the semester about the attitude they took when writing their reflective journals, the responses were "just to get it done” or "do it just well enough to pass". When asked why they had this attitude the SCs responded because it is a "pass fail course" and "writing a journal is time consuming there is other stuff to worry about.” These responses are similar to those real world coaches who participated in Knowles et al. (2006) study. The coaches in Knowles and colleagues (2006) study graduated from a university that taught reflective practices and required coaches to apply them throughout a program. However, most of these coaches stopped reflecting when they entered the real world of coaching. The two main reasons given were that it was time consuming and it was not required of them. In the current study SCs completed the reflective journals because completion was a requirement. In all likelihood, SCs completed the reflective journals the quickest way possible and did not think about applying the techniques taught in class or using the feedback to help them improve. If the SCs were not required to write reflective journals they would not have written them.

In addition, many SCs wrote journals that perfectly met or exceeded the 250 word limit by a few words. In general these journal entries were filled with Level 1 descriptive statements. SCs that wrote more words tended to write higher level reflective statements. The two SCs who averaged writing the most words per journal also wrote the most Level 4 statements over the entire study. This generalization was mentioned in Bain et al. (1999) research but not in the Hume (2009) research. If the SCs have a positive role frame with regards to reflective practice, then they may tend to assert more effort and write more words per journal that may lead to thinking and writing at higher levels of reflection. 
Student coaches accountability. Accountability is the last major concept that may have contributed to the intervention's lack of influence on the SCs' level of journal writing. The internship course in which the intervention took place was a pass-fail course. SCs only needed to score $70 \%$ in order to pass the course. SCs who achieved $100 \%$ did not get any more recognition than those who achieved $70 \%$. This fact alone could have been enough to negatively affect most SCs' motivation or autonomy, two important concepts related to learning and improvement (Race, 2005).

One purpose of this study was to create an environment that resembles the real world of coaching as much as possible by giving SCs freedom to write what they wanted and placing little accountability on SCs with regards to the reflective journal assignment. Currently most are not held accountable for completing or providing any reflective information in their jobs (Knowles et al., 2006). For this reason the only requirement for the SCs to receive a passing grade was to complete the journal on time, write about their internship experience, and to meet the minimum 250 word requirement. The instructor suggested that the SCs use the reflective concepts when writing their journals, but they were not held accountable if they didn't apply the concepts. The accountability from the class and the journal assignments could have been a potential problem. It may have caused the students to spend less time and place less emphasis on the journal assignment, which are two important factors in a person's ability to learn and improve.

The ultimate goal of any CEP should be to produce SCs that can and will take the content knowledge and pedagogical process taught in the program and use them in a real world setting. This being said, future research studies should first hold the SCs accountable for their reflective assignments and find suitable ways to improve SCs' reflective abilities. After proven methods for improving SCs' reflective abilities have been established in CEPs, then researchers can look 
for ways to reduce the accountability in the study to more closely resemble the real world of coaching.

\section{Initial Intervention and Post Intervention}

Each of the initial intervention classes started well with high engagement and conversation levels, but as the class progressed the SCs' engagement dropped even though the SCs were actively reading, discussing, and writing. In relation to the material taught, the SCs tended to grasp the concept of the reflective cycle (Galvin, 2006) and the necessary steps that need to be considered when thinking through a problem. The SCs showed their understanding of this concept through their descriptions and conversations in group discussions.

In relation to the reflective levels and the revised Five-Point Level of Reflection Scale, the SCs did not grasp this concept as well as the reflective cycle (Galvin, 2006). Students asked many more questions and seemed confused by some of the differences between levels. The example of high level of reflective writing did not seem to spark many questions or help to solve their confusion with regards to higher reflective levels. One reason for this could be the fact that the reflective example used was from a nurse and not a coach. The instructor tried to verbally compare a coaching example of high levels of reflection to increase the SCs' understanding and engagement. The researcher did not believe the lack of direct relevance to the coaching context would matter when in fact it may have contributed to the SCs' lack of engagement, questioning, and or understanding.

Having the SCs assess their own journals using the revised Five-Point Level of Reflection scale helped some SCs gain a better understanding of the level of reflective writing they achieved in their journals. This was evident through their evaluations and discussions of the 
reflective levels that they had reached. Having the SCs write reflective statements at different levels helped to deepen their understanding of the reflective level concept. SCs displayed this deeper understanding through their in-class written reflections and their conversations about the levels.

Instructor's post intervention reflections. Although the instructor felt that some SCs grasped the concept of reflective levels, some SCs were still confused at the end of the class.

The instructor took measures such as giving feedback further description to reduce the confusion as much as possible in the time allotted for the intervention class. When the SCs wrote statements in class at an inappropriate reflective level the instructor provided feedback to the SCs on what reflective level they had reached and how they could improve and write at the appropriate levels. Because the intervention class was designed to take place for only three hours, more time could not be spent to assure all SCs gained a better understanding. It was the hope of the instructor that the feedback given on all journals after participating in the intervention class, would help reduce the SCs' confusion and influence the SCs' to achieve higher levels of reflective writing.

\section{Future Research}

The results of this study and previous research suggest that reflection should be taught and utilized throughout a program (e.g., Bain et al., 1999; Knowles et al., 2001; Hume, 2009). In previous studies in which students improved their level of reflective writing the students had experience with reflective practice prior to participation in the research (e.g., Bain et al., 1999; Bain et al., 2002; Hume, 2009; Knowles et al., 2001). In the current study SCs had minimal experience with reflection before this class. Two important factors to learning a skill include: time and quality effort (Ericsson, 2003; Ericsson, Krampe, \& Tesch-Romer, 1993). Reflective 
skills are no exception to this rule. Reflective ideas, concepts, and tasks should be stranded throughout an entire CEP. Stranding the reflective concept throughout a CEP gives SCs more time to learn about the importance of reflection and to practice reflecting. The extra time also give coaching educators a chance better understand the SCs’ role frames that effect their beliefs and attitudes toward reflective practice; which is an important aspect if CEPs are to have a meaningful impact (Anderson, 1997; Chesterfield, Potrac, \& Jones, 2010). Future research should examine SCs' reflective abilities across an entire CEP that teaches reflective concepts and requires SCs to use reflective concepts.

Future studies on the reflective abilities of SCs should also examine the effect of requiring SCs to write more words. Evidence from this research and Bain et al. (1999) and Bain et al., (2002) give rise to the idea that requiring students to write more may help to increase the level that students reflect. Although some SCs may struggle to reach higher levels of reflection, it is the job of coaching educators working in CEPs to make sure the SCs learn how to reflect at higher levels. Requiring SCs to write more words requires them to spend more time reflecting, which is one important concept needed when learning a skill (Ericsson, 2003). More time writing could lead higher level thinking and reflections.

The final suggestion for future research is to establish more accountability placed on the SCs. Adding more accountability requires SCs reflections to include high quality writing, a second important factor when learning a skill (Caldwell et al., 1982; Ericsson, 2003; Ericsson et al., 1993). By requiring SCs to spend more quality time in acquiring these high-level reflective skills, coaching educators may have a better chance to improve SCs' reflective abilities. Coaching educators and researchers need to expand the research in this area to help CEPs 
improve SCs' refective abilities, which will give SCs a better chance of succeeding when they enter the complex world of coaching. 


\section{References}

Abraham, A., \& Collins, D. (1998). Examining and extending the research in coach development. Quest, 50, 59-79.

Anderson, A. (1997). Using personal histories to explore theories about teaching/learning process in physical education. Avante, 3(1), 71-82.

Anderson, A., Knowles, Z., \& Gilbourne, D. (2004). Reflective practice for applied sports psychologists: A review of concepts, models, practical implications, and thoughts on dissemination. The Sports Psychologist, 18, 188-201.

Baer, D. M., Wolf, M. M., \& Risley, T. R. (1968). Some current dimensions of applied behavior analysis. Journal of Applied Behavior Analysis, 1, 91-97.

Bain, J. D., Ballantyne, R., Packer, J., \& Mills, C. (1999). Using journal writing to enhance student teachers’ reflectivity during field experience placements. Teachers and Teaching; Theory and Practice, 5(1), 51-73.

Bain, J. D., Mills, C., Ballantyne, R., \& Packer, J. (2002). Developing reflection on practice through journal writing: Impacts of variation in the focus and level of feedback. Teachers and Teaching: Theory and Practice, 8(2), 171-196.

Ballantyne, R., \& Packer, J. (1995a). Making connections: Using student journals as a teaching/learning aids. Australian Capital Teritory, Australia: Higher Education Research and Development Society of Australasia Inc.

Ballantyne, R., \& Packer, J. (1995b). The role of student journals in facilitating reflection at the doctoral level. Studies in Continuing Education, 17(1-2), 29-45.

Bellg, A. J., Borrelli, B., Resnick, B., Hecht, J., Minicucci, D. S., Ory, M.,Ogedegbe, G.,Orwig, D.,Ernst, D., Czajkowski, S. (2004). Enhancing treatment fidelity in health behavior 
change studies: Best practices and recommendations from NIH Behavior Change Consortium. Health Psychology, 23, 443-451.

Biggs, J. B., \& Collis, K. F. (1982). Evaluating the Quality of Learning . New York, NY: Academic Press.

Boud, D., \& Fales, A. W. (1983). Reflective learning: Key to learning from experience. Journal of Humanistic Psychology, 23(2), 99-119.

Boud, D., Keogh, R., \& Walker, D. (1985). Reflection: Turning experience into learning. New York, New York : Nicholas Publishing Company.

Caldwell, J. H., Huitt, W. G., \& Graeber, A. O. (1982). Time spent in learning: Implications from research. Elementary School Journal, 82, 471-480.

Cassidy, T., Jones, R. L., \& Potrac, P. (2004). Understanding Sports Coaching: The Social, Cultural, and Pedagogical Foundations of Coaching Practice. New York, New York: Routledge.

Chesterfield, G., Potrac, P., \& Jones, R. (2010). Studentship and impression management in an advanced soccer education award. Sport, Education and Society, 15(3), 299-314.

Cooper, J. O., Heron, T. E., \& Heward, W. L. (2007). Applied behavior analysis. Upper Sadle River, New Jersey: Pearson Education Inc.

Côte, J., \& Gilbert, W. (2009). An integrative definition of coaching effectiveness and expertise. International Journal of Sports Science \& Coaching, 4(3), 307-323.

Côte, J., Salamela, J. H., Trudel, P., Baria, A., \& Russell, S. J. (1995). The coaching model: A grounded assessment of gymnastic coaches' knowledge. Journal of Sport and Exercise Psychology, 17, 1-17. 
Craft, M. (2005). Reflective writing and nursing education. Journal of Nursing Education, 44(2), 53-62.

Cushion, C. J. (2001, September). Coaching research and coach education: Do the sum of the parts equal a whole? . Retrieved January 2010, from SportPolis: http://www.sportsmedia.org/Sportapolisnewsletter4.htm.

Cushion, C. J., Armour, K. M., \& Jones, R. L. (2003). Coach education and continuing Professional development: Experience and learning to coach. Quest, 55, 215-230.

Dewey, J. (1933). How we think: A restatement of the relation of reflective thinking to the educative process. Chicago, IL: Henry Regnery Company.

Dumas, J. E., Lynch, A. M., Laughlin, J. E., Smith, E. P., \& Prinz, R. J. (2001). Promoting intervention fidelity: Conceptual issues, methods, and preliminary results from the Early Alliance prevention trial. American Journal of Preventive Medicine, 20, 38-47.

Erickson, K; Côte, J; \& Frazer-Thomas, J. (2007). Sport expereince, milestones, and educational activities associated with highperformance coaches' development. The sport psychologist, 21, 302-316.

Ericsson, K. A. (2003). Development of elite performance and deliberate practice: An update from the perspective of the expert performance approach. In J. L. Starkes \& K. A. Ericsson (Eds.) Expert performance in sports: Advances in research and sport exercise. (pp.49-83). Champaign, IL: Human Kinetics.

Ericsson, K. A., Krampe, R. T., \& Tesch-Romer, C. (1993). The role of deliberate practice in the acquisition of expert performance. Psychology Review, 100, 363-406.

Fisher, C., Filby, N., Marliave, R., Cahen, L., Dishaw, M., Moore, J., et al. (1978). Teaching behaviors: Academic learning time and student achievement: Final report of phase III-B, 
beginning teacher evaluation study. San Francisco, CA: Far West Laboratory for Educational Research and Development.

Galvin, B. (2006). A guide to mentoring sports coaches. Headingly, UK: Coachwise Business Solutions.

Ghaye, T., \& Lillyman, S. (2000). Reflection: Principles and practice for healthcare professionals. Salisbury, UK: Quay Books.

Gibbs, G. (1988). Learning by doing: A guide to teaching and learning methods. Oxford, England: Oxford Polytechnic.

Gilbert, W. D. (2001). Learning to coach through experience: Reflection in model youth sport coaches. Journal of Teaching in Physical Education, 21, 16-34.

Gilbert, W. D., \& Trudel, P. (2005). Learning to coach through experience: Conditions that influence reflections. Physical Educator, 62(1), 32-44.

Hume, A. (2009). Promoting higher levels of reflective writing in student journals. Higher Education Research \& Development, 28(3), 247-260.

Irwin, G., Hanton, S., \& Kerwin, D. G. (2004). Reflective practice and the origins of elite coaching knowledge. Reflective Practice, 5(3), 425-442.

Johns, C. (1994). Guided reflection. In A. Palmer, S. Burns, \& C. Bulman, Reflective practice in nursing (pp. 110-130). Oxford, UK: Pentaxion Ltd.

Jones, R. L. (2000). Towards a sociology of coaching. In R. Jones, \& K. Armour, The sociology of sport: Theory and practice (pp. 33-43). London, UK: Addison Wesley Longman.

Jones, R. L., \& Turner, P. (2006). Teaching coaches to coach holistically: Can problem based learning (PBL) Help? Physical Education \& Sport Pedagogy, 11, 181-202. 
Kegan, R. (1994). In over our heads: The mental demands of modern life. Cambridge, MA: Harvard University Press.

Kelly, P. (2006). What is teacher learning? A socio-cultural perspective. Oxford Review of Education, 32(4), 505-519.

Knowles, Z., Borrie, A., \& Telfer, H. (2005). Towards the reflective sports coach: Issues of context, education, and application. . Ergonomics, 48(11.14), 1711-1720.

Knowles, Z., Gilbourne, D., Borrie, A., \& Neville, A. (2001). Developing the reflective sports coach: Study exploring the process of reflective practice within a higher education coaching programme. Reflective Practice, 2, 186-207.

Knowles, Z., Tyler, G., Gilbourne, D., \& Eubank, M. (2006). Reflecting on reflection: Exploring the practice of sports coaching graduates. Reflective Practices, 7(2), 163-179.

Lueng, D. Y., \& Kimber, D. (2003). The relationship between approaches to learning and reflection upon practice. Educational Psychology, 23(1), 61-71.

Luikkonen, J., Laasko, L., \& Telama, R. (1996). Educational perspectives of youth sport coaches: Analysis of observed coaching behaviors . International Journal of Sports Psychology, 27, 439-453.

Lyle, J. (2007). A review of the research evidence for impact of coach education. International Journal of Coaching Science, 1(1), 19-36.

Lyle, J. (2002). Sports coaching concepts: A framework for coaches behavior. London, UK: Routledge.

Maas, J. (1991). Writing and reflection in teacher education. In B. Tabachnich; K. Zeichner, Issues and practices in inquiry-oriented teacher education (pp. 211-225). London, UK: Falmer Press. 
Marques, J. F., \& McCall, C. (2005). The application of interrater reliability as a solidification instrument in a phenomenological study. The Qualitative Report, 10(3), 439-462.

McDonald, D., \& Tinning, R. (1995). Physical education teacher education and the trend to proletarianisation: A case study. Journal of Teaching in Physical Education, 15, 98-118.

McMillan, J. H. \& Schumacher, S. (1997). Research in Education: A conceptual introduction. New York, NY: Longman.

Mezirow, J. (1981). A critical theory of adult learning and education. Adult Education, 32, 3-24.

Moon, J. A. (1999a). Learning journals: A handbook for academics, students and professional development. London, UK: Kogan Page.

Moon, J. A. (1999b). Reflection in learning and professional development: Theory and practice. . London, England: Kogan Page.

Nash, C. S. \& Sproule, J. (2009). Career development of expert coaches. International journal of sports science \& coaching, 4(1), 121-138.

NASPE. (2006). National Standards for Athletic Coaches. Retrieved February 12, 2010, from National Association for Sport and Physical Education.: http://www.aahperd.org/naspe/publications

Nelson, L. J., \& Cushion, C. J. (2006). Reflection in coach education: The case of the national governing body coaching certificate. The Sports Psychologist, 20, 174-183.

Osterman, K., \& Kottkamp, P. (1993). Reflective practice for educators . Newbury, CA: Corwin Press.

Perry, M. A. (2000). Reflections on intuition and expertise. Journal of Clinical Nursing, 9, 137145. 
Potrac, P., Brewer, C., Jones, R., Armour, K., \& Hoff, J. (2000). Towards a holistic understanding of the coaching process. Quest, 52(2), 186.

Powell, J. H. (1989). The reflective practitioner in nursing. Journal of Advanced Nursing, 14, 824-832.

Race, P. (2005). Making learning happen: A guide for post-compulsory education. London, UK: Sage.

Saury, J., \& Durand, M. (1998). Practical knowledge in expert coaches: On site study of coaching in sailing. Research Quarterly for Exercise and Sport, 69(3), 254-266.

Saylor, C. R. (1990). Reflection and professional education: Art, science, and competency. Nurse Educator, 15, 8-11.

Schempp, P. G., McCullick, B., \& Mason, S. (2006). The development of expert coaching. In R. L. Jones, The sports coach educator (pp. 145-161). New York, NY: Routledge.

Schön, D. A. (1983). The reflective practitioner: How professionals think in action. United States of America: Basic Books.

Schön, D. A. (1987). Educating the reflective practitioner. San Francisco, CA: Jossey-Bass.

Stevens, D. D., \& Cooper, J. E. (2009). Journal keeping: How to use reflective writing for learning, teaching, professional insight, and positive change. Sterling, VA: Stylus Publishing .

Trochim, W. M. (2006). Research methods knowledge base. Retrieved January 5, 2011, from Social research methods: http://www.socialresearchmethods.net/kb/index.php

Turner, A., \& Martinek, T. (1995). Teaching for understanding: A model for improving decision making during game play. Quest, 47, 44-63. 
Watson, P. J., \& Workman, E. A. (1981). The Non-concurrent multiple baseline acrossindividuals design: An extension of the traditional multiple baseline design. Journal of Behavior Therapy and Experimental Psychiatry, 12, 257-259.

Woodman, L. (1993). Coaching: A science, an art, an emerging profession . Sport Science Review, 2(2), 1-13. 
Table 1

Participant's Reflective Level Scoring Chart

\begin{tabular}{|c|c|c|c|c|c|c|c|c|c|c|c|c|c|c|c|}
\hline \multirow[t]{3}{*}{ Name } & \multicolumn{15}{|l|}{2} \\
\hline & Weeks & 1 & 2 & 3 & $\begin{array}{l}\text { Baseline } \\
\text { Total }\end{array}$ & $\begin{array}{c}\text { Baseline } \\
\text { Mean }\end{array}$ & 4 & 6 & 8 & $\begin{array}{l}1 \\
0\end{array}$ & $\begin{array}{l}1 \\
2\end{array}$ & $\begin{array}{l}1 \\
4\end{array}$ & $\begin{array}{c}\text { Intervention } \\
\text { Total }\end{array}$ & $\begin{array}{c}\text { Intervention } \\
\text { Mean }\end{array}$ & $\begin{array}{l}\text { Mean } \\
\text { Gains }\end{array}$ \\
\hline & Letters & & & & & & & & & & & & & & \\
\hline \multirow[t]{2}{*}{$\begin{array}{c}\text { LEVEL } \\
1\end{array}$} & A & 3 & 1 & 4 & 8 & 2.67 & 4 & 3 & 3 & 5 & 3 & 5 & 23 & 3.83 & 1.16 \\
\hline & Total & 3 & 1 & 4 & 8 & 2.67 & 4 & 3 & 3 & 5 & 3 & 5 & 23 & 3.83 & 1.16 \\
\hline \multirow[t]{6}{*}{$\begin{array}{l}\text { LEVEL } \\
2\end{array}$} & B & 0 & 0 & 0 & 0 & 0 & 1 & 0 & 0 & 0 & 0 & 0 & 1 & 0.167 & 0.167 \\
\hline & C & 3 & 2 & 1 & 6 & 2 & 0 & 3 & 2 & 0 & 3 & 2 & 10 & 1.667 & -0.33 \\
\hline & D & 0 & 0 & 0 & 0 & 0 & 0 & 0 & 0 & 0 & 0 & 0 & 0 & 0 & 0 \\
\hline & $E$ & 0 & 0 & 0 & 0 & 0 & 0 & 0 & 0 & 0 & 0 & 0 & 0 & 0 & 0 \\
\hline & Z & 0 & 0 & 0 & 0 & 0 & 0 & 0 & 0 & 1 & 1 & 0 & 2 & 0.333 & 0.333 \\
\hline & Total & 3 & 2 & 1 & 6 & 2 & 1 & 3 & 2 & 1 & 6 & 2 & 15 & 2.5 & 0.5 \\
\hline \multirow[t]{8}{*}{$\begin{array}{l}\text { LEVEL } \\
\mathbf{3}\end{array}$} & $\mathbf{F}$ & 0 & 0 & 1 & 1 & 0.333 & 0 & 0 & 0 & 1 & 1 & 0 & 2 & 0.333 & 0 \\
\hline & G & 0 & 0 & 1 & 1 & 0.333 & 1 & 0 & 0 & 1 & 0 & 1 & 3 & 0.5 & 0.167 \\
\hline & $\mathrm{H}$ & 0 & 0 & 0 & 0 & 0 & 0 & 1 & 0 & 0 & 0 & 0 & 0.167 & 0.167 & 0.167 \\
\hline & $I$ & 0 & 0 & 0 & 0 & 0 & 0 & 0 & 1 & 0 & 0 & 0 & 1 & 0.167 & 0.167 \\
\hline & $\mathrm{J}$ & 0 & 0 & 0 & 0 & 0 & 0 & 1 & 0 & 0 & 0 & 0 & 1 & 0.167 & 0.167 \\
\hline & $\mathrm{K}$ & 1 & 0 & 0 & 1 & 0.333 & 2 & 1 & 1 & 0 & 0 & 0 & 4 & 0.667 & 0.333 \\
\hline & $\mathbf{L}$ & 2 & 5 & 3 & 10 & 3.33 & 1 & 0 & 1 & 1 & 2 & 1 & 6 & 1 & -2.33 \\
\hline & Total & 3 & 5 & 5 & 13 & 4.333 & 4 & 3 & 3 & 3 & 3 & 2 & 18 & 3 & -1.33 \\
\hline \multirow[t]{7}{*}{$\begin{array}{l}\text { LEVEL } \\
4\end{array}$} & $\mathbf{M}$ & 0 & 0 & 0 & 0 & 0 & 0 & 0 & 0 & 0 & 0 & 0 & 0 & 0 & 0 \\
\hline & $\mathbf{N}$ & 0 & 0 & 0 & 0 & 0 & 0 & 0 & 1 & 0 & 0 & 0 & 1 & 0.167 & 0.167 \\
\hline & 0 & 0 & 0 & 0 & 0 & 0 & 0 & 1 & 0 & 0 & 0 & 0 & 1 & 0.167 & 0.167 \\
\hline & $\mathbf{P}$ & 0 & 0 & 0 & 0 & 0 & 1 & 1 & 1 & 0 & 0 & 0 & 3 & 0.5 & 0.5 \\
\hline & $\bar{Q}$ & 0 & 1 & 0 & 1 & 0.333 & 0 & 0 & 0 & 0 & 0 & 0 & 0 & 0 & -0.33 \\
\hline & $\mathbf{R}$ & 0 & 0 & 0 & 0 & 0 & 0 & 1 & 0 & 0 & 0 & 0 & 1 & 0.167 & 0.167 \\
\hline & Total & 0 & 1 & 0 & 1 & 0.333 & 1 & 3 & 2 & 0 & $\mathbf{0}$ & 0 & 6 & 1 & 0.667 \\
\hline \multirow[t]{4}{*}{$\begin{array}{l}\text { LEVEL } \\
5\end{array}$} & $S$ & 0 & 0 & 0 & 0 & 0 & 1 & 0 & 0 & 0 & 0 & 0 & 1 & 0.167 & 0.167 \\
\hline & $T$ & 0 & 0 & 0 & 0 & 0 & 0 & 0 & 0 & 0 & 0 & 0 & 0 & 0 & 0 \\
\hline & $U$ & 0 & 0 & 0 & 0 & 0 & 0 & 0 & 0 & 0 & 0 & 0 & 0 & 0 & 0 \\
\hline & Total & 0 & 0 & 0 & 0 & 0 & 1 & 0 & $\mathbf{0}$ & 0 & $\mathbf{0}$ & 0 & 1 & 0.167 & 0.167 \\
\hline
\end{tabular}




\section{Appendix A}

Improving Student Coaches’ Learning through Teaching Reflective Techniques

Review of Literature 


\section{Review of Literature}

The purpose of this review of literature is to examine previous research and scholarship associated with this study. The following is broken into four sections; (a) coaching education, (b) expert coaching, (c) reflective practice, and (d) reflective writing. These four sections will help elaborate on the factors and conditions that are associated with this study.

\section{Coaching Education}

Typically sport coaches have obtained their sport coaching knowledge through several different avenues (Irwin, Hanton, \& Kerwin, 2004; Erickson, Côte, \& Frazer-Thomas, 2007). These areas include playing many different sports, playing one or two sports competitively, observing coaches while playing, being a mentor or assistant coach, observing other coaches, reading books and articles about best practices, attending workshops, taking coaching classes, obtaining coaching degrees, talking with other coaches, and gaining coaching experience. Mallett and colleagues (2009) have divided these learning experiences into three categories: informal, non-formal, and formal.

\section{Informal Coaching Education}

Informal coaching education is not intentionally structured or designed to develop a coach’s learning. Informal learning occurs when coaches experience, observe, listen, read, or do anything that stimulates thoughts, beliefs, and ideas that will change or improve coaching knowledge or performance. Although the amount of influence informal learning has on coaches is not known, research has suggested that informal learning plays a significant role in coaching development (Gould, Giannani, Krane, \& Hodge, 1990; Irwin et al., 2004; Mallett et al., 2009; Wright, Trudel, \& Culver, 2007). 
A defined path for coaching effectiveness has not yet been established; many coaches begin learning informally by playing and observing sports in their youth (Cushion, Armour, \& Jones, 2003; Schempp, McCullick, \& Mason, 2006). These playing and observational experiences are types of informal learning. Through these experiences coaches mold and shape what is called in physical education a "subjective warrant" (Dewar \& Lawson, 1984) or beliefs and attitudes about the field. In coaching education the "subjective warrant" is better known as “role frames” (Gilbert \& Trudel, 2001; Gilbert \& Trudel, 2005). Future coaches begin to develop their own ideas and beliefs about what a sport is and how a sport should be played through informal learning experiences. As Schempp and Graber (1992) suggested, experiences and observation will influence coaches' future expectations. Coaches will understand and interpret coaching events based on their own sport foundation (Cushion, 2001) or role frame. A coach's perception of a sport continuously changes by gaining more experience and knowledge and will continue to influence coaches’ actions, beliefs, and thoughts.

Youth sports participation and observations are not the only types of informal learning experiences. Informal learning experiences can take place in both formal and non-formal situations. Informal learning can take place in mentorships, assistantships, workshops, classes, and while coaching. Mallett and colleagues (2009) suggest using the terms "guided informal learning" and "unguided informal learning”. Guided informal learning would take place in an unstructured setting where an expert coach informally facilitates a less experienced coach's learning (Mallett et al., 2009). Unguided informal learning is incidental and can happen in any situation. Research has suggested that coaches feel that they learn more from informally observing and listening to other higher level coaches or mentors (Gould et al., 1990; Irwin et al., 2004). 
Informal learning may be unstructured and incidental, but research suggest that it plays a significant role in a coach’s learning and development (Gould et al., 1990; Irwin et al., 2004; Wright et al., 2007). Through informal learning coaches have opportunities to concentrate on ideas they feel are most important and relevant to their own improvement. By concentrating on relevant topics, coaches may become more motivated and engaged, which are two important factors that influence positive learning experiences (Race, 2005).

On the other hand, Lyle, Mallett, Trudel and Rynne (2009) elaborated on McKenna’s caution to coaches. McKenna suggested that coaches should not overestimate the influence of informal learning because we know so little about coaching education, development, and learning. The infancy and current inabilities of coaching education programs may have influenced coaches to feel stronger about the significant role informal learning has had on their lives compared to formal learning (Bates, 2007).

Coaches should check and challenge the accuracy of information they learn in informal situations. For example, observing a winning coach yell at his players does not mean that it is the correct practice. It is essential for coaches to be critical of not only the place from which they draw their knowledge, but also of themselves to make sure that they learn correct practices. Studying the informal learning and development of coaches can help lead to better understand of the importance and influence of informal learning on a coach's development.

\section{Non-formal Coaching Education}

Non-formal education is the middle ground between formal and informal learning. Unlike informal education, non-formal education usually has some structure. Merriam, Caffarella, and Baumgartner, (2007) stated that non-formal education provides formal learning opportunities, 
organizes outside the educational system, requires little to no prerequisites, is usually short term, and is voluntary. Sports clubs or associations provide non-formal educational opportunities in the local settings where coaches may either be invited or attend voluntarily.

Non-formal coaching education has several positives aspects. First, they can be very specific in nature, emphasizing on specific topics that coaches may want to learn (Mallett et al., 2009). Second, coaches participating in non-formal education have more freedom to choose what they learn and how they apply it. Non-formal coaching education has advantages over formal education because coaches can choose what they want to learn. Coaches are not restricted to completing a certain type of information or amount of work. Non-formal coaching has advantages over informal education because the information is packaged so the coach does not have to search for information. Coaches in non-formal learning environments can be more certain of the information and knowledge they are obtaining.

Non-formal education also presents disadvantages as well. Compared to formal education, non-formal education usually does not involve accountability. How much a coach learns depends on their dedication and commitment. This is a disadvantage compared to formal education, which is usually based on formal curriculums teaching as much about coaching as possible while involving accountability through grades or certificates (Merriam et al., 2007).

Another non-formal education disadvantage, as Mallett and colleagues (2009) stated, is that non-formal education is usually guided by the knowledge of others. Although the information may come from experts, coaches must be extremely critical of the information they receive during non-formal settings. Is this knowledge of others based on research or facts? Or, is the knowledge based on opinion or observations? How much experiential knowledge and 
what kind of experience does the person providing information have? Does this information apply to all coaching situations or just the speaker's situation? Without this critical mind frame, coaches participating in non-formal education may be setting themselves up for failure by developing an incorrect knowledge base coaching schema or role frame.

\section{Formal Coaching Education}

Formal coaching education is a formal learning opportunity that measures, assures quality, and recognizes achievement (Mallett et al., 2009). Merriam and colleagues (2007) describe formal education as "highly institutionalized, bureaucratic, curriculum driven, and formally recognized with grades, diplomas, or certificates” (p. 29). The purpose of formal coaching education is to teach coaches a certain curriculum designed specifically to produce competent coaches. Formal coaching education courses break down content and teach student coaches (SC) the best practices known for coaching (Abraham \& Collins, 1998).

Formal coaching education is accompanied by numerous positive aspects. First and foremost, research shows that a coaching education program can improve coaching behaviors (Smoll \& Smith, 2006). The keys to the Smoll and Smith (2006) coaching course was providing alternative options to deal with certain situations and took the focus off of right or wrong. Smoll and Smith argued that coaching education needs to stress flexibility to help coaches think of alternative ways to handle situations instead of the just copying what former coaches have done.

Secondly, formal coaching education is usually based on curriculum that has been specifically designed to teach coaches the best content to improve their teams and athletes (Nelson, Cushion, \& Potrac, 2006). By assuring the information being taught is accurate, formal coaching education SC can be confident that the information is accurate and useful. Third, 
coaches can track their knowledge through assessment procedures (e.g. tests, grades, reports, papers) and feedback from teachers. Coaches can put more effort toward learning the material than criticizing who gives the information and where it comes from.

Fourth, formal coaching education can lead to the development of critical thinking skills (Mallett, et al., 2009). Critical thinking and cognitive skills have been suggested to be essential coaching behaviors (Abraham \& Collins, 1998; Côte, Salamela, Trudel, Baria, \& Russell, 1995). Finally, SC can receive rewards, recognition, and with accreditation through formal education programs. Several formal CEP are “accredited and with acknowledged standards of achievement” (Lyle et al., 2009, p. 360). In the United States, many higher education institutions have formal CEP but only nine programs have gained national accreditation through National Council for Accreditation of Coaching Education (NCACE, 2006).

The negative aspects of formal coaching education often go unnoticed. First, it does not encourage SC to criticize information and consider what is most useful to their specific coaching needs. Second, formal education has been designed around a wide angled lens. As a result, formal education is broad and not always specific to each sport or coaching situation. The information is taught as separate entities and not as interdependent subjects (Jones, 2000). SC now criticizes how the information best fits their specific type of coaching because of the immense amount of information and diversity in coaching.

Third, SC have little freedom to choose the information and classes that best suit their coaching needs because the curriculum and classes in a formal CEP are already designed. By providing little freedom, CEPs may negatively affect a coach's motivation and engagement in his or her own learning. Formal coaching education can also lead to thinking there is only one right 
way (Nelson et al., 2006). Smoll and Smith (2006) suggested the need to move away from this type of thinking and to give coaches the freedom. As these are not all of the negative aspects associated with coaching education, they are some of the more prevalent ones.

\section{Formal Coaching Education Programs}

CEPs are faced with the daunting task of educating SC to become effective competent coaches. This task is so daunting because little is known about the proper way to educate coaches and the complex nature of coaching. While there a several theoretical models developed and being developed to improve coaches' knowledge and performance, little is known about the influences these models have on coaches' behaviors. In a review of coaching research only two articles were classified as program evaluations (Lyle, 2007).

Because there is little evidential research to condemn or praise CEP, several prominent coaching education researchers have discussed the current problems with CEP. Cushion (2001) described the problems in the current model of coaching education as "the sum of the parts does not equal the whole”. The current coaching education model focuses on teaching how to improve athletes' performance and not on the development of coaching performance (Luikkonen, Laasko, \& Telama, 1996). If coaches are to perform in the field, CEP must focus more on developing coaches' abilities instead of just their athletes. Cushion (2001) describes current coaching education as presenting material in parts that require coaches to reassemble the information later. Turner and Martinek (1995) described the results of coaching education as a decontextualized view of the coaching process. Coaching education programs do not consider the human context (Jones, 2000) and the problems they create within real world situations. Too many contexts, variables, activities, as well as human characteristics are involved in coaching to be decontextualized in the education world. 
Several suggestions have been made to improve CEP that concentrate on one key aspect. Some examples are effectively communicating (Fouss \& Troppman, 1981), focusing on instructional abilities (Tinning, 1982), understanding motor learning (Fischman \& Oxendine, 1993), and improving athlete performance and achievement (Luikkonen et al., 1996). As Cushion (2001) suggested these coaches are right and wrong at the same time. All of these aspects are important to coaching, but the process is too complex to state that one coaching behavior is the most important. How do CEPs educate coaches if the process is so complex?

Because of the complex nature of coaching and the dissatisfaction with current CEP many coaching educators have begun to rethink the process of educating coaches. Lyle (1992) considered the need to look at educational theory when developing CEP. Lyle wanted to use a theory from Schön (1983) and Schön (1987) talking about a person's “knowledge-in-action”. Knowledge in action is a person's ability to perform while purposely applying their content and experiential knowledge to his or her actions. One major goal of all CEP should be to help SC to use the knowledge taught in CEP and apply it to current coaching situations.

If one goal of CEPs is to develop “knowledge-in-action”, what do we need to teach and how do we need to teach it? Abraham and Collins (1998) provided an extensive review of the coaching research literature. Recommendations made based on their finding include what knowledge should be taught, how the knowledge should be taught, and how assessment procedures to encourage learning should be designed. Their suggestions were to teach declarative or content knowledge including motor learning content, broad problem solving skills, and reflective skills. Combining content knowledge and problem solving skills with critical reflection was suggested to help students improve procedural knowledge or Schön’s (1987) 
stated "knowledge-in-action". While Abraham and Collins (1998) supported this idea with other literature and research they did not have any proof that it would work.

Côte and colleagues (1995) inferred the need to look at coaching in a more holistic light. Coaching is not a single occurrence and cannot be taught a single step at a time. By interviewing expert coaches about the concepts and strategies they utilize in their coaching, Côte and colleagues described four variables that affect coaching decisions: personal characteristics of the coach, personal characteristics of the athlete, level of development, and context. Coaches deal with these variables in different ways. Coaching educators can use this information to design programs that will improve coaching abilities related to the four variables.

Potrac, Brewer, Jones, Armour, and Hoff, (2000) reiterated the point of thinking about the holistic process of coaching. It is argued within their article that current methods of educating coaches do not work because a coach’s learning is decontextualized. Coaches are taught specific content knowledge as single subjects that are disconnected from the process as a whole. In turn the coach is unable to change and adapt to diverse world of coaching. To combat this, the authors argued coaching educators and researchers need to analyze the quantitative methods of systematic observation with the qualitative methods of interviews to better understand coaching as a holistic process.

Jones, Armour, and Potrac (2002) explain their framework for understanding the social aspects of coaching. They suggest that researching the social aspect of coaching will lead to a better understanding of the entire coaching process. Three concepts were suggested to help critically analyze coaching: (a) the role or position a coach takes within the social framework of a team; (b) interaction or how coaches act in the presence of their team; and (c) the dynamic 
relationship between individual players, the team and the coach. The authors argued that the interaction of the concepts is where investigation should take place.

Working off the idea of the interacting concept, Jones and Turner (2006) examined the use of problem based learning. Problem based learning is based on certain scenarios or problems in which groups of SCs must work together over several weeks to research and discuss a solution. The problems encompass many interacting concepts of coaching and end with reflective practices to help tie everything together and improve the understanding of what the coaches had learned through the process. By observing, reflecting, and interviewing students, the researchers found that problem based learning opened SC eyes to the complex nature of coaching (Jones \& Turner, 2006).

Knowles, Gilbourne, Borrie, and Neville (2001) and (Knowles, Tyler, Gilbourne, \& Eubank (2006) took the idea of utilizing reflection to another level by examining its influences of reflective practice in a coaching education program. The Knowles et al., (2001) study found reflective practices influenced SCs' learning. The Knowles et al., (2006) study was a follow up of the coaches involved in the 2001 coaching program to determine whether or not the coaches from the previous study continued to use reflective practice as a learning tool. The research suggested that coaches did not continue to utilize reflective practices in the real world due to factors such as little to no accountability, short term contracts, and high time consumption.

Although it is still unknown whether CEPs produce positive behavioral changes in their coaching graduates, there seems to be hope in the future. In the United States, in 2006, the National Standards for Sport Coaches (NASPE, 2006) were revamped to present coaching competencies under eight different sport domains. CEPs should utilize the new standards, the 
new progressive ideas, and the new research to help make positive behavioral changes in their coaching graduates and, as a result, producing competent coaches.

\section{Expert Coaching}

\section{Coaching Knowledge Development}

The principles that are required for coaches to learn are very similar if not the same as all other areas. By looking at educational research, there are several principles that are necessary for positive learning to take place. These principles include intrinsic motivation, autonomy (personal ownership over learning), engagement in the activity, ability and opportunity to apply content to make since of learning, quality feedback, accessibility and more (Race, 2005). Not all of these principles will be present in each formal, informal, and non-formal learning experience, but some of them must be present for learning to take place. A coach must be motivated, engaged, and take ownership of their learning.

Examining the factors that affect sports coaching is an important part of developing a coach’s knowledge. Sport coaching is a dynamic process presenting coaches with many situations that require “knowledge-in-action” (Schön, 1987) or craft knowledge. It has been suggested by Abraham and Collins (1998) that cognitive skills are the most important part of coaching expertise. Different types of cognitive skills are essential in developing competent effect sports coaches (Gould et al., 1990; Knowles et al., 2001). Many coaching education programs emphasize teaching professional knowledge (Knowles et al., 2005) and not on craft knowledge or knowledge-in-action. If coaches want to become effective sport coaches they must develop their craft knowledge (Gould et al, 1990; Salmela, 1995; Knowles et al., 2001; Knowles, Borrie, \& Telfer, 2005; Knowles et al., 2006). This evidence presents a strong case to change the 
current status of coaching education to focus on developing this craft knowledge or Schön's 1983 “knowledge-in-action”.

Saury and Durand (1998) suggested that the effectiveness of elite coaches is based on craft knowledge more than theoretical or content knowledge. Craft knowledge is developed through experience and interacting with other coaches (Gould et al., 1990; Salmela, 1995). While experience is crucial in a coach's learning, literature has also suggested that the experiential learning can be improved by developing reflective skills (Abraham \& Collins, 1998;

Knowles, et al., 2001; Knowles et al., 2005; Knowles et al., 2006). Through examining the research, it is essential for coaches to develop skills that help them utilize past experiences as coaches and players and lead to more effective "knowledge-in-action".

\section{Becoming an Expert Coach}

While there are many paths that coaches have taken to reach expert status, there is little research to suggest the best path for coaches to follow. The coaching profession and the research in coaching education must be explored to better understand what it means to be an expert coach and the process of becoming one. By doing this it might be possible to clear up some of the muddy waters on expertise and highlight essential knowledge and abilities of expert coaches.

Siedentop and Elder (1989) discussed expertise in teaching from a behavioral perspective. Six expert characteristics were explained: discriminatory capabilities; quickness of response; larger bodies of knowledge; control of the complex elements; extensive planning; and the process of articulation, rationalization and critiquing their own learning. These characteristics hold true for any field including coaching (Schempp et al., 2006). Although Siedentop and Elder (1989) mentioned these characteristics, they also explained that expertise is 
specific to the subject matter and the context and it is supported by other research (Rovegno, 1995; Schempp, Manross, Tan, \& Fincher, 1998), meaning that an expert professional coach may not be an expert college coach, or vice versa. This happens often when expert college coaches unsuccessfully move to professional ranks.

With an explanation of the basic behavioral principles associated with experts, where do researchers go from here? Salmela (1995) examined the knowledge development of expert coaches through extensive interviews. Coaches were found to develop knowledge in a variety of different ways and from a variety of different sources, including playing experience, mentors, coaching resources and coaching experience. Salmela (1995) concluded that many of issues affect the development of expert coaches and make it hard to copy or implement into an academic education.

The behaviors of an expert, the areas of knowledge acquisition, and the way in which the content could be taught in education are evident, but researchers do not yet know the specific path coaches take to become experts. Erickson and colleagues (2007) researched high performance coaches to discover the steps they took to become an expert. They found five steps or milestones that coaches go through during their development including (a) participating in a diversity of sports during youth, (b) participating in competitive sports, (c) participating in elite sports, (d) coaching part time, and (e) coaching full time with high performance athletes. It is easy to see in this research that playing and coaching experience are necessary components. This information could lay a foundation for future coaching development.

While Erickson and colleagues (2007) examined the entire life of a coach, Schempp and colleagues (2006) described the four stages of coaching development after becoming a coach. 
The four stages include in (a) beginner, (b) competent, (c) proficient, and (d) expert. Beginning coaches usually have three or less years of experience. Beginner coaches worry about establishing routines, managing, externalizing problems, and usually place blame on others. Competent coaches transform and start helping athletes realize their potential within the sport and as a person. A competent coach identifies common experiences to develop strategic knowledge and contingency plans by using reflection. The third coaching stage is proficiency and is only reached by the top 20 to 25 percent of coaches. A proficient coach has thousands of hours of coaching experience, makes deliberate efforts toward improving, understanding their coaching, and developing a sense that they can teach anyone willing to learn how to play their sport.

The fourth and final stage of Schempp and colleagues (2006) model, is expert. The differences between proficient and expert lie in factors such as intuition, decision making skills, and usually more experience. While experts have the ability to rely on their intuition or gut instinct, proficient coaches still use logical progression to drive their decision making. Experts have developed fluency in their actions or strong craft knowledge. Experts plan in great detail, can describe their actions from past years, and predict actions they will take in future years to improve their team. Experts continuously strive to learn more and admit that they will never know everything about their respective sport. Experts are also realistically self-aware of their own actions, knowledge, and abilities, while beginners are usually over confident and usually are unable to admit their deficiencies. Schempp and colleagues (2006) take home message was that anyone can become an expert coach by purposefully developing the aspects of expertise in coaching. 
Nash and Sproule (2009) again examined the career development of expert coaches. They found very similar information to Schempp and colleagues (2006) and Erickson and colleagues (2007) works. The contributions by Nash and Sproule (2009) include the positive outlooks and experience that each coach experienced at the youth level, networking with other coaches, and the fact that expert coaches could not provide insight to how they became experts except through informal processes.

Côte and Gilbert (2009) redefined coaching expertise and effectiveness. They suggest that any definition of coaching expertise or effectiveness should include three variables: (a) the coach's knowledge base, (b) the ability to transform athlete performance or personal attributes, and (c) the context. The definition given for effectiveness was "the consistent application of integrated professional, interpersonal, and intrapersonal knowledge to improve athletes' competence, confidence, connection, and character in specific coaching context” (Côte \& Gilbert, 2009, p. 316). It was concluded that expert coaches consistently demonstrate all aspects of the effectiveness definition while non-experts will be inconsistent in one or more area.

Through examining the research, the characteristics of an expert coach can easily be seen. However, there is not one clear direction that coaches take along the road of becoming an expert. Even though a perfect coaching plan does not exist there are many areas that are essential in the process to become an effective, competent, or expert coach. These areas include having positive playing experience, learning from and networking with other respected coaches, gaining coaching experience, having a purposeful drive toward learning and improvement, and utilizing tools such as reflection to enhance the process. 


\section{Reflective Practice}

\section{Conceptual Framework}

Coaching educators can use Schön $(1983,1987)$ works to improve and enhance coaching education. Both works explain reflective practice and how it aids in the learning process. Schön describes, "knowledge-in-action” as abilities or the immediate or subconscious review of similar and previous experience, recognizing variables, outcome knowledge, and alternative actions that allows the person act successfully; “reflection-in-action” or a person’s ability to think and apply while performing; and “reflection-on-action” or a person’s ability to think and understand personal experiences. Reflecting allows people to understand how something is done and the importance of why it is done. Schön (1983) and Schön (1987) argue that education must teach people how to not only reflect in action but on action as well. Schön (1987) elaborated on the importance of personal reflection by citing Dewey (1974),

He has to see on his own behalf and his own way the relations between means and methods employed and results achieved. Nobody else can see for him, and he can’t see just by being told, although the right kind of telling may guide his seeing and thus help him see what he needs to see (p. 151)

This statement suggests the need for education to be grounded in experience while requiring students to reflect in action and on action to allow people to develop their own understandings. Reflection allows individuals to construct new understandings of experiences (Schön, 1983). Lyle (1992) supports this idea of grounding education in experience while using reflective practice to enhance the learning from the experience. 
As Academic Learning Time (ALT) research has shown, the more a person properly engages in an activity the more likely he or she will learn the activity (Caldwell, Huitt, \& Graeber, 1982; Fisher, et al., 1978). ALT shows that students' actions directly affect what they learn and that teachers' actions indirectly affect what students learn. Teachers only affect student learning through designing tasks, presenting material, giving feedback, and other indirect factors. Students will not actually learn until they are directly engaged in an activity cognitively or physically.

The ALT theory has a couple of implications for reflective practice. First, participating in reflective practice is not going to directly enhance a coach's ability because the coach because they are not actively engaged in coaching. Reflection can help improve a coach’s learning and understanding of the coaching process, which will in turn give the coach more tools to improve his or her coaching behaviors. Second, coaches cannot be expected to possess the ability to reflect appropriately without the ALT to improve upon these skills. The more time a coach has to learn and appropriately practice reflection, the better they will be.

The most important concept for coaching education researchers examining reflective practice is not the fact that they need to provide students with substantial time to reflect that concept is clearly evident. Instead researchers need to investigate the best ways to present and teach reflective practice. Also, researchers must understand how reflection can help coaches develop differently. Because people are so diverse and reflective practice is so complicated, it necessary to understand what types of reflective practice suits what types of learners. 


\section{Factors Influencing Reflection}

Reflective practice has been suggested to be an integral part of coaches’ knowledge development (Gilbert and Trudel, 2001; Gilbert and Trudel, 2005; Knowles et al., 2001; Knowles et al., 2005; Knowles et al., 2006; Lyle, 1992; Lyle, 2007; Nelson and Cushion, 2006; Schempp et al., 2006), which suggests the need for all coaches in all situations to reflect. Gilbert and Trudel (2001) completed a study on how youth sport coaches learn to coach through experience. They found six factors coaches use that encompassed some type of reflection. These factors include coaching issues, role frames, issue setting, strategy generation, experimentation, and evaluation. The results suggested that coaches' role frames were central to what and how they reflected. Other issues such as access to peers, stages of learning, issues, and environments also had some effects on the coaches’ abilities to reflect.

The idea of role frames was discussed in Schön’s $(1983,1987)$ experiential learning

theory. Schön describes role framing as how practitioners build the reality in which they live and function. Each person has their own role frame and functions differently in them. Schön (1983) said

When a practitioner becomes aware of his frames, he also becomes aware of the possibility of alternative ways of framing the reality of his practice. He takes note of the values and norms to which he has given priority, and those he has given less importance, or left out of account altogether. Frame awareness tends to entrain awareness of dilemmas. (p. 310)

In Gilbert and Trudel’s (2004) study they examined model youth sports coaches’ role frames. What they found were three factors affecting roles frames including age group, 
competitive level, and gender. Inside of the frame were nine other factors including ideas such as growth and development, sport development, fun, winning, and more. Role frames can be extensive in size and complicated to understand but they play a major role in a coaches' ability to reflect and learn from situations. Schön (1983) felt that practitioners should not only have the ability to understand their role frames but to change or alter their role frames through reflectingin and reflecting-on their experiences. Dewey (1933) felt that reflection allowed a person to know what they were about when they acted.

Gilbert and Trudel (2005) examined other factors that influence reflection of youth sport coaches. Six youth sports coaches with an average of almost 11 years of experience were studied over an entire sports season. The results of the study showed four major categories that affected the reflective practice of coaches: (a) access to knowledgeable peers, (b) stage of learning, (c) issue characteristics, and (d) environment.

Access to information is essential to any learning experience (Race, 2005; Schön, 1983). If coaches do not have access to knowledgeable, respected, and trusted peers then coaches most likely will not utilize that type of reflection (Gilbert and Trudel, 2001; Gilbert and Trudel, 2005). Seeking knowledgeable peers for reflection purposes has been suggested to be important (Smith \& Smoll, 1997; Schön, 1983). Gilbert and Trudel (2005) suggested developing coaching groups in which coaches could refer to for information and reflective purposes.

Coaches must be at the proper stages of learning described by Rumelhart and Norman (1978) (as cited in Gilbert \& Trudel, 2005). The stages of Rumelhart and Norman’s (1978) learning include learning and storing in memory, refining schemas or knowledge structures using learning and stored information, and restructuring to create new schemas and understandings. 
Gilbert and Trudel (2005) third factor affecting reflection is the issue characteristic or the degree of the problem presented. The more challenging the problem, the harder it will be for the coaches to find a solution to the problem. The fourth factor affecting reflection was the environment or context, which has a huge impact on reflection and is why Schön (1983) suggested developing an environment that is cooperative, nurtures creativity, and remains open.

Knowles and colleagues (2006) also examined factors influencing reflective practice. They explained five factors affecting coaches' ability to reflect, including no requirements, short term contracts, time constraints, technique, and interpretation. By not requiring reflection, coaches may not feel the need to reflect, especially if they are winning. Coaches who sign short term contracts are not assured of their position, making them less likely to participate in reflective practices. Reflection can be a long process that takes a significant amount of time. Coaches must know how to reflect and interpret their experiences so they can learn and understand what took place and why. Also by understanding different techniques and process associated with reflection coaches can reduce the amount of time it takes to reflect.

How can CEP negate the inhibiting factors discussed by Gilbert and Trudel (2005) and Knowles and colleagues (2006) and improve coaches' reflective practice? There are several suggestions that have been made to override the inhibiting factors. Gilbert and Trudel (2005) suggested enhancing reflective practice of coaches. These suggestions include (a) developing groups for discussion, (b) making assessment tools for training, (c) locating resource and educational partnerships, (d) focusing on issues faced in coaching, (e) developing a program culture with shared visions of all involved, and (f) fostering coaching environments that value reflection. The reflective process may also be improved by educating coaches on the reflective theories or models, different processes of reflecting, and the different types of reflection. 
Knowles and colleagues (2006) suggested that coaches should also reflect on the whole coaching process and not just on positive and negative aspects related to the experience. Another suggestion to make reflection relevant to coaches is to let coaches reflect on what they feel is most meaningful. Letting coaches reflect on ideas they feel most relevant might increase their motivation. Motivated coaches are more likely to proactively engage themselves in improvement (Reade, Rodgers, \& Spriggs, 2008).

\section{Uses of Reflection in Education}

Reflective practice is one process used by many fields to enhance learning, including education, (Bain, Ballantyne, Packer, \& Mills, 1999; Hume, 2009; Osterman, \& Kottkamp, 1993), nursing (Ghaye, \& Lillyman, 2000), sports psychology, (Anderson, Knowles, \& Gilbourne, 2004), and sports coaching (Knowles et al., 2001). These fields have used reflective practice for many different reasons but one main reason is to help students gain a deeper and more developed understanding of the decisions and actions they make. Decisions made and actions taken by professionals in these respective fields are types of craft knowledge, tactical knowledge, or knowledge-in-action. Formal coaching education may be able to use reflective practices as many other educational fields have done to improve SCs' knowledge, understanding, decision making, and problem solving skills.

\section{Models of Reflection}

Several different models or conceptual frameworks of reflective practice have been developed as guides for the reflective process. These models have been used in different research and organizations to help people understand not only the process of reflecting but also what reflecting means and how it can enhance the learning process. Five reflective models or 
frameworks will be discussed in the section: (a) Shulman (1987), (b) Gibbs (1988), (c) Atkins and Murphy’s (1994), and (d) United Kingdom’s National Coaching Foundation Reflective Cycle (Galvin, 2006).

Shulman's (1987) model was the earliest of the five to be developed. The model was indirectly based on reflection by developing the seven most important categories in which teachers should reflect upon. Because the important areas of teaching are stated the students can use them as guides or areas to reflect upon. This may help build a solid knowledge base for becoming effective teachers. Shulman wanted to promote comprehension, transformation, reasoning, and reflection within teachers. Realizing the complex nature of teaching, Shulman's (1987) model includes seven concepts in which teachers can reflect upon to build a knowledge base. These categories include (a) content knowledge, (b) general pedagogical knowledge, (c) curriculum knowledge, (d) pedagogical content knowledge, (e) knowledge of learners and their characteristics, (f) knowledge of educational context, and (g) knowledge of educational ends. This model was used as a tool to guide teachers' reflective journal writing and learning in Hume’s (2009) research.

While Shulman’s (1987) model looked at the areas in which to reflect, Gibbs' (1988) model describes the process of reflection. Gibb’s model describes six steps in the reflective cycle, (a) description, (b) feelings, (c) evaluation, (d) analysis, (e) conclusions, and (f) action plan. Reflection is a critical examination of a prior event or experience that helps build a better understanding of an event or experience. The first part of understanding the event or experience as the Gibbs (1988) model suggests is to describe the event or experience exactly the way it happened. This does not include feelings or biases; it is purely an objective description of events. To understand something, students must first know exactly what happened. The second 
step in the cycle is for students to describe the feelings they had about the event. Examples include answering questions such as what they were thinking during the event or experience or what their emotions and feelings were during this time. The third step in the cycle is to evaluate. Evaluation means to describe what was good and bad about the situation. Was the experience or event a success? Were the goals accomplished? Fourth, students must analyze the event that happened. Just knowing if something worked is not enough, a person must dig deeper to find out the reasons the experience happened and why things worked out the way they did. If an event was successful, what happened that made it successful? The fifth step in the cycle is the conclusion. Now that students know the situation, their feelings, the outcomes, and why the events happened, they can come to a conclusion about the event and decide the direction they need to follow. The sixth and final step is the action plan. This step is the consideration of all the knowledge from the previous five steps while deciding on the best plan of action to fix the situation or to deal with the event or experience if something similar happens again.

One problem with the action plan step is the fact that all coaching situations are different. There is never going to be a context that is exactly the same. Even if a coach develops an action plan for the next day's practice the context will still not be the same. Something will be different, if not a number of things. For example, the mindset of the players, the weather, the time of day, the actual day, what happened in-between practices, injuries, or an infinite number of other things. The goal of reflection is to gain a better understanding of everything that occurred so when similar events happen coaches can more quickly adjust their actions and improve their knowledge in action. With this improved knowledge, coaches can continue, change, enhance, or improve the current or future situations. 
The United Kingdom National Coaching Foundations adapted their reflective cycle from Gibbs' (1988) model. The six steps in this adapted model include (a) the experience, (b) description, (c) evaluation, (d) analysis, (e) conclusion, and (f) action plan that lead back into another experience. This program model is used in the process of self-reflection. Reflective learning is more influential when it is related to one's own experiences. The descriptions of the reflective steps are very similar to Gibbs' (1988) model with the exception that it is directed toward the coaching experience. Two important factors were described in this model. First, is one of the most difficult parts of this process is searching for alternative approaches to improve coaching. This is where educational knowledge and information can help increase the potential by providing students with multiple avenues of coaching information. The reward for this process is obtaining new knowledge and providing new ideas that coaches might implement. Second, the action plan must have a direct effect on the coach's behavior. The intentions of the reflective process should be to improve the coach's knowledge and or behaviors.

Atkins and Murphy’s 1994 model resembled Gibbs' (1988) model of reflection. This model has been developed and used within the area of nursing. The model includes a four step cycle. First are the uncomfortable feelings and thoughts. This happens by being aware of yourself and your surroundings. These types of discomfort or lack of understanding can trigger the need for reflection, but discomfort or lack of understanding does not need to be the only reason to reflect. Positive events can also contribute to the reasons for reflection (Boud, Keogh, \& Walker, 1985). Second, a person must describe the situation or event, including key thoughts and feelings. This stages start with a person examining their knowledge about a situation and feelings to help understand how they affected their action. After a person understands how they were affected by their knowledge and feelings, they have to understand how they affected the 
situation. The third stage of the process is analyzing feelings and the knowledge of the situations. Within this process one must not only analyze the experience but understand if it was successful. This is where a person challenges the assumption of right or wrong and tries to imagine or explore alternative options, change a behavior, solve a problem, or find a new way of thinking. The last stage in this cycle is action. A person can choose to stay the same, change completely, or make improvements to certain areas.

Atkins and Murphy, (1994) provided some positive incite to the uses of reflective practice. First, reflection can be a driving force to develop knowledge and competence by helping individuals critically reflect (Carr \& Kemmis, 1986). Second, reflection may also help people articulate or illuminate the nature of practice. Third, reflection may help "generate new knowledge” by helping people to examine unique situations. Fourth, reflection can help "facilitate social change" by helping people become aware of issues affecting practice. All of these factors could be used and developed within the coaching education situation.

\section{Reflective Writing}

\section{Journal Writing}

Reflective journal writing has been established as one type of reflective learning in multiple disciplines: teacher education, (Bain et al., 1999; Bain, Mills, Ballantyne, \& Packer, 2002; Hume, 2009); nursing, (Landeen, Byrne, \& Brown, 1992); psychology, (Hettich, 1990); and coaching education, (Knowles et al., 2001). Journal writing is used by these fields above to help increase student learning and knowledge.

Journal writing has been used as a reflective learning tool in education for many years. Bain, et al., (1999) examined journal writing of secondary teacher education students. The 
purpose of the research was focused on improving the quality of reflection of secondary student teachers by using LaBosky’s (1993) framework of reflection to guide students' journal writing. LaBoskey's (1993) framework establishes four areas of reflection: (a) purpose, or the motivation and need to understand certain issues; (b) context, the aids of reflection or tasks, timing, location, and other observers; (c) procedures, or the process undertaken during reflection; and (d) content, or the focus of reflection. This research specifically focused on two of LaBoskey's four essential areas in reflective journal writing; the context and content. Four different interventions conditions were used to examine the reflection of the students.

In the Bain, et al., (1999) study, students were first divided into cognitive or experiential groups. Students in the cognitive group were required to focus on how they applied theoretical concepts from previous courses in their student teaching experience. Students in the experience group were required to focus on their experience during student teaching and what they felt to be most important. Both of these groups were subdivided by having students self-analyze or conduct student reflective meetings with the researcher. The self-analysis students were required to reconsider their first reflection with the addition of teacher written feedback by briefly elaborating on old and new thoughts. The student-researcher reflective meetings groups used the weekly journal entry as the subject during the meetings. The conversations took place the week after the journals were written and they lasted approximately 15 minutes.

Results from this study helped shed some light on the various issues that face students and their reflective writing. First, the students enter the reflective process with different attitudes and reflective skills. Second, feedback and instruction help manipulate students' reflective content in journal writing. Third, the students mentioned that constructive feedback challenges their previous beliefs and helped develop deeper thoughts in their reflective writing. 
Using the feedback concept from Bain et al. (1999), Bain and colleagues (2002) follow up study examined the types of feedback given to students. Thirty-five students were divided into four different groups. Each group received different types of feedback. The two chosen as the areas in which teachers would focus on feedback were the process of reflection or the issues reflected upon. These two topics were subdivided into low or high levels of feedback. The low and high levels of feedback challenged the students on different levels by asking more in depth questions for high level feedback. The different types of feedback and the process in which the students reflected produced four groups, one receiving low level feedback on the process, one receiving high level feedback on the process, one receiving low level feedback about the content, and one receiving high level feedback about the content.

Bain, et al., (1999) findings regarding the low and high level feedback were interesting. The high level feedback groups obtained higher scores with regards to reflective writing. A higher number of students reported the feedback having an influence on both their writing and their thoughts about teaching. Although the higher ratings did not produce significantly different results from the lower ratings there is some suggestion that higher level feedback is better and should be studied further. The feedback related to the process of reflective writing also produced better scores. The five students who did not reach a higher level of reflective writing received feedback about issues rather than about the writing process. Four of the five students also were in the low feedback group. This data seems to suggest the need for teachers to provide more high level feedback related to the thought of the writing and not the content the students write about.

One other interesting piece of information from the Bain, et al., (1999) came from the post class interviews. The students viewed reflective practice in one of three ways: a record, 
motivator, or extension of reflection. What makes this data important is the fact that the five students who never used reasoning in their journals thought of the process as a record. It seems important for teachers to find a way to help students think about reflective journal writing as a motivator or an extension of the learning process but not as only a record. Research has suggested that higher level reflecting students say that their ideas develop while writing; therefore, the students are not just reporting previously developed ideas (Maas, 1991).

Hume (2009) took another perspective into examining reflective practice. In the study, she examined the effects Shulman's (1987) model of reflective practice had on enhancing the reflective thinking and writing on her science education students. Shulman's (1987) model described seven basic areas related to teaching science: (a) content knowledge, (b) general pedagogical knowledge, (c) curriculum knowledge, (d) pedagogical knowledge, (e) knowledge of learners and their characteristics, (f) knowledge of educational context, and (g) knowledge of educational ends. Also, she conducted post workshop interviews to gain a perception on the interventions effectiveness in enhancing their reflective writing and science teaching.

Hume's (2009) study had two phases. In the first phase students were required to reflect on any of the seven categories of Shulman's model. No improvements in students' journal writing were found when the students only received instructions to reflect on teaching experiences using Shulman's model as a guide. In the second phase Hume developed many types of interventions to improve the students learning through reflective writing. Students were exposed to exemplar reflective writings to help gain an understanding of quality reflective writing. Workshop activities were designed to challenge the student ideas and think about teaching science. After these activities students were allotted 10 minutes for reflective writing. Students received feedback on the journals related to their reflective writing process. The idea 
for giving feedback related to reflective writing came from Bain and colleagues (2002) research. The students' reflective journals were evaluated over both phases using a scoring rubric that was developed from questions in Shulman's (1987) model.

The results from Hume's (2009) study suggest that students improved most over the first part of the interventions and made smaller incremental jumps as it progressed. All of the study's interventions, challenging the students' ideas, providing quality examples, and giving feedback appeared to enhance student reflective journal writing. The major problem with this study is the fact that she cannot discern what intervention helped increase the reflective writing skills the most. The post class interviews were her only avenue to discern what was the most influential to the students. All examples in the article explained how students thought they learned from the different experiences. None of the examples showed any negative aspects toward any of the tasks. Although this study does not discern between the different types of intervention and their effects on reflective writing, there is clear evidence that all of these interventions can have a positive effect. More research should be done to help understand the difference between the interventions used and encourage using these types of interventions within classrooms.

Knowles and colleagues (2001) investigated the process of reflection within the coaching education realm. The study involved eight coaching education students enrolled in a University in the United Kingdom. This study was very intense, working through four different phases of preparation: early placement data collection, workshop program, post-placement data collection, and researcher reflections. During the preparation faze the researchers' recruited students in their second year of the coaching education program. These SCs were already enrolled in classes that were beginning to develop their reflective writing skills. The early placement data collection phase was used to examine the SCs' reflective skills. The workshop programme 
consisted of one hour sessions every two weeks in which the SCs learned and reflected on different topics associated with coaching through discussion. The fourth phase was postplacement and the SCs' reflective activities were evaluated again. The researchers used semistructured interviews to ask the coaches questions about the types of reflective practice they were using. The interviews were transcribed and reviewed for the amount and types of reflection coaches were using. In phase five the researcher gave a post study reflection summing up the study.

Knowles et al., (2001) assessed transcribed interviews using a design adapted from Mezirow (1981), Goodman (1984), and Powell (1989) research on reflective practice. This model of evaluation had six different levels in which students could reach with respects to their reflective practice. The levels are labeled progressively from lowest to highest: (a) reflectivity or description of event; (b) affective reflectivity or awareness of feelings about the event and level one; (c) reflection to reach given objectives or realizing a need to readjust to meet lesson goals including the first two levels; (d) reflection on the relationships between principles and practice or assessment of action and belief with rationale for certain practices including first three levels; and (e) wider reflection or discussions with others about morals, beliefs, and other issues in coaching including critical reflection or the student making connections of practice with broader social goals and contemplating the professional goals of coaching and practice.

The results of Knowles et al., (2001) showed that student reflective practice increased over time. The students reported both old and new thoughts on reflective practice. The group discussions helped most SC discuss more topics related to their experiences while developing action plans to solve problems that coaches were facing. While receiving more positive than negative comments two coaches stated that the group discussions did not enhance their reflective 
development. Related to journal writing, the students perceived the need for more structure to the process and that the process was time consuming. Because of these inhibitors to reflection, two students started taking notes and recording thoughts during practices. Even with the negative aspects of the process most students improved their reflective writing.

One other major finding from Knowles et al., (2001) is the level of reflection might depend on the topic. Different types of reflective practices could produce more reflections, depending on the coaches' personal preferences or role frames. Different coaching placement experiences can influence the improvement of reflective practice and abilities. It was suggested that teachers should develop a "one to one" relationship with the coaches to help listen and provide feedback. Because the reflecting is such a complex process there is a need to broaden the research and provide more studies to enhance the power of the results.

\section{Level of Reflection}

The students' reflective journal writing in each of the previous studies was measured using a scale that depicts a hierarchical level of thinking. The scale in Knowles (2001) study was based on an adaptation made from three different places: Mezirow (1981), Goodman, (1984), and Powell (1989). The scale depicts the lowest level of reflection as the ability to describe the experience and the highest level of reflection was making links between practice and outside factors that contribute to decision making.

Mezirow’s (1981) seven levels of reflection were used to differentiate different aspect of reflection shown by individuals. Mezirow (1981) considered the first four levels as a person's consciousness and the last three level as critical consciousness. The seven levels are called, (1) reflectivity, (2) affective reflectivity, (3) discriminate reflectivity, (4) judgmental reflectivity, (5) 
conceptual reflectivity, (6) psychic reflectivity, and (7) theoretical reflectivity and placed in order of lowest to highest order of reflective thinking. Level one represents a person's awareness of their situation and ability to describe and experience. Level two is a person's awareness of feelings. Level three is the assessment of the efficacy of a perception or thought. Level four is placing value judgments of thoughts or actions. Level five is questioning whether the concepts used to make judgments were adequate. Level six is the recognition of your own judgments based on limited information. Lastly level seven is the awareness of the routine practice that does not give a full answer where obvious learning or a perspective change has taken place. Powell (1989) used this scale of reflection to assess the reflection-in action of nurses. Powell made one change to the scale which was to combine level five and level six because the small difference between did not allow enough information to distinguish if a reflective thought could be considered level five or level six.

The Five-Point Level of Reflection Scale used in Bain and colleagues (1999) and (2002) studies was based on previous research done by Biggs \& Collis, (1982); Biggs, (1992); Richert, (1992); Tann (1993); and Ballantyne \& Packer, (1995). This research used to develop the scale proves to be very similar in nature to the levels of reflection in Mazirow's (1981) and Powell's (1989) scales. The concepts of higher level of reflections are still used and described just in a different fashion.

Biggs and Collis (1982) developed what they called the SOLO Taxonomy or structure of observed learning outcomes. The SOLO Taxonomy model describes the complexity levels in peoples' comprehension and understanding of subjects. The five different concepts of understanding are, pre-structural, uni-structural, multi-structural, relational, and extended abstract and are in hierarchical order starting with the lowest level of understanding and ending 
with the highest. At the pre-structural level of understanding people explain problems or events in a simplistic way which can lead to improper decision making. At the uni-structural level of understanding people use one relevant aspect of the concept which will only lead to correct decision making if the relevant aspect and process work together perfectly and obtain the one correct solution. At the multi-structural level of understanding a person focus on many different concepts but the concept are not synthesized to help lead to a solution. At the relational level of understanding people synthesize the concept and use them as a whole to solve a problem. At this level Biggs and Collis (1982) suggest that people have a good understanding of the topic or concept. At the extended abstract level of understanding people are able to synthesize concepts but also apply them to new areas.

The Five-Point Level of Reflection Scale developed by Bain and colleagues (1999) represents that same hierarchical level of reflective thought. There are five levels in the scale which include (1) reporting, (2) responding, (3) relating, (4) reasoning, and (5) reconstructing. In the first level students only describe or report the experience. In the second level students only make judgments about their experiences or report their feelings about the experience. In the third level of reflection students begin to relate to the experience by identifying personal aspects of the experiences, seeking superficial understandings of the experience or giving superficial explanations or the experiences. The first three levels are very similar to that of Mezrow's (1981) and Powell’s (1989) scales and to Biggs and Collis (1982) SOLO Taxonomy. The lower levels represent lower orders of thinking where people do not demonstrate an in-depth understanding or conceptualization of a concept or experience. The fourth level of Bain and colleagues (1999) scale show a person's deep of understanding or grasp on concepts. At this level people use data in appropriate relationships with concepts or experiences. There is depth 
and an extensive description when explaining or relating to experiences or concepts. The fifth level represents a person’s ability to generalize and apply learning, draw original conclusions, and or internalize the personal significance of their learning. In the last two levels it is easy to see the similarities to all of the previous research and scales used to measure a person's level of thinking, understanding, or reflectivity.

The purpose of the present study is to determine whether the intervention will influence the level of their journal writing. This study was small step to examine how reflective techniques and concepts can be taught within a CEP. 


\section{References}

Abraham, A., \& Collins, D. (1998). Examining and extending the research in coach development. Quest, 50, 59-79.

Anderson, A., Knowles, Z., \& Gilbourne, D. (2004). Reflective practice for applied sports psychologists: A review of concepts, models, practical implications, and thoughts on dissemination. The Sports Psychologist, 18, 188-201.

Atkins, S., \& Murphy, K. (1994). Reflective practice. Nursing Standard, 8(39), 49-56.

Bain, J. D., Ballantyne, R., Packer, J., \& Mills, C. (1999). Using journal writing to enhance student teachers’ reflectivity during field experience placements. Teachers and Teaching; Theory and Practice, 5(1), 51-73.

Bain, J. D., Mills, C., Ballantyne, R., \& Packer, J. (2002). Developing reflection on practice through journal writing: Impacts of variation in the focus and level of feedback. Teachers and Teaching: Theory and Practice, 8(2), 171-196.

Ballantyne, R., \& Packer, J. (1995). The role of student journals in facilitating reflection at doctoral level. Studies in Continuing Education, 17(1-2), 29-45.

Bates, I. (2007). Coaching experience, coaching performance. In J. Denison, Coaching knowledges: Understanding the dynamics of sport performance (pp. 68-82). London, UK: A \& Black Publishers.

Biggs, J. B. (1992). A qualitative appraoch to grading students. HERDSA News, 14(3), 3-6.

Biggs, J. B., \& Collis, K. F. (1982). Evaluating the quality of learning . New York, NY: Academic Press.

Boud, D., Keogh, R., \& Walker, D. (1985). Reflection: Turning experience into learning. New York, New York : Nicholas Publishing Company. 
Caldwell, J. H., Huitt, W. G., \& Graebar, A. O. (1982). Time spent in learning: Implications from research. Elementary School Journal, 82, 471-480.

Carr, W., \& Kemmis, S. (1986). Becoming critical: Education, knowledge and action research. London, England: RouteledgeFalmer.

Cote, J., \& Gilbert, W. (2009). An integrative definition of coaching effectiveness and expertise. International Journal of Sports Science \& Coaching, 4(3), 307-323.

Côte, J., Salamela, J. H., Trudel, P., Baria, A., \& Russell, S. J. (1995). The coaching model: A grounded assessment of gymnastic coaches' knowledge. Journal of Sport and Exercise Psychology, 17, 1-17.

Cushion, C. J. (2001, September). Coaching research and coach education: Do the sum of the parts equal a whole? . Retrieved January 2010, from SportPolis: http://www.sportsmedia.org/Sportapolisnewsletter4.htm.

Cushion, C. J., Armour, K. M., \& Jones, R. L. (2003). Coach education and continuing professional development: Experience and learning to coach. Quest, 55, 215-230.

Dewar, A. M., \& Lawson, H. A. (1984). The subjective warrant and recruitment into physical education. Quest, 36, 15-25.

Dewey, J. (1933). How we think: A restatement of the relation of reflective thinking to the educative process. Chicago, IL: Henry Regnery Company.

Dewey, J. (1974). John Dewey on education: Selected writings. Chicago, IL: University of Chicago Press.

Erickson, K., Côte, J., \& Frazer-Thomas, J. (2007). Sport experiences, milestones, and educational activities associated with high-performance coaches’ development. The Sport Psychologist, 21, 302-316. 
Fischman, M. G., \& Oxendine, J. B. (1993). Motor skill learning for effective coaching and performance. In J. M. Williams, Applied sport psychology: Personal growth to peak performance (pp. 36-57). Mountain View, CA: Mayfield Publishing Company.

Fisher, C., Filby, N., Marliave, R., Cahen, L., Dishaw, M., Moore, J., et al. (1978). Teaching behaviors: Academic learning time and student achievement: Final report of phase III-B, beginning teacher evaluation study. San Francisco, CA: Far West Laboratory for Educational Research and Development.

Fouss, D., \& Troppman, R. (1981). Effective coaching: A psychological approach. New York, NY: John Wiley \& Sons.

Galvin, B. (2006). A guide to mentoring sports coaches. Headingly, UK: Coachwise Business Solutions.

Ghaye, T., \& Lillyman, S. (2000). Reflection: principles and practice for healthcare professionals. Salisbury, UK: Quay Books.

Gibbs, G. (1988). Learning by doing: A guide to teaching and learning methods. Oxford, England: Oxford Polytechnic.

Gilbert, W. D., \& Trudel, P. (2001). Learning to coach through experience: Reflection in model youth sport coaches. Journal of Teaching in Physical Education, 21, 16-34.

Gilbert, W. D., Trudel, P. (2004). Analysis of coaching science research published from 19702001. Research Quarterly for Exercise and Sport, 75, 388-399.

Gilbert, W. D., \& Trudel, P. (2005). Learning to coach through experience: Conditions that influence reflections. Physical Educator, 62(1), 32-44.

Goodman, J. (1984). Reflection and teacher education: A case study and theoretical analysis. Interchange, 15, 9-27. 
Gould, D., Giannani, J., Krane, V., \& Hodge, K. (1990). Educational needs of elite US National, Pan-American and Olympic coaches. Journal of Teaching in Physical Education, 9, 332344.

Hettich, P. (1990). Journal writing: Old fare or nouvelle cuisine? Teaching of Psychology, 17, 36-39.

Hume, A. (2009). Promoting higher levels of reflective writing in student journals. Higher Education Research \& Development, 28(3), 247-260.

Irwin, G., Hanton, S., \& Kerwin, D. G. (2004). Reflective practice and the origins of elite coaching knowledge. Reflective Practice, 5(3), 425-442.

Jones, R. L. (2000). Towards a sociology of coaching. In R. L. Jones \& K. M. Armour, The Sociology of Sport: Theory and Practice (pp. 33-43). London, UK: Addison Wesley Longman.

Jones, R., Armour, K., \& Potrac, P. (2004). Sports coaching cultures: From Practice to Theory. London, UK: Routledge.

Jones, R. L., \& Turner, P. (2006). Teaching coaches to coach holistically: Can problem based learning (PBL) help? Physical Education \& Sport Pedagogy, 11, 181-202.

Knowles, Z., Borrie, A., \& Telfer, H. (2005). Towards the reflective sports coach: Issues of context, education, and application. . Ergonomics, 48(11.14), 1711-1720.

Knowles, Z., Gilbourne, D., Borrie, A., \& Neville, A. (2001). Developing the reflective sports coach: Study exploring the process of reflective practice within a higher education coaching programme. Reflective Practice, 2, 186-207.

Knowles, Z., Tyler, G., Gilbourne, D., \& Eubank, M. (2006). Reflecting on reflection: Exploring the practice of sports coaching graduates. Reflective Practices, 7(2), 163-179. 
LaBoskey, V. K. (1993). A conceptual framework for reflection in preservice teacher education. In J. Calderhead \& P. Gates, Conceptualizing reflection in teacher development (pp. 2338). London, UK: Falmer Press Limited.

Landeen, J., Byrne, C., \& Brown, B. (1992). Journal keeping as an educational strategy in teaching psychiatric nursing. Journal of Advanced Nursing, 17, 347-355.

Luikkonen, J., Laasko, L., \& Telama, R. (1996). Educational perspectives of youth sport coaches: Analysis of observed coaching behaviors . International Journal of Sports Psychology, 27, 439-453.

Lyle, J. W. (1992). Systematic coaching behaviors: An investigation into the coaching process and the implications of the findings for Ccoach education. Sport and Physical Activity, 463-469.

Lyle, J. W. (2007). A review of the research evidence for impact of coach education. . International Journal of Coaching Science, 1(1), 19-36.

Lyle, J., Mallett, C. J., Trudel, P., \& Rynne, S. B. (2009). Formal vs. informal ocach education: A response to commentary . International Journal of Sport Science \& Coaching, 4(3), 359-364.

Maas, J. (1991). Writing and reflection in teacher education. In B. R. Tabachnich \& K. Zeichner, Issues and Practices in Inquiry-Oriented Teacher Education (pp. 211-225). London, UK: Falmer Press.

Mallett, C. J., Trudel, P., Lyle, J., \& Rynne, S. B. (2009). Formal vs. informal coaching education. International Journal of Sports Science \& Coaching, 4(3), 325-334.

Merriam, S. B., Caffarella, R. S., \& Baumgartner, L. M. (2007). Learning in adulthood: A comprehensive guide. San Francisco, CA: Jossey-Bass. 
Mezirow, J. (1981). A critical theory of adult learning and education. Adult Education, 32, 3-24.

Nash, C. S., \& Sproule, J. (2009). Career development of expert coaches. International Journal of Sports Science \& Coaching, 4(1), 121-138.

NASPE. (2006). National standards for athletic coaches. Retrieved February 12, 2010, from National Association for Sport and Physical Education.: http://www.aahperd.org/naspe/publications

National Council for Accreditation of Coaching Education (NCACE) (2006). Coaching Education Program Registry \& Approved Program List. Retrieved from http://aysosection10.d4sportsclub.com/object.aspx?id=8

Nelson, L. J., \& Cushion, C. J. (2006). Reflection in coach education: The case of the national governing body coaching certificate. The Sports Psychologist, 20, 174-183.

Nelson, L. J., Cushion, C. J., \& Potrac, P. (2006). Formal, non-formal and informal coach learning: A holistic conceptualization. International Journal of Sports Science \& Coaching, 1(3), 247-259.

Osterman, K., \& Kottkamp, P. (1993). Reflective practice for educators. Newbury, CA: Corwin Press.

Potrac, P., Brewer, C., Jones, R., Armour, K., \& Hoff, J. (2000). Towards a holistic understanding of the coaching process. Quest, 52(2), 186.

Powell, J. H. (1989). The reflective practitioner in nursing. Journal of Advanced Nursing, 14, 824-832.

Race, P. (2005). Making learning happen: A guide for post-compulsory education. London, UK: Sage. 
Reade, I., Rodgers, W., \& Spriggs, K. (2008). New ideas for high performance coaches: A sase study of knowledge transfer in sport science. International Journal of Sports Science \& Coaching, 3(3), 335-354.

Richert, A. E. (1992). The content of student teachers' reflections within different structures for facilitating the reflective process. In T. Russell \& H. Munby (Eds). Teachers and teaching: From classroom to reflection. London. The Falmer Press.

Rovegno, I. (1995). Theoretical perspectives on knowledge and learning and a student teacher’s pedagogical content knowledge of dividing and sequencing subject matter. Journal of Teaching in Physical Education, 4, 158-166.

Rumelhart, D. E., \& Norman, D. A. (1978). Accretion tuning and restructuring: Three modes of learning. In J. W. Cotton \& R. Klatzky, Semantic factors in cognition (pp. 37-53). Hillsdale, NJ: Lawrence Erlbaum Associates.

Salmela, J. H. (1995). Learning from the development of Eexpert coaches. Coaching \& Sports Science Journal, 2, 3-13 .

Saury, J., \& Durand, M. (1998). Practical knowledge in expert coaches: On site study of coaching in sailing. Research Quarterly for Exercise and Sport, 69(3), 254-266.

Schempp, P. G., \& Graber, K. (1992). Teacher socialization from a dialectical perspective: Pretraining through Induction. Journal of Teaching in Physical Education, 11, 329-348.

Schempp, P. G., Manross, D., Tan, S. K., \& Fincher, M. D. (1998). Subject expertise and teachers’ knowledge. Journal of Teaching in Physical Education, 17, 342-356.

Schempp, P. G., McCullick, B., \& Mason, S. (2006). The development of expert coaching. In R. L. Jones, The sports coach educator (pp. 145-161). New York, NY: Routledge. 
Schön, D. A. (1983). The reflective practitioner: How professionals think in action. United States of America: Basic Books.

Schön, D. A. (1987). Educating the reflective practitioner. San Francisco, CA: Jossey-Bass.

Shulman, L. S. (1987). Knowledge and teaching: Foundations of the new reform. Harvard Educational Review, 57(1), 1-22.

Siedentop, D., \& Eldar, E. (1989). Expertise, experience, and effectiveness. Journal of Teaching in Physical Education, 8(3), 254-260.

Smith, R. B., \& Smoll, F. L. (1997). Coach-mediated team building in youth sports. Journal of Applied Sports Psychology, 9, 114-132.

Smoll, F. L., \& Smith, R. E. (2006). Development and implementation of coach-training programs: Cognitive behavioral principles and techniques. In J. M. Williams, Applied sport psychology: Personal growth to peak performance. Boston, MA: McGraw-Hill.

Tann, S. (1993). Eliciting student teachers' personal theories. In J Calderhead \& P Gates (Eds). Conceptualizing reflection in teacher development. London. The Falmer Press.

Tinning, R. (1982). Improving coaches' instructional effectiveness. Sports Coach, 5(4), 37-41.

Turner, A., \& Martinek, T. (1995). Teaching for understanding: A model for improving decision making during game play. Quest, 47, 44-63.

Wright, T., Trudel, P., \& Culver, D. (2007). Learning how to coach: The different learning situations reported by youth ice hockey coaches. Physical Education and Sport Pedagogy, 12, 127-144. 


\section{Appendix B}

Participant Informing Letter 


\section{Participant Informing Letter}

August 2010

Dear Participant,

This letter is a request for you to take part in a research project using your personal reflective journals from the ACE 491 Coaching Internship class as data. This project is being conducted by Wesley Meeteer, graduate assistant in the Physical Education Teacher Education doctoral program at WVU under the supervision of Dr. Kristen Dieffenbach, assistant professor in the College of Physical Activity and Sports Sciences. Your participation in this project is greatly appreciated. Participation does not require you to complete or participate in any extra work.

Your participation in this project is completely voluntary and will be kept as confidential as legally possible. All data will be reported in the aggregate, so no individual will be identifiable. You must be 18 years of age or older to participate. You will not be required to provide any information that could lead to your identity as a participant being reveled. Your student standing will not be affected if you decide either not to participate or to withdraw from participation. West Virginia University's Institutional Review Board acknowledgement of this project is on file.

I hope that you will participate in this research project, as it could be beneficial in understanding the impact reflective writing has on your learning in the Athletic Coaching Education program. Thank you very much for your time. Should you have any questions about this letter or the research project, please feel free to contact Wesley Meeteer at (304) 910-1952 by e-mail at wesley.meeteer@mail.wvu.edu or Kristen Dieffenbach at (304) 293-0847or by email at kristen.dieffenbach@mail.wvu.edu . For information about your rights as a research subject, you may call the WVU Office of Research Integrity and Compliance at (304) 293-7073.

Thank you for your time and help with this project.

Sincerely,

Wesley Meeteer 


\section{Appendix C}

Workload Requirements 
Workload Requirements

\begin{tabular}{|c|c|c|c|c|}
\hline Assignments & $\begin{array}{l}\text { 1-3 Credit } \\
\text { Hours }\end{array}$ & 4-6 Credit Hours & 7-9 Credit Hours & $\begin{array}{l}\text { 10-12 Credit } \\
\text { Hours }\end{array}$ \\
\hline $\begin{array}{c}\text { Personal } \\
\text { Coaching } \\
\text { Philosophy }\end{array}$ & $\begin{array}{l}1 \text { Related to the } \\
\text { sport and level in } \\
\text { which you are } \\
\text { coaching }\end{array}$ & $\begin{array}{l}1 \text { Related to the } \\
\text { sport and level in } \\
\text { which you are } \\
\text { coaching }\end{array}$ & $\begin{array}{l}1 \text { Related to the } \\
\text { sport and level in } \\
\text { which you are } \\
\text { coaching }\end{array}$ & $\begin{array}{l}1 \text { Related to the } \\
\text { sport and level in } \\
\text { which you are } \\
\text { coaching }\end{array}$ \\
\hline $\begin{array}{l}\text { Emergency } \\
\text { Action Plan }\end{array}$ & $\begin{array}{l}\text { (1)Emergency } \\
\text { action plan for } \\
\text { the team. }\end{array}$ & $\begin{array}{l}\text { (1)Emergency } \\
\text { action plan for the } \\
\text { team. }\end{array}$ & $\begin{array}{l}\text { (1) Emergency } \\
\text { action plan for the } \\
\text { team. } \\
\text { (1)Emergency } \\
\text { action plan for the } \\
\text { spectators. }\end{array}$ & $\begin{array}{l}\text { (1) Emergency } \\
\text { action plan for the } \\
\text { team. } \\
\text { (1)Emergency } \\
\text { action plan for the } \\
\text { spectators. }\end{array}$ \\
\hline $\begin{array}{c}\text { Facility } \\
\text { Checklists }\end{array}$ & $\begin{array}{l}\text { (1)Facility } \\
\text { checklist }\end{array}$ & $\begin{array}{l}\text { (2)Facility } \\
\text { checklists }\end{array}$ & $\begin{array}{l}\text { (3)Facility } \\
\text { checklists }\end{array}$ & $\begin{array}{l}\text { (4)Facility } \\
\text { checklists }\end{array}$ \\
\hline $\begin{array}{l}\text { Equipment } \\
\text { Checklists }\end{array}$ & $\begin{array}{l}\text { (1)Equipment } \\
\text { checklist }\end{array}$ & $\begin{array}{l}\text { (2)Equipment } \\
\text { checklists }\end{array}$ & $\begin{array}{c}\text { (3)Equipment } \\
\text { checklists }\end{array}$ & $\begin{array}{c}\text { (4)Equipment } \\
\text { checklists }\end{array}$ \\
\hline $\begin{array}{l}\text { Conditioning } \\
\text { Practice Plan }\end{array}$ & $\begin{array}{l}\text { (1)Conditioning } \\
\text { practice plan }\end{array}$ & $\begin{array}{l}\text { (2)Different } \\
\text { conditioning } \\
\text { practice plan }\end{array}$ & $\begin{array}{l}\text { (3)Different } \\
\text { conditioning } \\
\text { practice plan }\end{array}$ & $\begin{array}{l}\text { (4)Different } \\
\text { conditioning } \\
\text { practice plan }\end{array}$ \\
\hline Practice Plans & (2)Practice Plans & (4)Practice Plans & (6)Practice Plans & (8)Practice Plans \\
\hline $\begin{array}{c}\text { Player } \\
\text { Evaluations }\end{array}$ & $\begin{array}{l}\text { (2)Player } \\
\text { evaluations }\end{array}$ & $\begin{array}{c}\text { (4)Player } \\
\text { evaluations }\end{array}$ & $\begin{array}{c}\text { (6)Player } \\
\text { evaluations }\end{array}$ & $\begin{array}{c}\text { (8)Player } \\
\text { evaluations }\end{array}$ \\
\hline $\begin{array}{c}\text { Coaches } \\
\text { Evaluations }\end{array}$ & $\begin{array}{l}\text { (1)Coach } \\
\text { evaluation }\end{array}$ & $\begin{array}{l}\text { (1)Coach } \\
\text { evaluation }\end{array}$ & $\begin{array}{l}\text { (2)Coach } \\
\text { evaluation }\end{array}$ & $\begin{array}{l}\text { (2)Coach } \\
\text { evaluation }\end{array}$ \\
\hline $\begin{array}{c}\text { Journal } \\
\text { Reflections }\end{array}$ & $\begin{array}{l}\text { (13) Journal } \\
\text { Reflections }\end{array}$ & $\begin{array}{l}\text { (13) Journal } \\
\text { Reflections }\end{array}$ & $\begin{array}{l}\text { (13) Journal } \\
\text { Reflections }\end{array}$ & $\begin{array}{l}\text { (13) Journal } \\
\text { Reflections }\end{array}$ \\
\hline $\begin{array}{c}\text { Final } \\
\text { Reflections }\end{array}$ & $\begin{array}{c}\text { (1)-(2-page) } \\
\text { Final Reflection }\end{array}$ & $\begin{array}{l}\text { (1)-(4-page) Final } \\
\text { Reflection }\end{array}$ & $\begin{array}{l}\text { (1)-(6-page) Final } \\
\text { Reflection }\end{array}$ & $\begin{array}{l}\text { (1)-(8-page) Final } \\
\text { Reflection }\end{array}$ \\
\hline $\begin{array}{l}\text { Contact } \\
\text { Hours }\end{array}$ & $\begin{array}{c}\text { (45) Contact } \\
\text { hours }\end{array}$ & $\begin{array}{c}\text { (90) Contact } \\
\text { hours }\end{array}$ & $\begin{array}{c}\text { (120) Contact } \\
\text { hours }\end{array}$ & $\begin{array}{c}\text { (180) Contact } \\
\text { hours }\end{array}$ \\
\hline
\end{tabular}




\section{Appendix D}

Class Work Schedule 


\section{Class Work Schedule}

\begin{tabular}{|c|c|c|}
\hline \multirow{5}{*}{ Week 1} & Intervention Groups & $\begin{array}{l}\text { Collect demographic information for use in dividing SCs into } \\
\text { groups. }\end{array}$ \\
\hline & Objectives & $\begin{array}{l}\text { (1)Introduce SCs to the course } \\
\text { (2)Discuss all required work } \\
\text { (3)Collect paperwork } \\
\text { (4)Explain research } \\
\text { (5)Gain permission from SCs }\end{array}$ \\
\hline & Key Points & $\begin{array}{l}\text { Demographic information and permission } \\
\text { Explain research }\end{array}$ \\
\hline & $\begin{array}{l}\text { Assigned for next } \\
\text { week }\end{array}$ & $\begin{array}{l}\text { (1)Write reflective journal \#1 (Due Thursday night by 12) } \\
\text { (2)Join the groups online, introduce yourselves, talk about } \\
\text { each of your coaching internships, and decide when you will } \\
\text { have your group discussions for the next week. }\end{array}$ \\
\hline & Assignments Due & (1)Signed agreement contract from the coach. \\
\hline \multirow{5}{*}{ Week 2} & Intervention Groups & All groups will remain in the baseline stage. \\
\hline & Objectives & Read and review the importance of a coaching philosophy \\
\hline & Key Points & Coaching Philosophy, Reflection \\
\hline & $\begin{array}{l}\text { Assigned for next } \\
\text { week }\end{array}$ & $\begin{array}{l}\text { (1)Write reflective journal\#2 (Due Thursday night by 12) } \\
\text { (2)Participate in discussion groups related to coaching } \\
\text { philosophy } \\
\text { (3)Read first assigned article/chapter on coaching philosophy }\end{array}$ \\
\hline & Assignments Due & (1)Turn in reflective journal \#1. (Due Thursday night by 12) \\
\hline \multirow{5}{*}{ Week 3} & Intervention Groups & $\begin{array}{l}\text { No groups will receive or participate in intervention } \\
\text { activities. }\end{array}$ \\
\hline & Objectives & $\begin{array}{l}\text { (1)Write a personal coaching philosophy for the sport and } \\
\text { level in which the SCs are coaching } \\
\text { (2)Discuss the coaching philosophy and how it is used as a } \\
\text { coach } \\
\text { (3)Read and review the importance of being a safe coach. }\end{array}$ \\
\hline & Key Points & Coaching Philosophy, Safety, Reflection \\
\hline & $\begin{array}{l}\text { Assigned for next } \\
\text { week }\end{array}$ & $\begin{array}{l}\text { (1)Write reflective journal \#3 } \\
\text { (2)Participate in group discussion related to safety } \\
\text { (3)Read article/chapter on coaching safety } \\
\text { (4)First group will attend the on campus class the next week. }\end{array}$ \\
\hline & Assignments Due & $\begin{array}{l}\text { (1)Turn in reflective journal \#2 (Due Thursday night by 12) } \\
\text { (3)Participate in group discussion related to philosophy } \\
\text { (2)Turn in personal coaching philosophy }\end{array}$ \\
\hline \multirow{4}{*}{ Week 4} & Intervention Groups & $\begin{array}{l}\text { The first group (group A) will attend the intervention on } \\
\text { campus class. }\end{array}$ \\
\hline & Objectives & $\begin{array}{l}\text { Develop an emergency action plan, discuss ideas and safety } \\
\text { issues in sport, and read and review coaching ethics. }\end{array}$ \\
\hline & Key Points & Intervention, Safety, Ethics, Reflection \\
\hline & $\begin{array}{l}\text { Assigned for next } \\
\text { week }\end{array}$ & $\begin{array}{l}\text { (1)Write reflective journal \#4 (Group A starts using } \\
\text { reflective cycle as a guide) (Due Thursday night by 12) }\end{array}$ \\
\hline
\end{tabular}




\begin{tabular}{|c|c|c|}
\hline & & $\begin{array}{l}\text { (2)Participate in discussion groups related to ethics } \\
\text { (4)Read article/chapter on coaching ethics. }\end{array}$ \\
\hline & Assignments Due & $\begin{array}{l}\text { (1)Turn in reflective journal \#3 (Due Thursday night by 12) } \\
\text { (2)Participate in discussion groups related to safety } \\
\text { (3)Turn in emergency action plan }\end{array}$ \\
\hline \multirow{5}{*}{ Week 5} & Intervention Groups & $\begin{array}{l}\text { Group A will continue to use the Reflective Cycle as a guide } \\
\text { for writing their journals and receive feedback on their } \\
\text { journals while groups B to E are still in the baseline stage. }\end{array}$ \\
\hline & Objectives & $\begin{array}{l}\text { Perform safety checks, discuss ethical issues facing a coach, } \\
\text { and read and review physical conditioning for sport. }\end{array}$ \\
\hline & Key Points & Safety, Ethics, Physical Conditioning, Reflection \\
\hline & $\begin{array}{l}\text { Assigned for next } \\
\text { week }\end{array}$ & $\begin{array}{l}\text { (1)Write reflective journal \#5 (Due Thursday night by 12) } \\
\text { (2)Participate in group discussions related to physical } \\
\text { conditioning } \\
\text { (3)Read article/chapter on physical conditioning. } \\
\text { (4)Second group will attend the on campus class next week }\end{array}$ \\
\hline & Assignments Due & $\begin{array}{l}\text { (1)Turn in reflective journal \#4 (Due Thursday night by 12) } \\
\text { (2)Participate in discussion groups related to ethics } \\
\text { (3)Turn in facility and equipment checklists }\end{array}$ \\
\hline \multirow{5}{*}{ Week 6} & Intervention Groups & $\begin{array}{l}\text { The second group will participate in the intervention class. } \\
\text { The first group that already received the intervention will } \\
\text { continue to use the Reflective Cycle as a guide to their } \\
\text { writing. The other three groups will continue in the baseline } \\
\text { phase turning in assigned work. }\end{array}$ \\
\hline & Objectives & $\begin{array}{l}\text { (1)Demonstrate and understanding of physical conditioning } \\
\text { by developing a physical conditioning practice plan } \\
\text { (2)Read and review athlete growth and development. }\end{array}$ \\
\hline & Key Points & $\begin{array}{l}\text { Intervention, Physical Conditioning, Growth/Development, } \\
\text { Reflection }\end{array}$ \\
\hline & $\begin{array}{l}\text { Assigned for next } \\
\text { week }\end{array}$ & $\begin{array}{l}\text { (1)Write reflective journal \#6 (Group B starts using the } \\
\text { reflective cycle as a guide) (Due Thursday night by 12) } \\
\text { (2)Participate in group discussions related to growth and } \\
\text { development } \\
\text { (3)Read chapter/article on growth and development. }\end{array}$ \\
\hline & Assignments Due & $\begin{array}{l}\text { (1)Turn in reflective journal \#5 (Due Thursday night by 12) } \\
\text { (2)The group that received the intervention two weeks prior } \\
\text { will also turn in an assessment of one journal entry using the } \\
\text { Five-point Level of Reflection Scale (Bain et al., 1999). } \\
\text { (3)Participate in discussion group related to physical } \\
\text { conditioning } \\
\text { (4)Turn in a practice plan detailing just warm ups, cool } \\
\text { downs, and conditioning }\end{array}$ \\
\hline \multirow[t]{2}{*}{ Week 7} & Intervention Groups & $\begin{array}{l}\text { The first and second groups will use the reflective cycle as a } \\
\text { guide for their journal writing while the other three groups } \\
\text { stay in the baseline stage. }\end{array}$ \\
\hline & Objectives & (1)Discuss how coaches develop and grow athletes \\
\hline
\end{tabular}




\begin{tabular}{|c|c|c|}
\hline & & $\begin{array}{l}\text { (2)Read and review teaching and communication areas of } \\
\text { coaching. }\end{array}$ \\
\hline & Key Points & $\begin{array}{l}\text { Growth/Development, Teaching/Communications, } \\
\text { Reflection }\end{array}$ \\
\hline & $\begin{array}{l}\text { Assigned for next } \\
\text { week }\end{array}$ & $\begin{array}{l}\text { (1)Write reflective journal \#7 (Due Thursday night by 12) (2) } \\
\text { Participate in discussion groups related to teaching and } \\
\text { communication. } \\
\text { (3)Read chapters/articles on teaching and communication } \\
\text { skills of coaches. } \\
\text { (4)Third group will attend the on campus class next week }\end{array}$ \\
\hline & Assignments Due & $\begin{array}{l}\text { (1)Turn in the sixth reflective journal (Due Thursday night } \\
\text { by 12) } \\
\text { (2)Participate in discussion groups related to growth and } \\
\text { development }\end{array}$ \\
\hline \multirow{5}{*}{ Week 8} & Intervention Groups & $\begin{array}{l}\text { The third group will participate in the intervention class. The } \\
\text { first and second groups will continue to use the reflective } \\
\text { cycle as guides for their journal writing while the other two } \\
\text { groups stay in the baseline stage. }\end{array}$ \\
\hline & Objectives & $\begin{array}{l}\text { (1)Discuss the teaching and communication skills needed } \\
\text { and used in coaching } \\
\text { (2)Read and review sport skills and tactics. }\end{array}$ \\
\hline & Key Points & $\begin{array}{l}\text { Intervention, Teaching/Communications, Skills/Tactics, } \\
\text { Reflection }\end{array}$ \\
\hline & $\begin{array}{l}\text { Assigned for next } \\
\text { week }\end{array}$ & $\begin{array}{l}\text { (1)Write reflective journal \#8 (Due Thursday night by 12) } \\
\text { (2)The group that received the intervention two weeks prior } \\
\text { will also turn in an assessment of one journal entry using the } \\
\text { Five-point Level of Reflection Scale (Bain et al., 1999). } \\
\text { (3)Participate in discussion groups related to sport skills and } \\
\text { tactics } \\
\text { (4)Read chapters/articles on sport skills and tactics. }\end{array}$ \\
\hline & Assignments Due & $\begin{array}{l}\text { (1)Turn in seventh reflective journal (Due Thursday night by } \\
\text { 12) } \\
\text { (2)Participate in discussion groups related to teaching and } \\
\text { communication }\end{array}$ \\
\hline \multirow{4}{*}{ Week 9} & Intervention Groups & $\begin{array}{l}\text { The three groups that received the intervention will continue } \\
\text { to use the reflective cycle as a guide when writing their } \\
\text { journals while the other two groups remain at baseline stage. }\end{array}$ \\
\hline & Objectives & $\begin{array}{l}\text { (1)Demonstrate knowledge of planning a practice by } \\
\text { developing practice plans. } \\
\text { (2)Discuss of sport skills and tactics are used by coaches and } \\
\text { read and review the organization and administrative skills } \\
\text { needed to coach. }\end{array}$ \\
\hline & Key Points & $\begin{array}{l}\text { Practice Planning, Skills/Tactics, } \\
\text { Organization/Administration, Reflection }\end{array}$ \\
\hline & $\begin{array}{l}\text { Assigned for next } \\
\text { week }\end{array}$ & $\begin{array}{l}\text { (1)Write reflective journal } \# 9 \text { (Due Thursday night by } 12 \text { ) } \\
\text { (2)Participate in discussion groups related organization and }\end{array}$ \\
\hline
\end{tabular}




\begin{tabular}{|c|c|c|}
\hline & & $\begin{array}{l}\text { administration } \\
\text { (3)Read chapters/articles on coaching organization on } \\
\text { administration. } \\
\text { (4)Forth group will attend the on campus class next week }\end{array}$ \\
\hline & Assignments Due & $\begin{array}{l}\text { (1)Turn in eighth reflective journal (Due Thursday night by } \\
\text { 12) } \\
\text { (2)Participate in discussion groups related to teaching and } \\
\text { communication } \\
\text { (3)Turn in practice plans }\end{array}$ \\
\hline \multirow{5}{*}{ Week 10} & Intervention Groups & $\begin{array}{l}\text { The fourth group will participate in the intervention class. } \\
\text { The first three groups to receive the intervention will } \\
\text { continue to use the reflective cycle as a guide and the fifth } \\
\text { group will remain at the baseline stage. }\end{array}$ \\
\hline & Objectives & $\begin{array}{l}\text { (1)Discuss organizational and administrative coaching skills } \\
\text { (2)Read and review player assessment techniques. }\end{array}$ \\
\hline & Key Points & $\begin{array}{l}\text { Intervention, Organization/Administration, } \\
\text { Assessment/Evaluation, Reflection }\end{array}$ \\
\hline & $\begin{array}{l}\text { Assigned for next } \\
\text { week }\end{array}$ & $\begin{array}{l}\text { (1)Write reflective journal \#10 (Due Thursday night by 12) } \\
\text { (2)Participate in discussion groups related to player } \\
\text { assessment and evaluation } \\
\text { (3)Read chapter/articles associated with player assessment } \\
\text { and evaluation. }\end{array}$ \\
\hline & Assignments Due & $\begin{array}{l}\text { (1)Turn reflective journal \#9 (Due Thursday night by 12) } \\
\text { (2)The group that received the intervention two weeks prior } \\
\text { will also turn in an assessment of one journal entry using the } \\
\text { Five-point Level of Reflection Scale (Bain et al., 1999). } \\
\text { (3)Participate in group discussions related to organization } \\
\text { and administrative skills used in coach. }\end{array}$ \\
\hline \multirow{5}{*}{ Week 11} & Intervention Groups & $\begin{array}{l}\text { The four groups that have received the intervention will } \\
\text { continue to use the reflective cycle as a guide for writing } \\
\text { their journals while the fifth group will remain at baseline } \\
\text { stage. }\end{array}$ \\
\hline & Objectives & $\begin{array}{l}\text { (1)Demonstrate knowledge of assessing athletes by turning } \\
\text { in player assessments and discussing the issues related with } \\
\text { player assessments. } \\
\text { (2)Read and review coaching and assessment and evaluation. }\end{array}$ \\
\hline & Key Points & $\begin{array}{l}\text { Athlete Assessment/Evaluation, Coach } \\
\text { Assessment/Evaluation, Reflection }\end{array}$ \\
\hline & $\begin{array}{l}\text { Assigned for next } \\
\text { week }\end{array}$ & $\begin{array}{l}\text { (1)Write reflective journal \#11 (Due Thursday night by 12) } \\
\text { (2)Participate in discussion groups related coaching } \\
\text { assessment and evaluations } \\
\text { (3)Read chapter/article on coaching assessment and } \\
\text { evaluation. } \\
\text { (4)Fifth group will attend the on campus class next week }\end{array}$ \\
\hline & Assignments Due & $\begin{array}{l}\text { (1)Turn reflective journal \#10 (Due Thursday night 12) } \\
\text { (2)Participate in discussion groups related to player }\end{array}$ \\
\hline
\end{tabular}




\begin{tabular}{|c|c|c|}
\hline & & $\begin{array}{l}\text { assessment } \\
\text { (2)Turn in two player evaluations }\end{array}$ \\
\hline \multirow{5}{*}{ Week 12} & Intervention Groups & $\begin{array}{l}\text { The fifth and final group will receive the intervention. All } \\
\text { other groups will continue to use the reflective cycle to guide } \\
\text { the journal writing. }\end{array}$ \\
\hline & Objectives & $\begin{array}{l}\text { (1)Demonstrate an understanding of coaching assessment by } \\
\text { turning in an assessment of the head coach and discussing the } \\
\text { areas related with assessment. } \\
\text { (2)Read and review current topics within the coaching world. }\end{array}$ \\
\hline & Key Points & $\begin{array}{l}\text { Intervention, Coach Assessment/Evaluation, Current Topics, } \\
\text { Reflection }\end{array}$ \\
\hline & $\begin{array}{l}\text { Assigned for next } \\
\text { week }\end{array}$ & $\begin{array}{l}\text { (1)Write reflective journal \#12 (Due Thursday night by 12) } \\
\text { (2)Participate in discussion groups related current hot topics } \\
\text { (3)Read chapter/articles/internet site on current hot topics } \\
\text { related to coaching. }\end{array}$ \\
\hline & Assignments Due & $\begin{array}{l}\text { (1)Turn in eleventh reflective journal (Due Thursday night } \\
\text { by 12) } \\
\text { (2)The group that received the intervention two weeks prior } \\
\text { will also turn in an assessment of one journal entry using the } \\
\text { Five-point Level of Reflection Scale (Bain et al., 1999). } \\
\text { (3)Participate in discussion groups related to coaching } \\
\text { assessment and evaluation } \\
\text { (4)Turn in the evaluation of the head coach }\end{array}$ \\
\hline \multirow{5}{*}{ Week 13} & Intervention Groups & $\begin{array}{l}\text { All groups will continue to use the reflective cycle as a guide } \\
\text { to their journals. }\end{array}$ \\
\hline & Objectives & $\begin{array}{l}\text { (1)Discuss the current topics in coaching and how the topics } \\
\text { may relate to their own coaching situations }\end{array}$ \\
\hline & Key Points & Current Topics, Reflection \\
\hline & $\begin{array}{l}\text { Assigned for next } \\
\text { week }\end{array}$ & $\begin{array}{l}\text { (1)Write reflective journal \#13 } \\
\text { (2)Participate in discussion groups related to current topics } \\
\text { within coaching }\end{array}$ \\
\hline & Assignments Due & $\begin{array}{l}\text { (1)Turn reflective journal \#12 (Due Thursday night by 12) } \\
\text { (2)Turn in practice plans }\end{array}$ \\
\hline \multirow{5}{*}{ Week 14} & Intervention Groups & $\begin{array}{l}\text { The reflective journals and treatment will be completed by } \\
\text { the end of this week. }\end{array}$ \\
\hline & Objectives & $\begin{array}{l}\text { (1)Review the experiences from the internship } \\
\text { (2)Summarize what was learned. }\end{array}$ \\
\hline & Key Points & Reflection \\
\hline & $\begin{array}{l}\text { Assigned for next } \\
\text { week }\end{array}$ & (1)Write the final reflective paper. \\
\hline & Assignments Due & $\begin{array}{l}\text { (1)Turn reflective journal \#13 (Due Thursday night by 12) } \\
\text { (2)The group that received the intervention two weeks prior } \\
\text { will also turn in an assessment of one journal entry using the } \\
\text { Five-point Level of Reflection Scale (Bain et al., 1999) } \\
\text { (3)Participate in discussion groups related to current topics } \\
\text { within coaching }\end{array}$ \\
\hline
\end{tabular}




\begin{tabular}{|c|c|c|}
\hline \multirow{4}{*}{ Week 15} & Assignments Due & $\begin{array}{l}\text { (1)Turn in portfolios containing all of the previously } \\
\text { assigned work and coaches certification of hours completed } \\
\text { (2) Turn in reflective journal \#15. (Due Thursday night by } \\
\text { 12) }\end{array}$ \\
\hline & Objectives & $\begin{array}{l}\text { (1)Summarize the internship experience in group discussions } \\
\text { (2)Demonstrate what was learned throughout the semester by } \\
\text { developing a portfolio with all the material completed in the } \\
\text { class }\end{array}$ \\
\hline & Key Points & Learning, Reflection \\
\hline & $\begin{array}{l}\text { Assigned for next } \\
\text { week }\end{array}$ & There are no assignments due for the following week. \\
\hline
\end{tabular}


Appendix E

Multiple Baseline Design 


\section{Multiple Baseline Design}

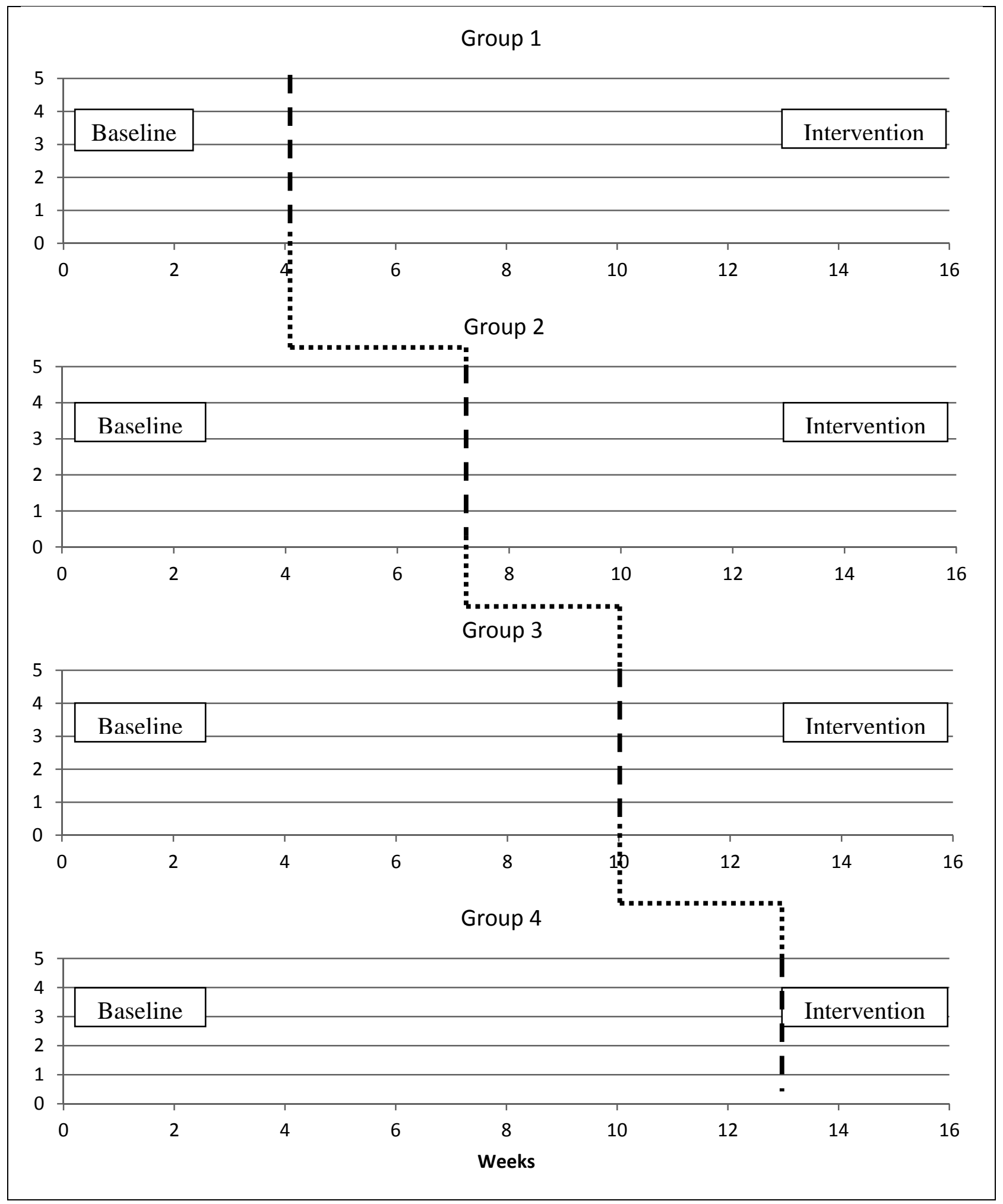




\section{Appendix F}

The United Kingdom’s National Coaching Foundation Reflective Cycle (Galvin, 2006) 
The United Kingdom's National Coaching Foundation Reflective Cycle (Galvin, 2006)
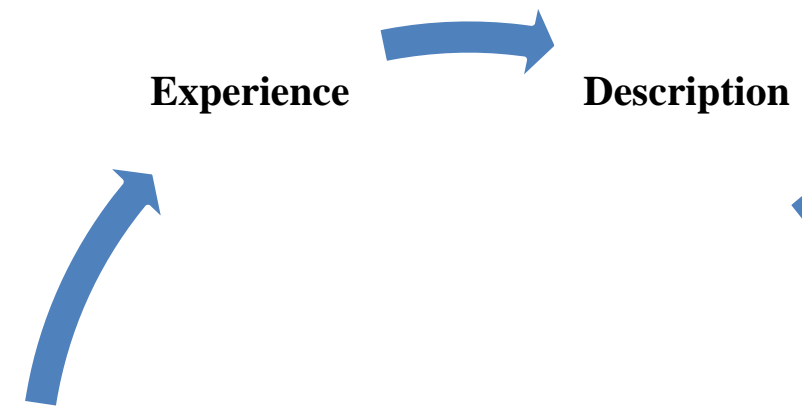

\section{Action Plan}

Evaluation

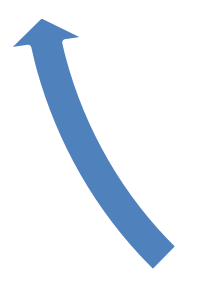

Conclusion

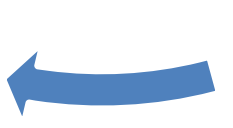

Analysis

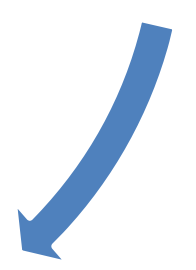




\section{Appendix G}

High Level of Reflective Writing 


\section{High Level of Reflective Writing (Perry, 2000)}

The student, even if he notices cues from the patient, does not always feel himself in a position to act. My responsibility, in a student-teacher relationship, is that the student continues his professional development whilst the patient receives quality care. Even when our type of learning contract (which I endorsed), I cannot simply remain observer of the student's actions. My role lies also in strategies to foster his rapid reflection, analysis and planning before during (rather than after) his contact with a patient. In using these strategies, I could make better use of my own perceptions even with limited knowledge I had of Mrs. Diaz. I had already interpreted her covert way of watching us. I need to know and trust myself, and respect my knowledge and interpretations.

Both Pierre and I were aware of the ward climate regarding the division between medical and nursing staff. I have learned that this climate is continually reproduced almost unconsciously as students are socialized into the team. Thus our expectations of the behavior of the medical staff became self-fulfilling prophecies.

Above all this reflection has endorsed the importance of knowing the patient in every sense. I originally saw my place as secondary to that of Pierre's direct relationship with his patients. I was not there to demonstrate some superior ability in handling a complex situation but to support and guide him in his professional development. As such, I set a distance between my observations, interpretations and actions. But these interpretations are not neutral. Whilst Pierre was concentrated on tasks, I had the liberty and the experience to take a more global view, and to draw on empathetic skills. My attention and openness to fine detail cues allowed me to know the patient beyond the confines of verbal communication. The ability to look beyond signs, symptoms and medical diagnosis (I knew little of these), to understand beyond utter words (there were few of these), allows me to act beyond action. My power in this situation lies in my recognition of this strength. (Perry, 2000) 


\section{Appendix $\mathbf{H}$}

Example of Feedback 


\section{Example of Feedback}

You do a great job trying to apply the reflective concepts that we discussed in class throughout this journal which has increased the depth and level of reflection.

In this section of the journal you are analyzing the factors that could be affecting your athletes. At this point you are writing at the $4^{\text {th }}$ level of reflection. To reach the $5^{\text {th }}$ level, consider examining what you have learned about this type of situation and how you might be able to avoid or prepare for similar situations in the future. Considering the age level of the athletes, type of motivational techniques, and or consequences could help you improve their behavior.

In this section you have done a nice job exploring the options that you could have taken to increase the productive behaviors of the athletes. Again you are writing at the fourth level of reflection by analyzing the option you could take any the athletes reactions to this. To push up to the $5^{\text {th }}$ level of reflection try to determine how you might apply future coaching situations that are similar in nature to the current situation. More extensive planning and taking steps to learn more about behaviors and motivational techniques could be help for you during this process.

Related to the reflective cycle here you have made a conclusion about the current experience. The next step in the cycle is the action plan. To design an action plan review your reflections, previous experiences, coaching knowledge, the best coaching best practices, and coaching theory to help design the best plan possible. One way to think about this is to take step to prevent this situation first and then design plans to deal with the situation if it is not possible to avoid. 
Appendix I

Five-Point Level of Reflection Scales 


\section{Five-Point Level of Reflection Scale (Bain et al., 1999)}

\begin{tabular}{|c|c|}
\hline Level 1 (reporting) & $\begin{array}{l}\text { 1-The student coach SC describes, reports or re-tells with minimal transformation, no } \\
\text { added observation or insights }\end{array}$ \\
\hline \multirow{4}{*}{$\begin{array}{c}\text { Level } 2 \\
\text { (responding) }\end{array}$} & $\begin{array}{l}\text { 2-The SC uses the source of data in some way, but with little transformation or } \\
\text { conceptualization }\end{array}$ \\
\hline & $\begin{array}{l}\text { 3-The SC makes an observation or judgment without making any further inferences or } \\
\text { detailing the reasons for the judgment }\end{array}$ \\
\hline & $\begin{array}{l}\text { 4-The SC asks a 'rhetorical' question without attempting to answer it or consider } \\
\text { alternatives }\end{array}$ \\
\hline & 5-The SC reports a feeling such as relief, anxiety, happiness, etc. \\
\hline \multirow{4}{*}{ Level 3 (relating) } & $\begin{array}{l}\text { 6-The SC identifies aspects of the data which have personal meaning or which } \\
\text { connect with their prior or current experience }\end{array}$ \\
\hline & 7-The SC seeks a superficial understanding of relationships \\
\hline & $\begin{array}{l}\text { 8-The SC identifies something they are good at, something they need to improve, a } \\
\text { mistake they have made, or an area in which they have learned from their practical } \\
\text { experience }\end{array}$ \\
\hline & $\begin{array}{l}\text { 9-The SC gives a superficial explanation of the reason why something has happened } \\
\text { or identifies something they need or plan to do or change }\end{array}$ \\
\hline \multirow{4}{*}{$\begin{array}{c}\text { Level } 4 \\
\text { (reasoning) }\end{array}$} & $\begin{array}{l}\text { 10-The SC integrates the data into an appropriate relationship, e.g. with theoretical } \\
\text { concepts, personal experience, involving a high level of transformation and } \\
\text { conceptualization }\end{array}$ \\
\hline & 11-The SC seeks a deep understanding to why something has happened \\
\hline & $\begin{array}{l}\text { 12-The SC explores or analyses a concept, event or experience, asks, questions and } \\
\text { looks for answers, considers alternative, speculates or hypothesizes about why } \\
\text { something is happening }\end{array}$ \\
\hline & $\begin{array}{l}\text { 13-The SC attempts to explain their own or others' behaviors or feelings using their } \\
\text { own insight, inferences, experiences or previous learning, with depth and of } \\
\text { understanding } \\
\text { 14-The SC explores the relationship between theory and practice in some depth }\end{array}$ \\
\hline \multirow{3}{*}{$\begin{array}{l}\text { Level } 5 \\
\text { (reconstructing) }\end{array}$} & $\begin{array}{l}\text { 15-The SC displays a high level of abstract thinking to generalize and/or apply } \\
\text { learning }\end{array}$ \\
\hline & $\begin{array}{l}\text { 16-The SC draws an original conclusion from their reflections, generalizes from their } \\
\text { experience, extracts general principles, formulates a personal theory of coaching or } \\
\text { takes a position on an issue }\end{array}$ \\
\hline & $\begin{array}{l}\text { 17-The SC extracts and internalizes the personal significance of their learning and/or } \\
\text { plans their further learning on the basis of their reflections }\end{array}$ \\
\hline
\end{tabular}


Reasons for and changes made to the Five-Point Level of Reflection Scale (Galvin, 2006)

\begin{tabular}{|c|c|c|c|}
\hline Levels & Criteria & Changes & Reasoning \\
\hline 1 & A & $\begin{array}{l}\text {---Student was replaced with } \\
\text { student coach (SC). } \\
\text {---The negative wording was } \\
\text { removed. } \\
\text {---The words events or experiences } \\
\text { were added. }\end{array}$ & $\begin{array}{l}\text {---Examining SCs not teachers. } \\
\text {---Removing the negative wording } \\
\text { made it possible for SCs to each of } \\
\text { the } 22 \text { criteria. } \\
\text {---These words made the statement } \\
\text { easier for the researchers to code }\end{array}$ \\
\hline \multirow{5}{*}{2} & B & $\begin{array}{l}\text {---The negative wording was } \\
\text { removed. } \\
\text {---The words “to augment their } \\
\text { knowledge or understanding” were } \\
\text { added. }\end{array}$ & $\begin{array}{l}\text {---Removing the negative wording } \\
\text { made it possible for SCs to achieve } \\
\text { each of the } 22 \text { criteria. } \\
\text {---When student coaches wrote B } \\
\text { statements in the } 21 \text { journals } \\
\text { assessed before the study the } \\
\text { information written seemed to } \\
\text { augment their understanding of a } \\
\text { concept or experience. }\end{array}$ \\
\hline & C & $\begin{array}{l}\text {---The negative wording was } \\
\text { removed. } \\
\text {---The category was reduced to } \\
\text { only say “The SC makes a } \\
\text { judgment”. }\end{array}$ & $\begin{array}{l}\text {---Removing the negative wording } \\
\text { made it possible for SCs to achieve } \\
\text { each of the } 22 \text { criteria. } \\
\text {---Making this category only a } \\
\text { judgment made it easier to code } \\
\text { consistently. }\end{array}$ \\
\hline & D & ---Removed the negative wording. & $\begin{array}{l}\text {---Removing the negative wording } \\
\text { made it possible for SCs to achieve } \\
\text { each of the } 22 \text { criteria. }\end{array}$ \\
\hline & $\mathbf{E}$ & \begin{tabular}{|l}
---Nothing was changed. \\
\end{tabular} & \\
\hline & $\mathbf{Z}$ & ---This category was added. & $\begin{array}{l}\text {---When assessing the } 21 \text { student } \\
\text { coaches journals prior to the study } \\
\text { the student coaches wrote many } \\
\text { statements about their purposes, } \\
\text { goals, and objective. }\end{array}$ \\
\hline \multirow{3}{*}{3} & $\mathbf{F}$ & \begin{tabular}{|l}
---Nothing was changed. \\
\end{tabular} & \\
\hline & G & $\begin{array}{l}\text {---The words “and others feelings" } \\
\text { were added. }\end{array}$ & $\begin{array}{l}\text {---The student coaches did not seek } \\
\text { to understand relationships or } \\
\text { feelings instead they portrayed a } \\
\text { superficial understanding of them. } \\
\text { Made it easier for the researchers to } \\
\text { code. } \\
\text {---The student coaches talked about } \\
\text { others feelings more so then } \\
\text { relationships. }\end{array}$ \\
\hline & $\mathbf{H}$ & $\begin{array}{l}\text {---This criterion in the original } \\
\text { scale was divided into these four } \\
\text { categories. }\end{array}$ & $\begin{array}{l}\text {---The journals assessed before the } \\
\text { study showed that SCs wrote several } \\
\text { positive and negative statements }\end{array}$ \\
\hline
\end{tabular}




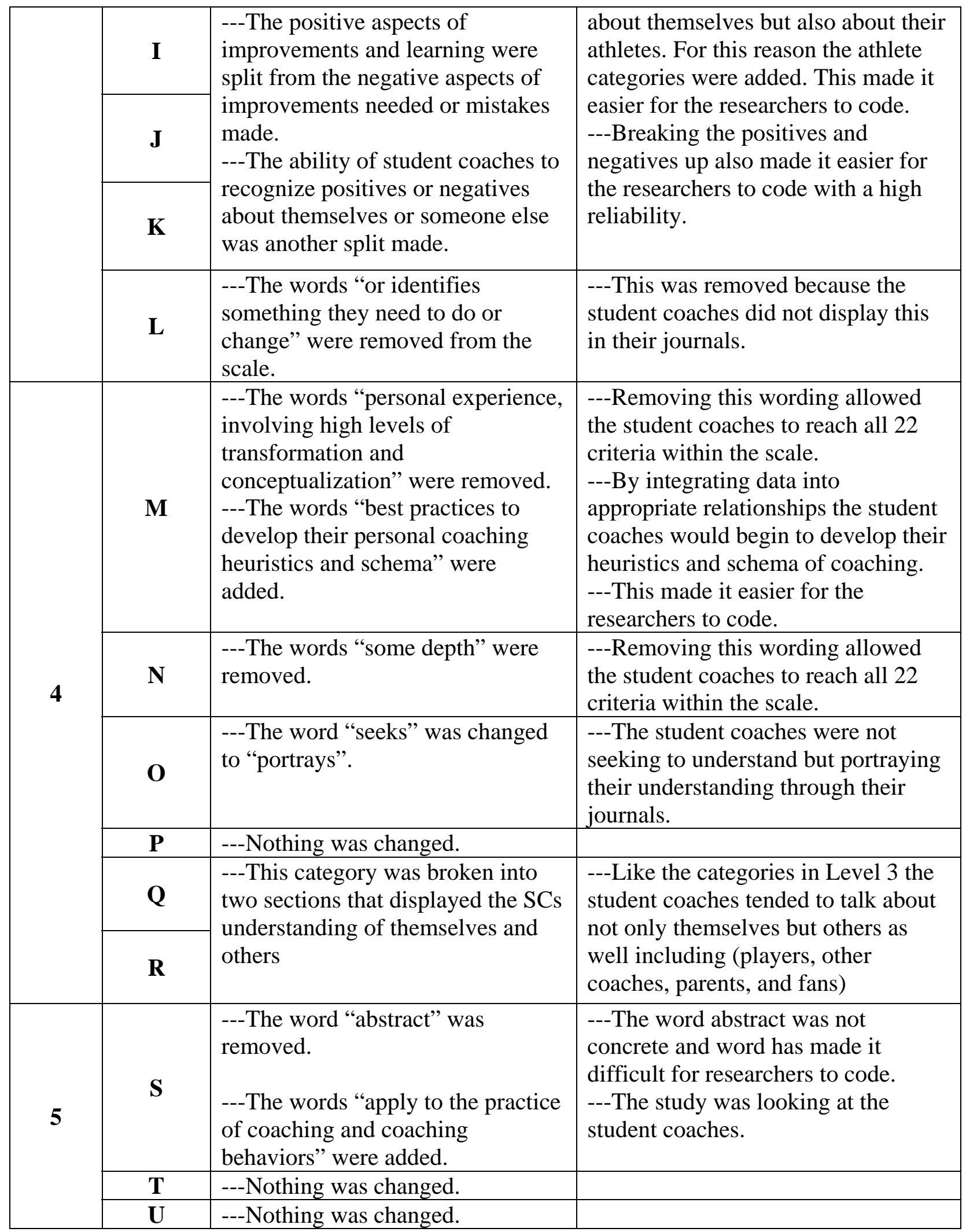




\section{Revised Five-Point Level of Reflection Scale}

\begin{tabular}{|c|c|}
\hline Level 1 (reporting) & A. The SC (SC) describes reports or re-tells the events or experiences. \\
\hline \multirow{5}{*}{$\begin{array}{c}\text { Level } 2 \\
\text { (responding) }\end{array}$} & $\begin{array}{l}\text { B. The SC uses a secondary source of data or information to augment their } \\
\text { understanding or knowledge. }\end{array}$ \\
\hline & C. The SC makes a judgment. \\
\hline & D. The SC asks a 'rhetorical' question. \\
\hline & E. The SC reports a personal feeling such as relief, anxiety, happiness, etc. \\
\hline & Z. The SC identifies a purpose, goal or objective. \\
\hline \multirow{7}{*}{ Level 3 (relating) } & $\begin{array}{l}\text { F. The SC identifies aspects of the data or information which have personal meaning } \\
\text { or which connect with their prior or current experience. }\end{array}$ \\
\hline & $\begin{array}{l}\text { G. The SC portrays a superficial understanding of personal relationships and others } \\
\text { feelings. }\end{array}$ \\
\hline & $\begin{array}{l}\text { H. The SC identifies something they are good at or an area in which they have } \\
\text { learned from their practical experience. }\end{array}$ \\
\hline & I. The SC identifies something they need to improve or a mistake they have made. \\
\hline & $\begin{array}{l}\text { J. The SC identifies something a player, coach, or parent is good at or an area in } \\
\text { which they have improved. }\end{array}$ \\
\hline & $\begin{array}{l}\text { K. The SC identifies something a player, coach, or parent needs to improve or a } \\
\text { mistake they have made. }\end{array}$ \\
\hline & $\begin{array}{l}\text { L. The SC gives a superficial explanation of the reason why something has } \\
\text { happened. }\end{array}$ \\
\hline \multirow{6}{*}{$\begin{array}{l}\text { Level } 4 \\
\text { (reasoning) }\end{array}$} & $\begin{array}{l}\text { M. The SC integrates data or information into an appropriate relationship with } \\
\text { theoretical concepts or best practices to develop their personal coaching heuristics } \\
\text { and schema. }\end{array}$ \\
\hline & N. The SC extensively explores the relationship between theory and practice. \\
\hline & O. The SC portrays a deep understanding to why something has happened. \\
\hline & $\begin{array}{l}\text { P. The SC explores or analyzes a concept, event or experience, asks questions and } \\
\text { looks for answers, considers alternatives, speculates or hypothesizes about why } \\
\text { something is happening. }\end{array}$ \\
\hline & $\begin{array}{l}\text { Q. The SC attempts to explain their own behaviors or feelings using their own } \\
\text { insight, inferences, experiences or previous learning, with depth and understanding. }\end{array}$ \\
\hline & $\begin{array}{l}\text { R. The SC attempts to explain others behaviors or feelings using their own insight, } \\
\text { inferences, experiences or previous learning, with depth and understanding. }\end{array}$ \\
\hline \multirow{3}{*}{$\begin{array}{c}\text { Level } 5 \\
\text { (reconstructing) }\end{array}$} & $\begin{array}{l}\text { S. The SC displays a high level of thinking and generalizing to apply learning to the } \\
\text { practice of coaching and coaching behaviors. }\end{array}$ \\
\hline & $\begin{array}{l}\text { T. The SC draws an original conclusion from their reflections, generalizes from their } \\
\text { experience, extracts general principles, formulates a personal theory of coaching or } \\
\text { takes a position on an issue }\end{array}$ \\
\hline & $\begin{array}{l}\text { U. The SC extracts and internalizes the personal significance of their learning and/or } \\
\text { plans their further learning on the basis of their reflections }\end{array}$ \\
\hline
\end{tabular}




\section{Appendix $\mathbf{J}$}

Examples of Inter-Rater Reliability Scores 


\section{Examples of Inter-Rate Reliability Scores}

1---represents Researcher 1

2---represents Researcher 2

3---represents Researcher 3

Letters A-U and Z represent the Reflective Level Score from the revised Five-Point Level of Reflection Scale

\begin{tabular}{|c|c|c|c|c|c|}
\hline $\begin{array}{l}\text { Examples of Inter-Rater } \\
\text { Reliability Scores }\end{array}$ & Rese & $\begin{array}{l}\text { lers } \\
\text { el S }\end{array}$ & ctive & $\begin{array}{c}\text { Inter-Rater } \\
\text { Reliability } \\
\text { Score } 1\end{array}$ & $\begin{array}{c}\text { Inter-Rater } \\
\text { Reliability } \\
\text { Score } 2\end{array}$ \\
\hline Sentence & 1 & 2 & 3 & & \\
\hline All three researchers & ted $t$ & nten & e sam & & \\
\hline $\begin{array}{l}\text { This week at practice was a short } \\
\text { one because we cancelled practice } \\
\text { early on Tuesday because of the } \\
\text { tornado warnings and storm } \\
\text { warnings. }\end{array}$ & A & A & A & $2 / 2$ & $2 / 2$ \\
\hline $\begin{array}{l}\text { The bulls have really been a thorn in } \\
\text { our side the last few years, they } \\
\text { match up with us extremely well, } \\
\text { many people may have looked at } \\
\text { them as down since they lost to } \\
\text { Syracuse, but that was just a bad } \\
\text { matchup for them, as they don't deal } \\
\text { with pressure well and they don't } \\
\text { deal with teams running power } \\
\text { football at them, however they do } \\
\text { play against spread offenses pretty } \\
\text { good because of their overall team } \\
\text { speed }\end{array}$ & $\mathbf{L}$ & $\mathbf{L}$ & $\mathbf{L}$ & $2 / 2$ & $2 / 2$ \\
\hline Only two of three researc & rs ra & he st & ce the & ame & \\
\hline $\begin{array}{l}\text { Before we ended practice we just } \\
\text { worked on serving because this } \\
\text { seems to be our weakest thing }\end{array}$ & $\mathbf{K}$ & $\mathbf{L}$ & $\mathbf{K}$ & $1 / 2$ & $2 / 2$ \\
\hline $\begin{array}{l}\text { During the week I found a quote } \\
\text { from him from last season after our } \\
\text { game about "West Virginia not } \\
\text { being able to handle a guy with my } \\
\text { speed." and then took a bunch of } \\
\text { pictures from him killing us last year } \\
\text { and posted them in all of the } \\
\text { defensive meeting rooms, it's safe to } \\
\text { say our guys wanted to get after the } \\
\text { kid }\end{array}$ & C & C & $\mathbf{L}$ & $1 / 2$ & $1 / 2$ \\
\hline
\end{tabular}




\begin{tabular}{|c|c|c|c|c|c|}
\hline \multicolumn{5}{|c|}{ None of the researchers rated the sentence the same. } & \multirow[b]{2}{*}{$2 / 2$} \\
\hline $\begin{array}{l}\text { She has also improved because at } \\
\text { the first practice she was scared of } \\
\text { the ball and wouldn't even catch it } \\
\text { and now she is passing and bumping }\end{array}$ & $\mathbf{J}$ & $\mathbf{L}$ & G & $0 / 2$ & \\
\hline \multicolumn{6}{|c|}{ Only two researchers rated the sentence and one rated it as a repeat. } \\
\hline $\begin{array}{l}\text { I'm very thankful that I've had the } \\
\text { opportunity to be a part of the } \\
\text { Potomac State Women's Soccer } \\
\text { Team }\end{array}$ & $\mathbf{E}$ & $\mathbf{E}$ & Repeat & $1 / 1$ & $1 / 1$ \\
\hline $\begin{array}{l}\text { We will run most of the time, but we } \\
\text { will throw a pass out of one of our } \\
\text { Wildcat formations just to keep the } \\
\text { defense honest and to try and catch } \\
\text { them off guard }\end{array}$ & $\mathbf{Z}$ & Repeat & A & $0 / 1$ & $0 / 1$ \\
\hline \multicolumn{6}{|c|}{$\begin{array}{l}\text { A complex sentence broken into two statements by two researchers and kept } \\
\text { as one statement by the third researcher. }\end{array}$} \\
\hline $\begin{array}{l}\text { We had a good week of practice, we } \\
\text { put in some new defensive line drills } \\
\text { as we are really preaching causing } \\
\text { turnovers, also I had one of our } \\
\text { defensive lineman try out a new pass } \\
\text { rush move that I have never seen } \\
\text { anybody use, so I'm hoping we put it } \\
\text { to good use in the game Saturday }\end{array}$ & C & C & A & $1 / 2$ & $1 / 2$ \\
\hline $\begin{array}{l}\text { We had a good week of practice, we } \\
\text { put in some new defensive line drills } \\
\text { as we are really preaching causing } \\
\text { turnovers, also I had one of our } \\
\text { defensive lineman try out a new pass } \\
\text { rush move that I have never seen } \\
\text { anybody use, so I'm hoping we put it } \\
\text { to good use in the game Saturday }\end{array}$ & $\mathbf{Z}$ & $\mathbf{Z}$ & None & $1 / 1$ & $1 / 1$ \\
\hline $\begin{array}{l}\text { Many of the players wanted to hit } \\
\text { the ball with their palms, but with } \\
\text { practice and constant reminding they } \\
\text { got the hang of it }\end{array}$ & $\mathbf{K}$ & $\mathbf{K}$ & $\mathbf{K}$ & $2 / 2$ & $2 / 2$ \\
\hline
\end{tabular}




\section{Appendix K}

Aggregated Data for Groups and Individual Participants 


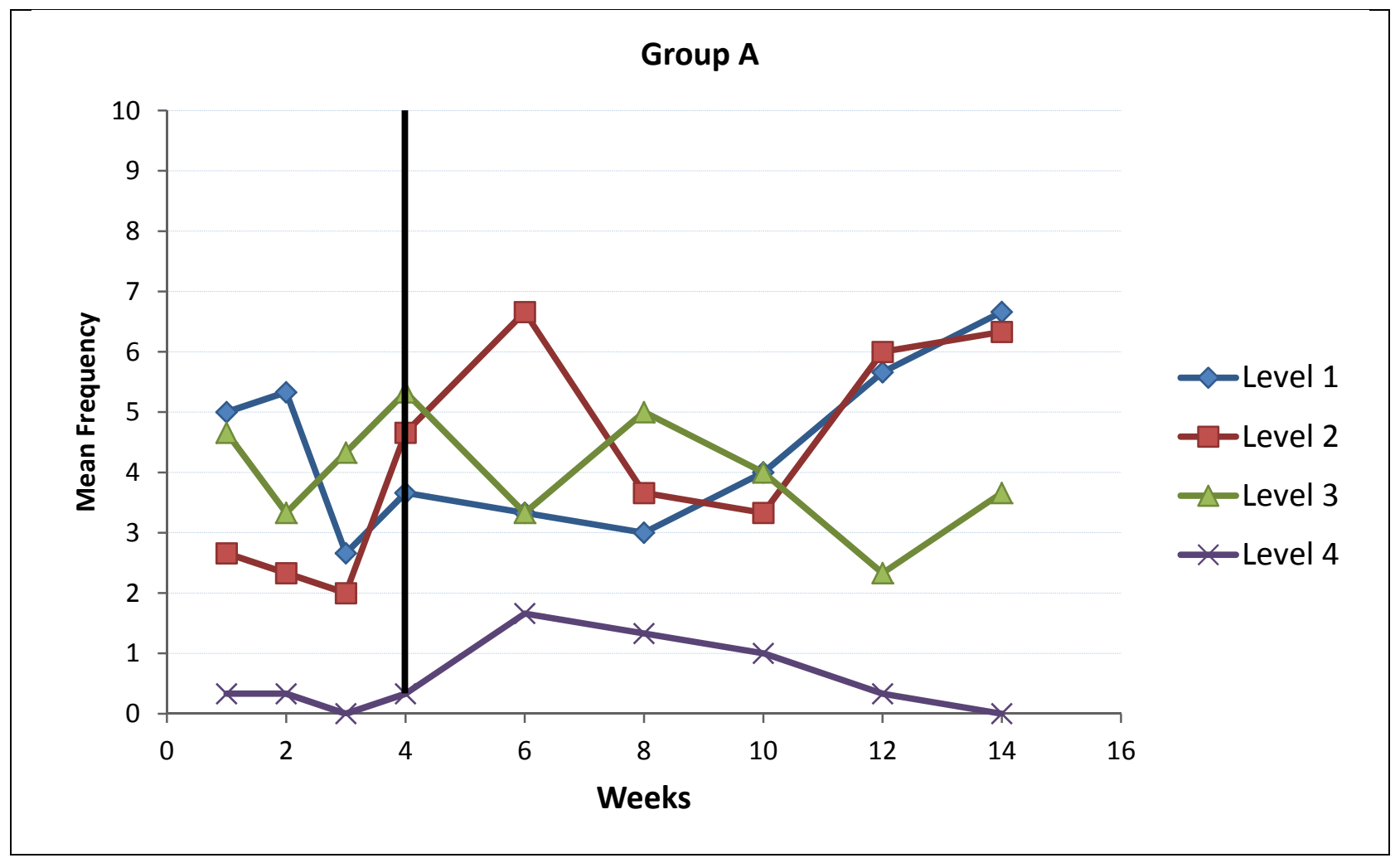

Figure 5. Group A's mean frequencies of reflective level responses per week. 


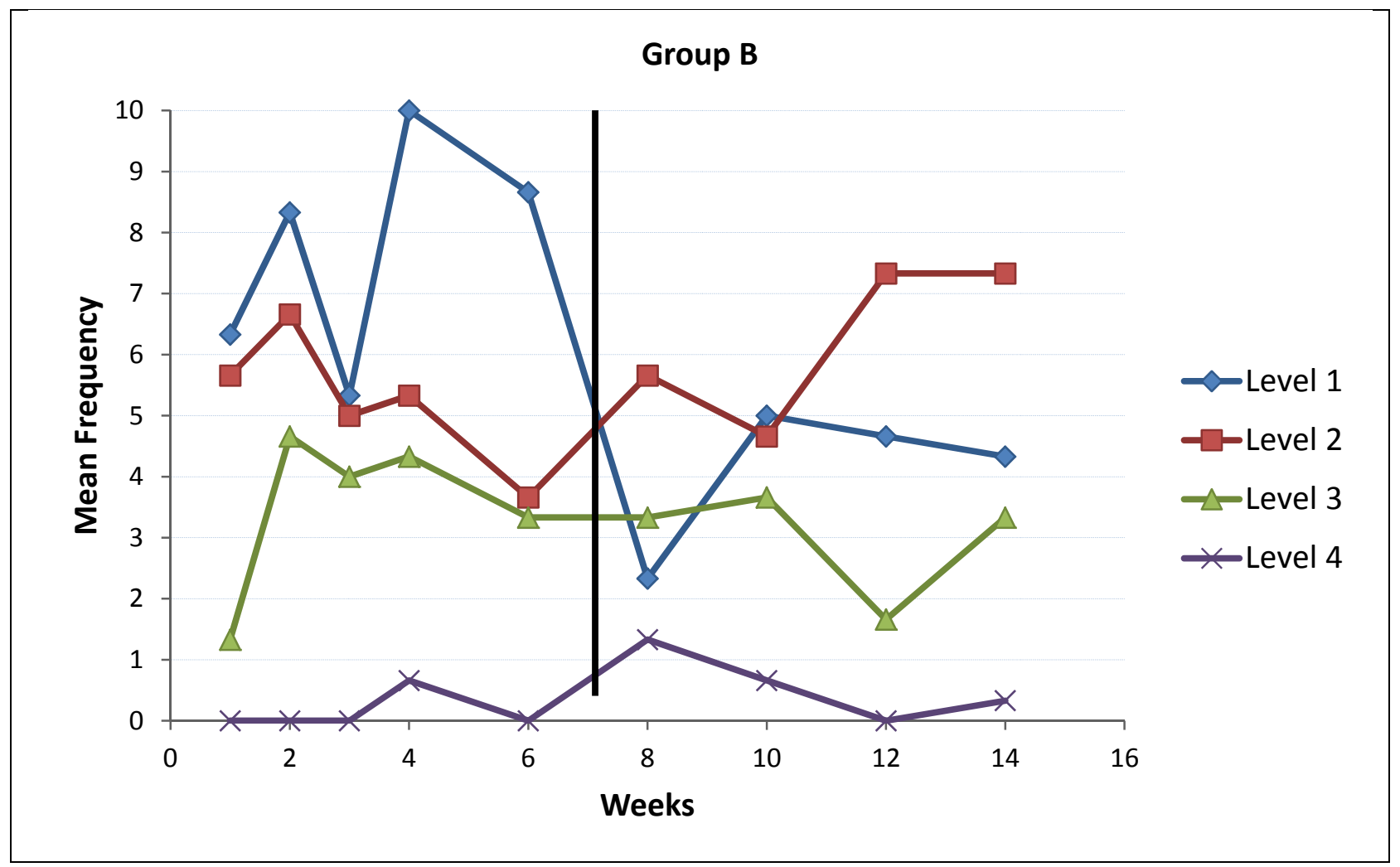

Figure 6. Group B’s mean frequencies of reflective level responses per week. 


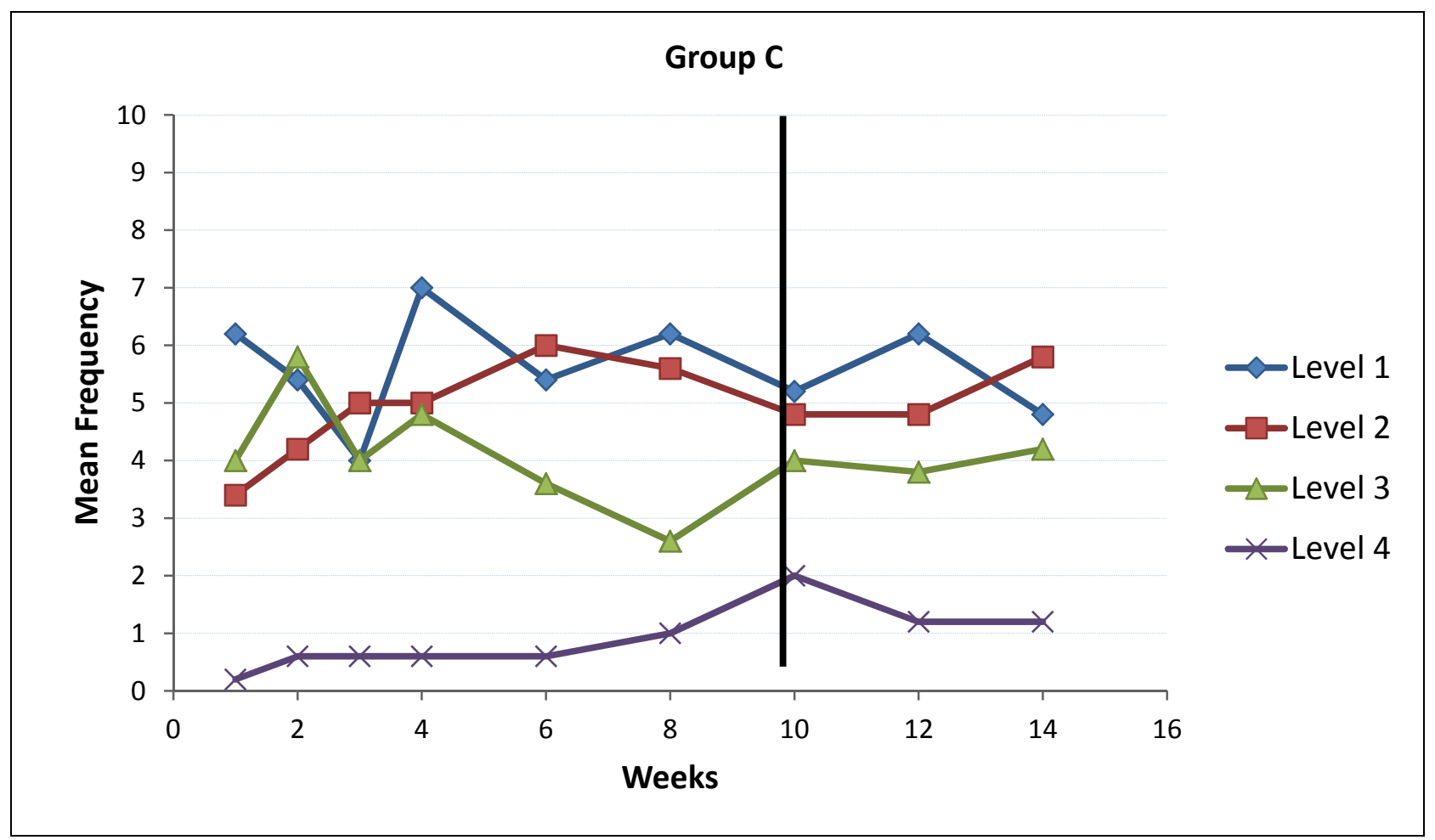

Figure 7. Group C’s mean frequencies of reflective level responses per week. 


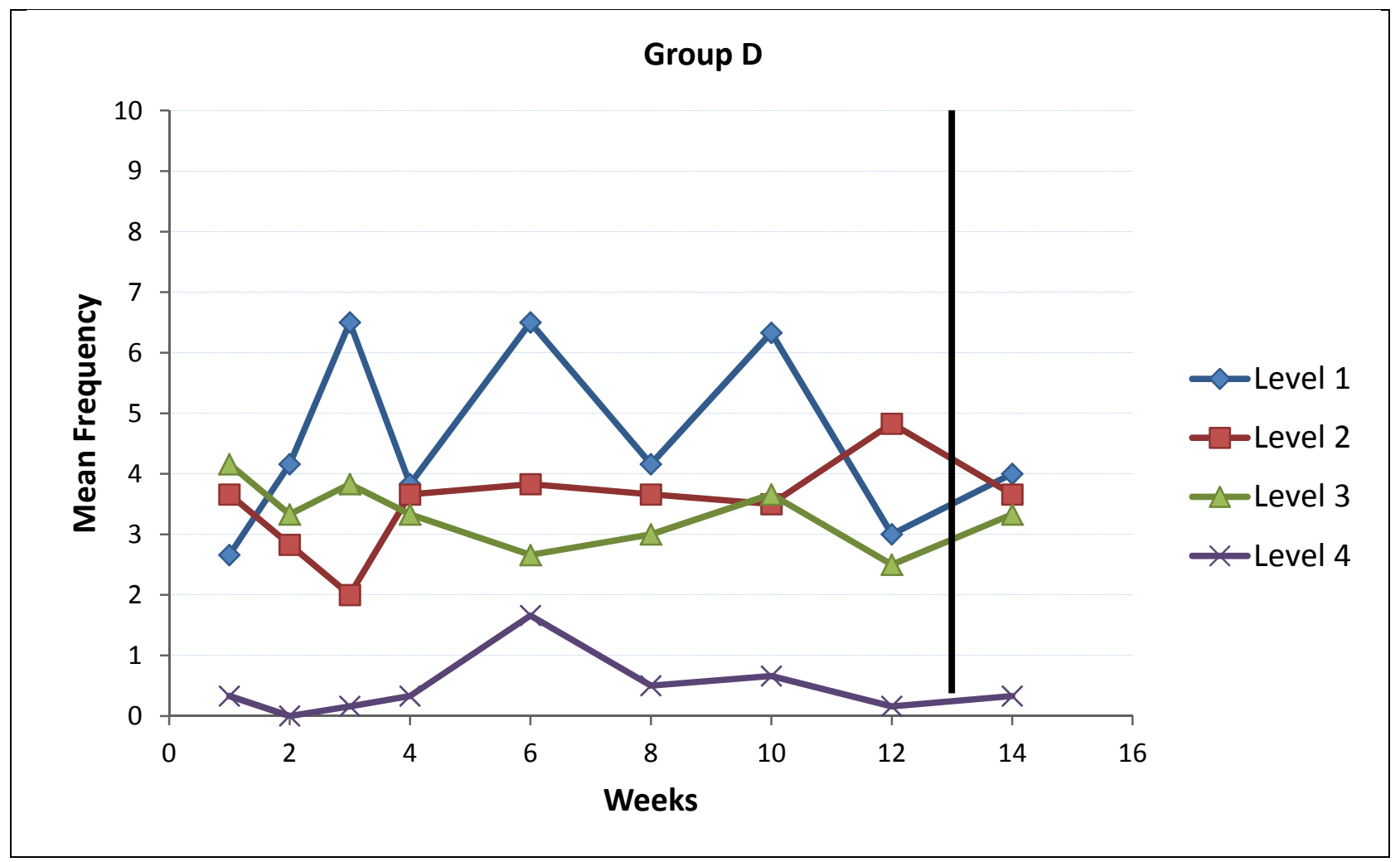

Figure 8. Group D’s mean frequencies of reflective level responses per week. 


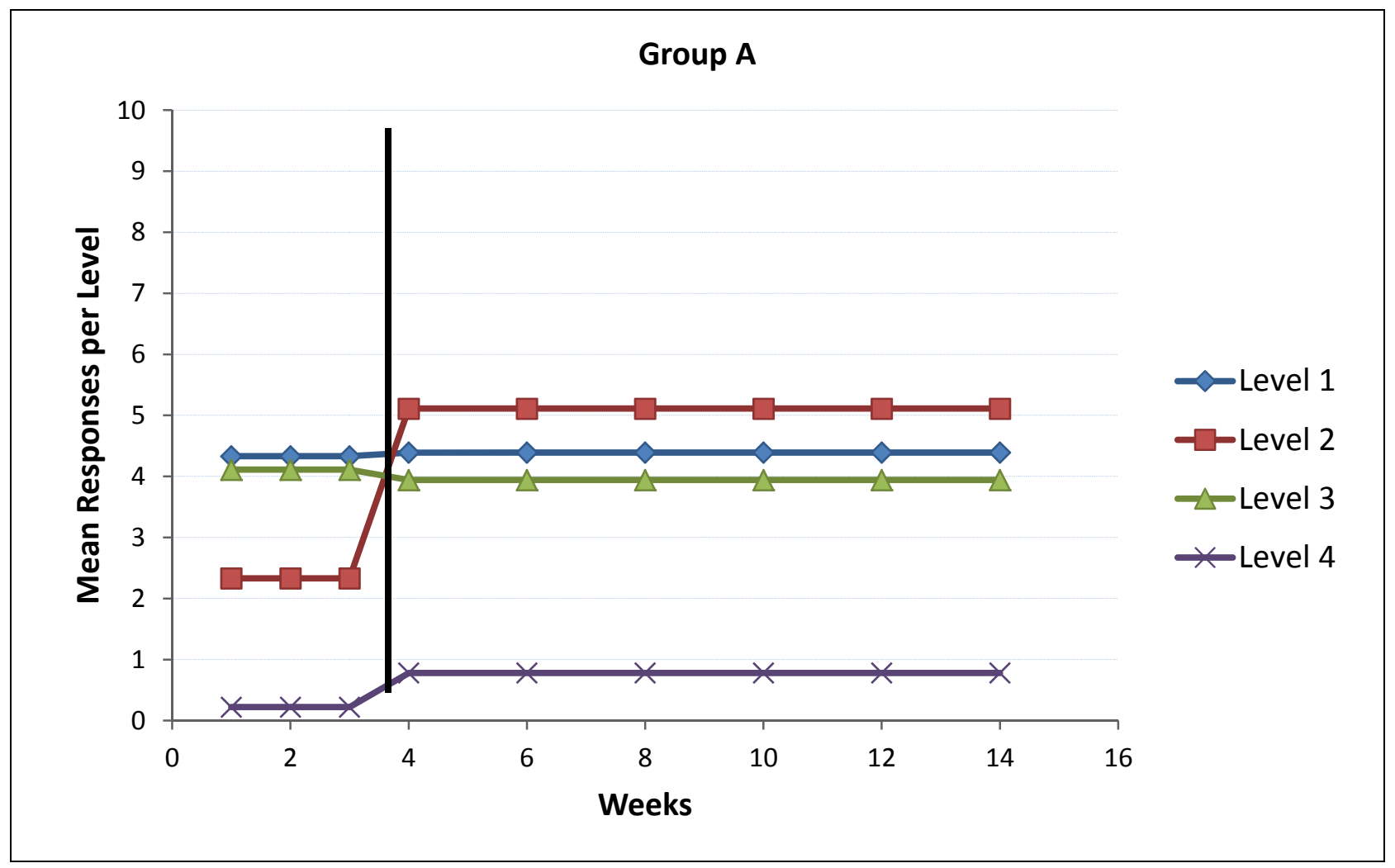

Figure 9. Group A's mean responses of each reflective level per week. 


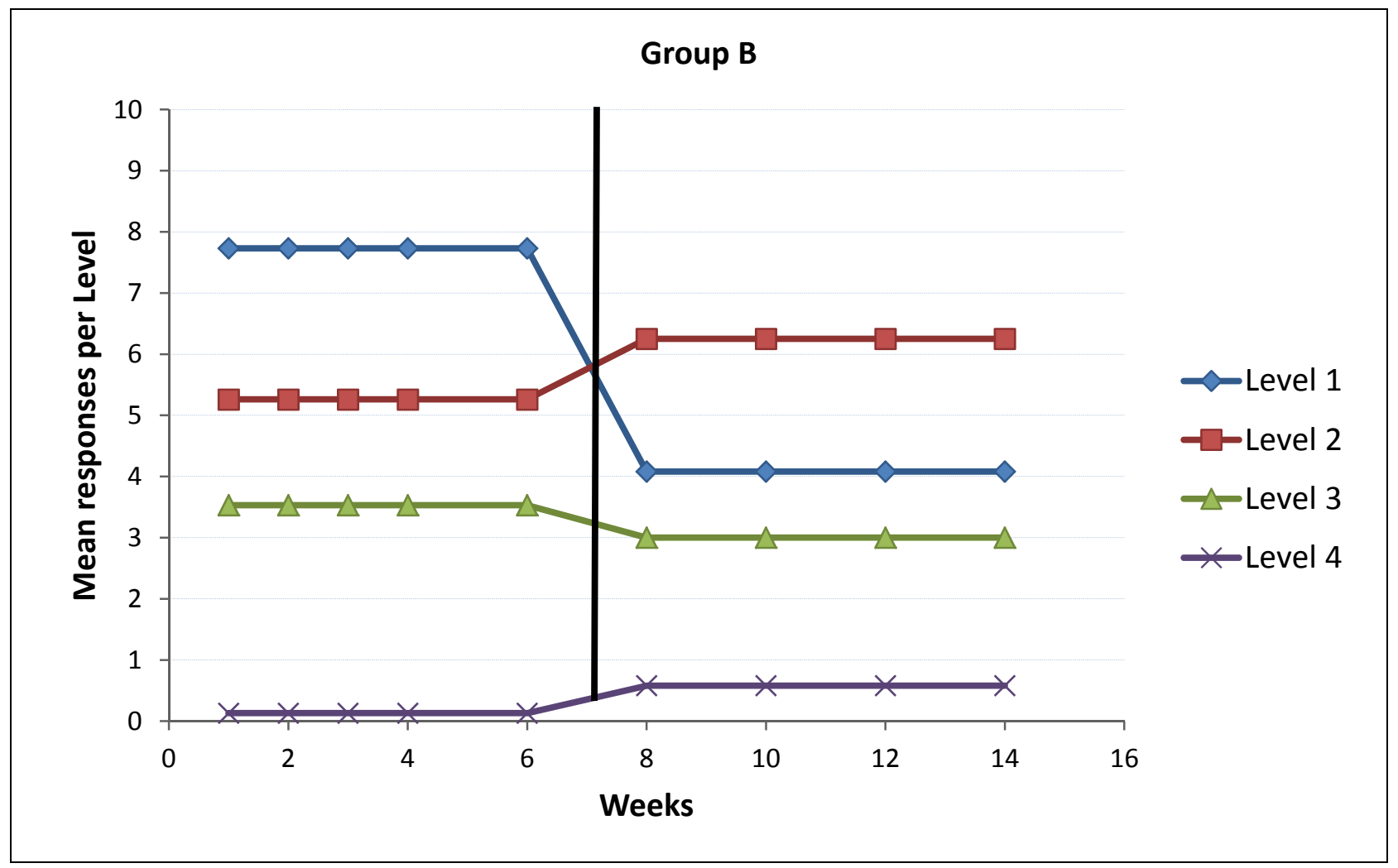

Figure 10. Group B's mean responses of each reflective level per week. 


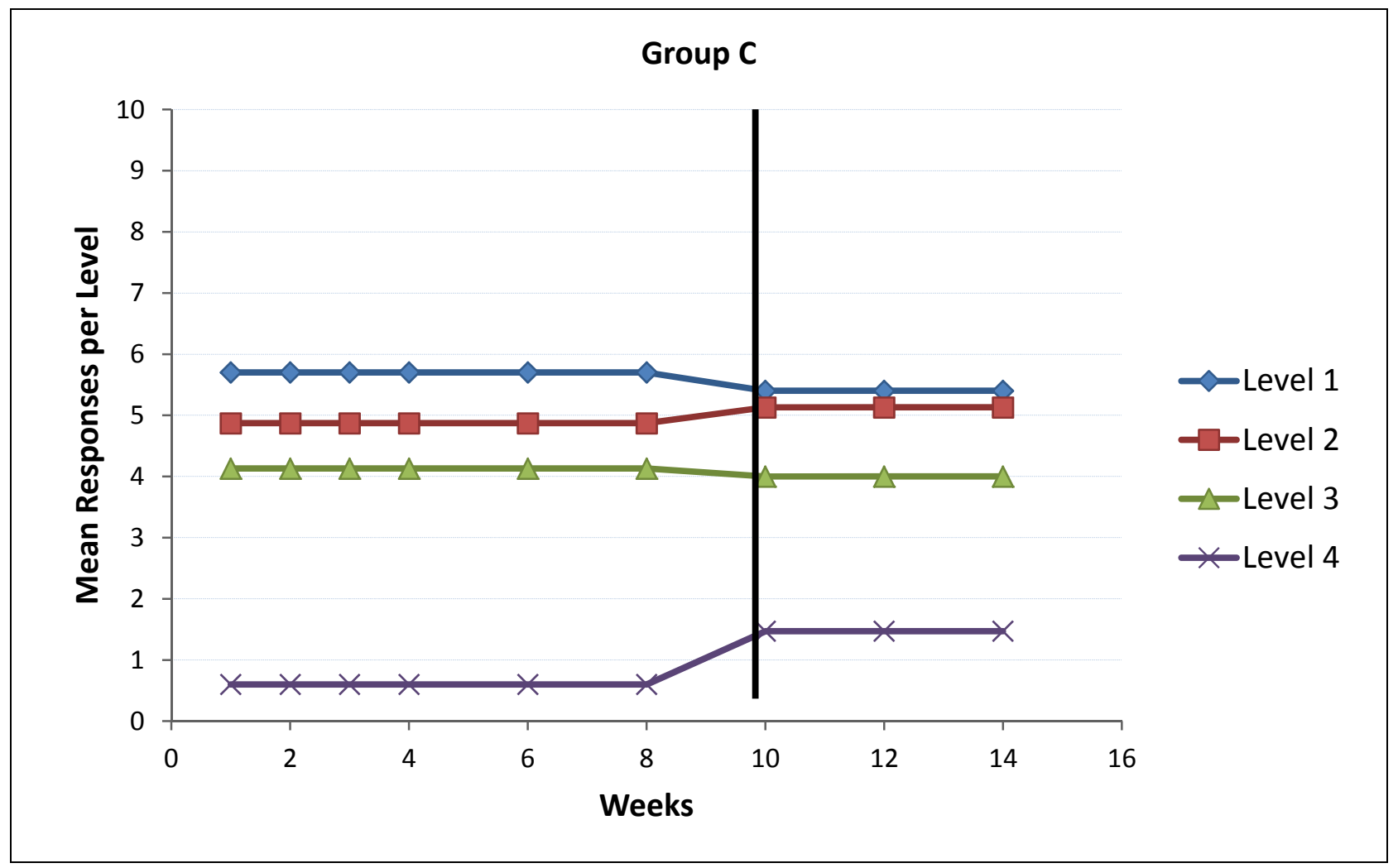

Figure 11. Group C's mean responses of each reflective level per week. 


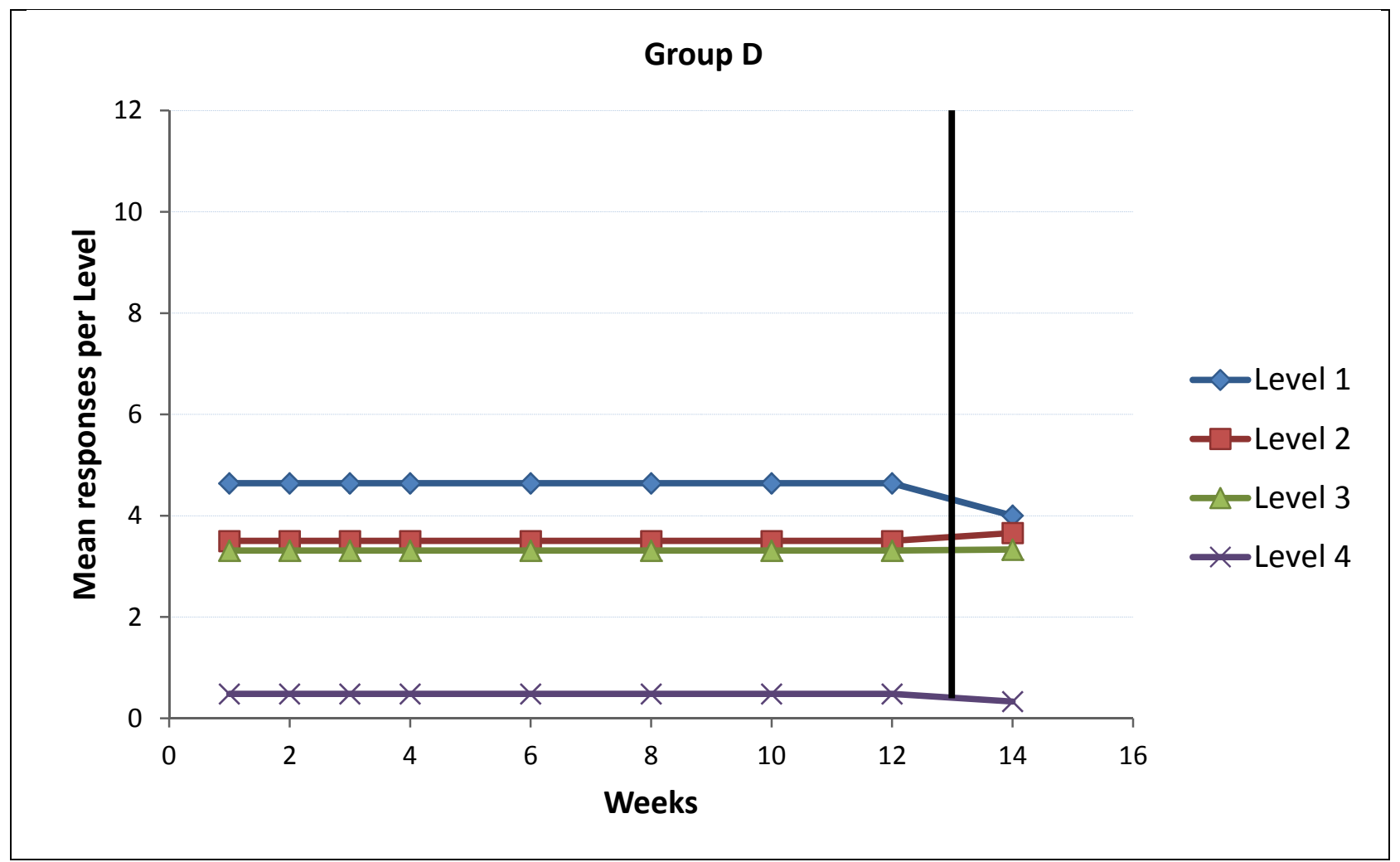

Figure 12. Group D's mean responses of each reflective level per week. 


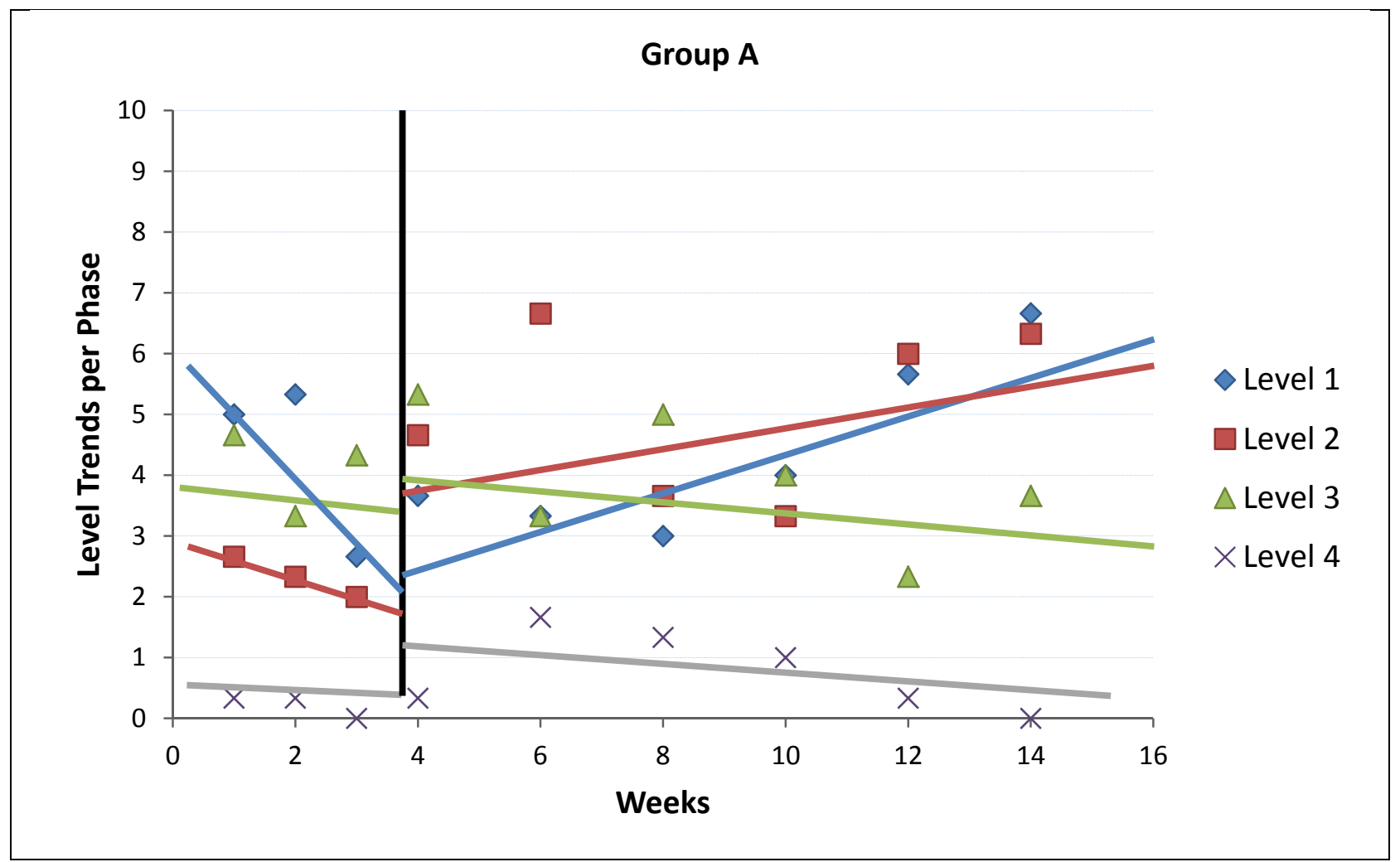

Figure 13. Group A’s trends in each reflective level per phase. 


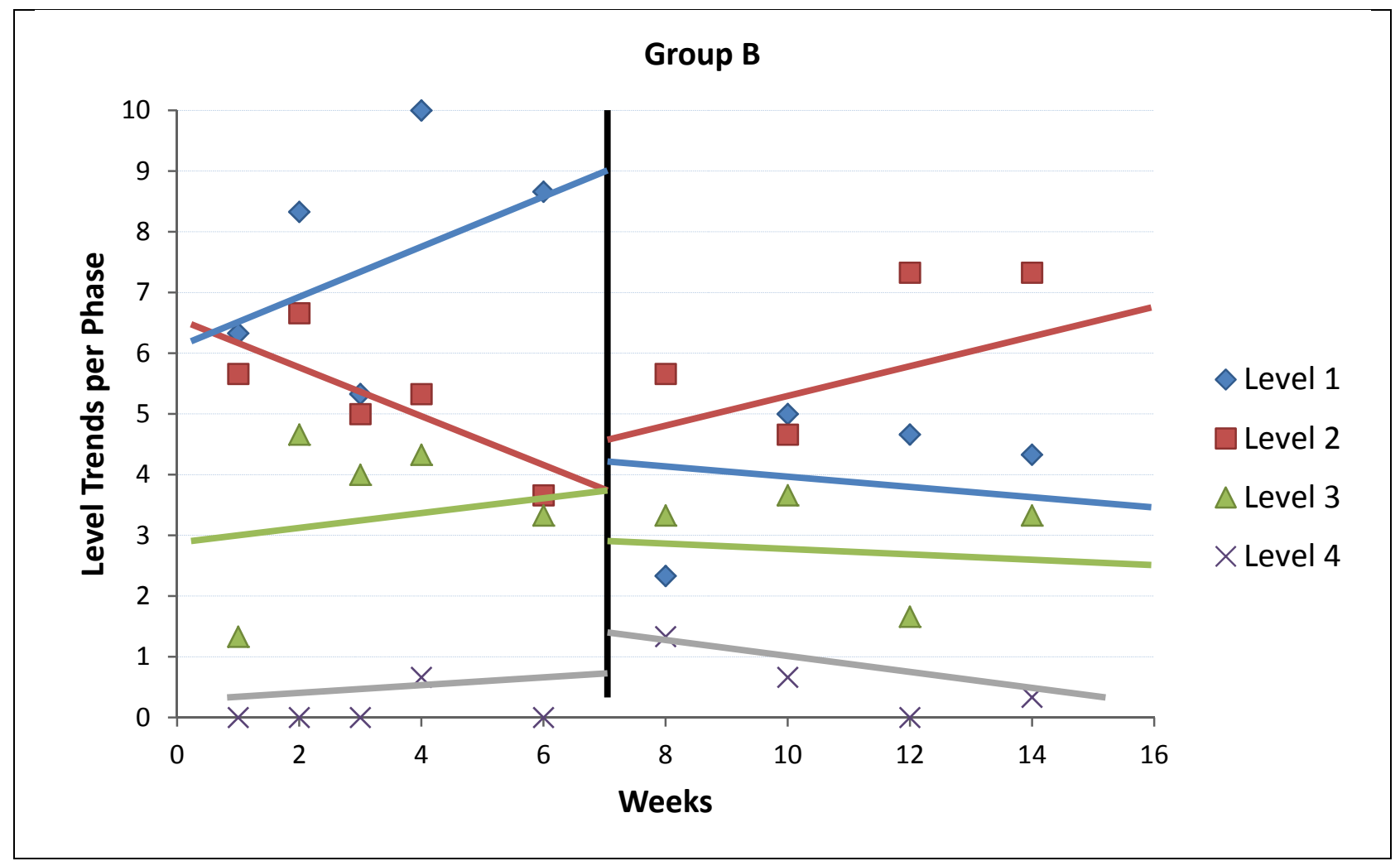

Figure 14. Group B’s trends in each reflective level per phase. 


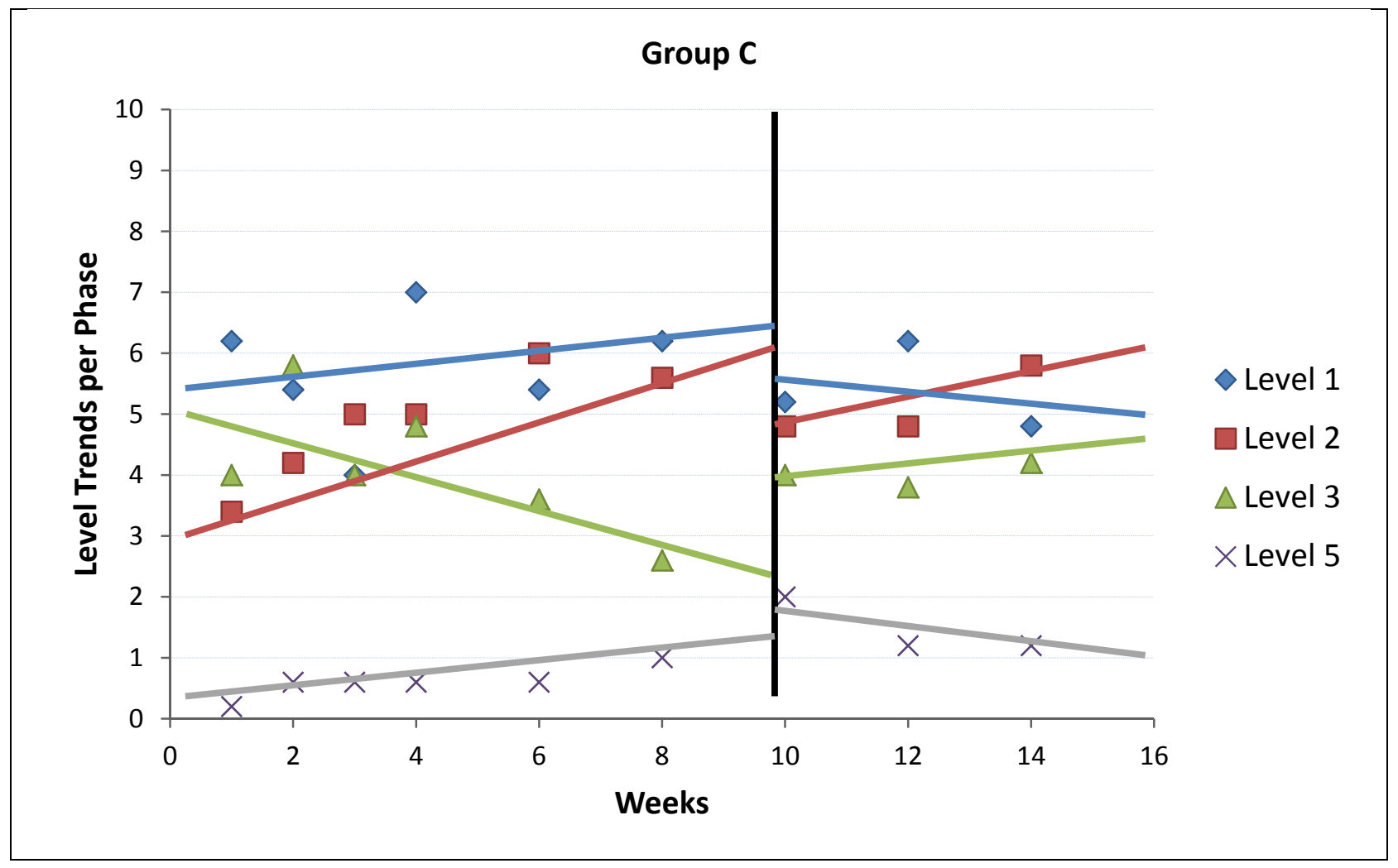

Figure 15. Group C’s trends in each reflective level per phase. 


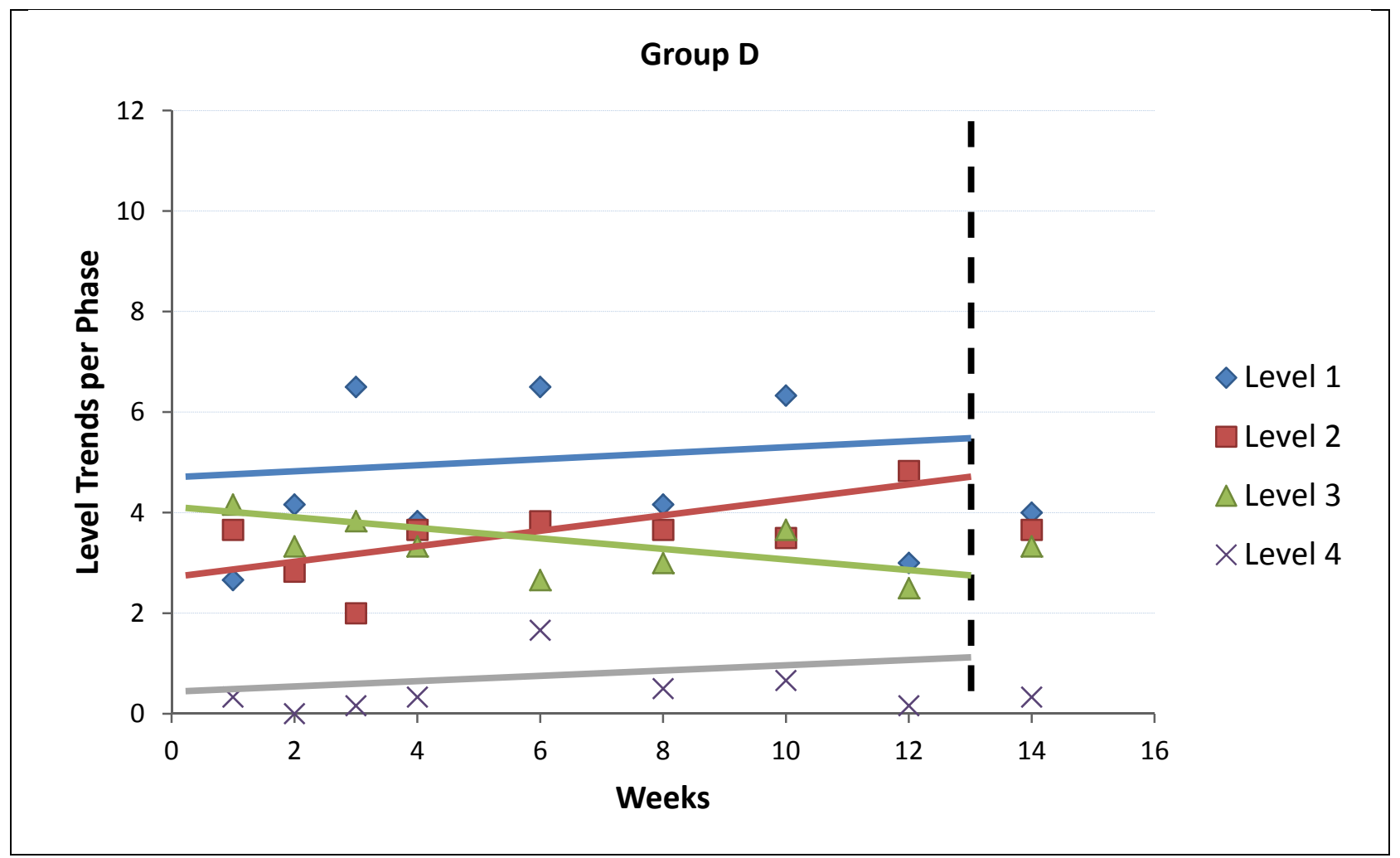

Figure 16. Group D’s trends in each reflective level per phase. 


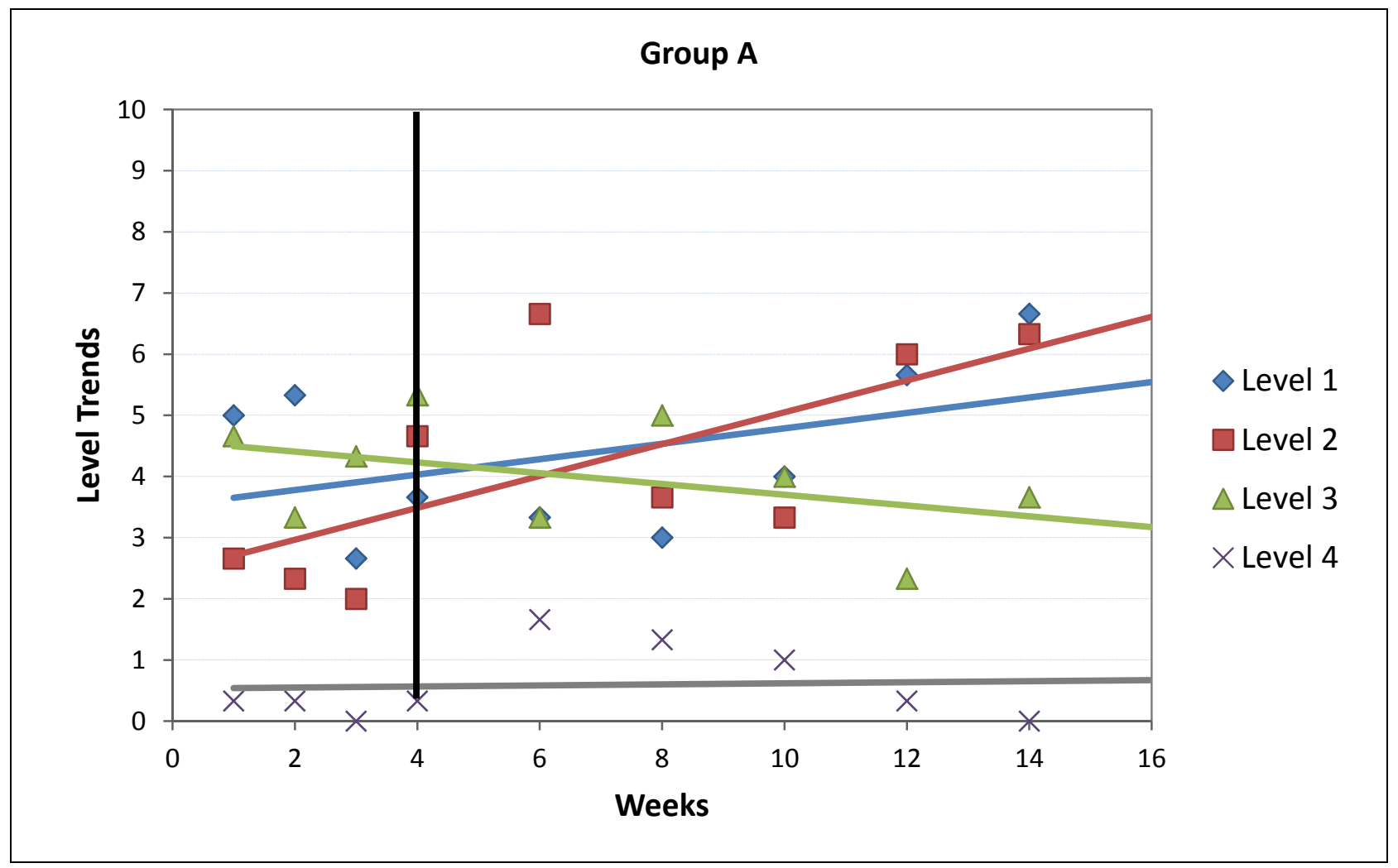

Figure 17. Group A’s overall reflective level trends in the intervention. 


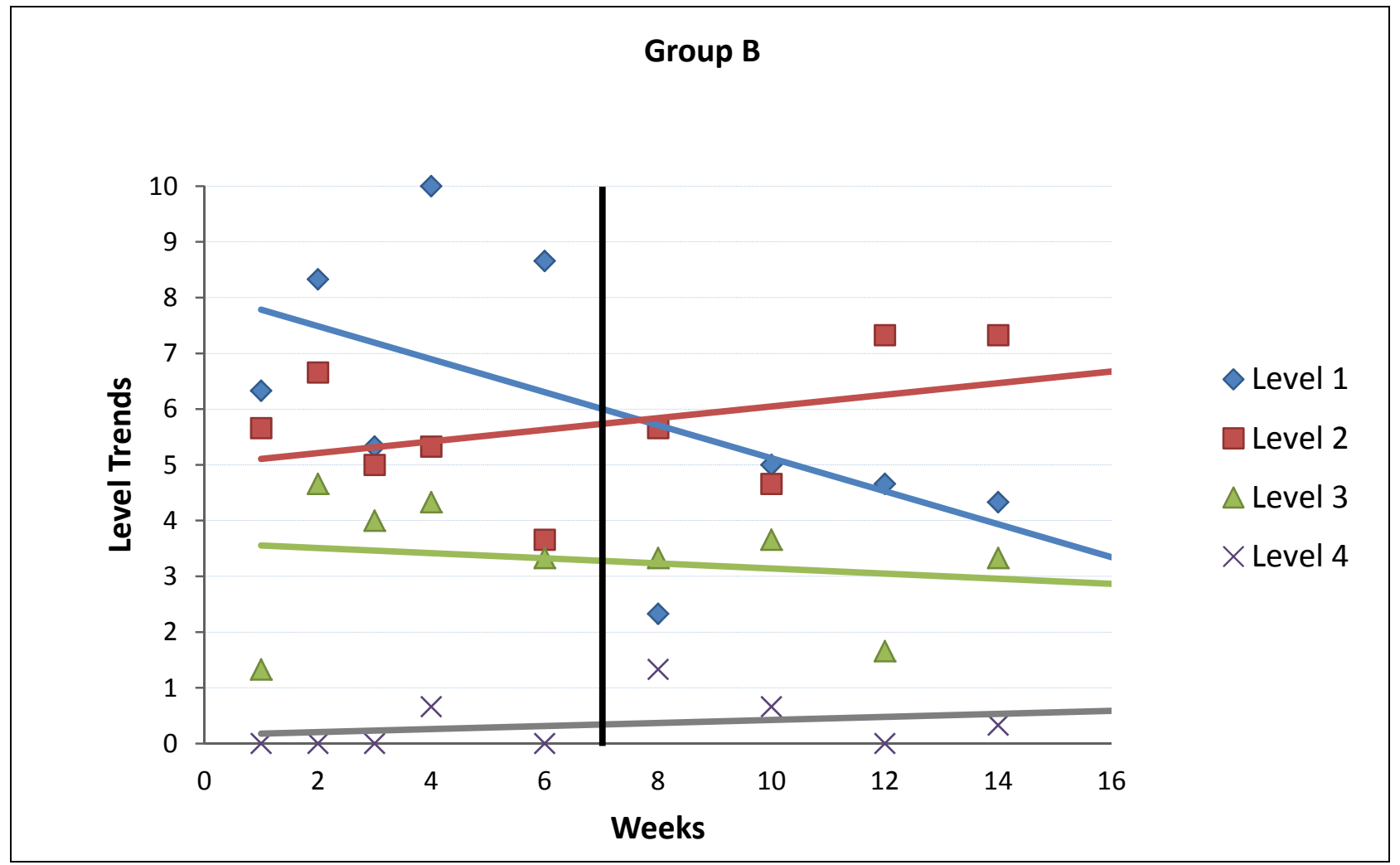

Figure 18. Group B's overall reflective level trends in the intervention. 


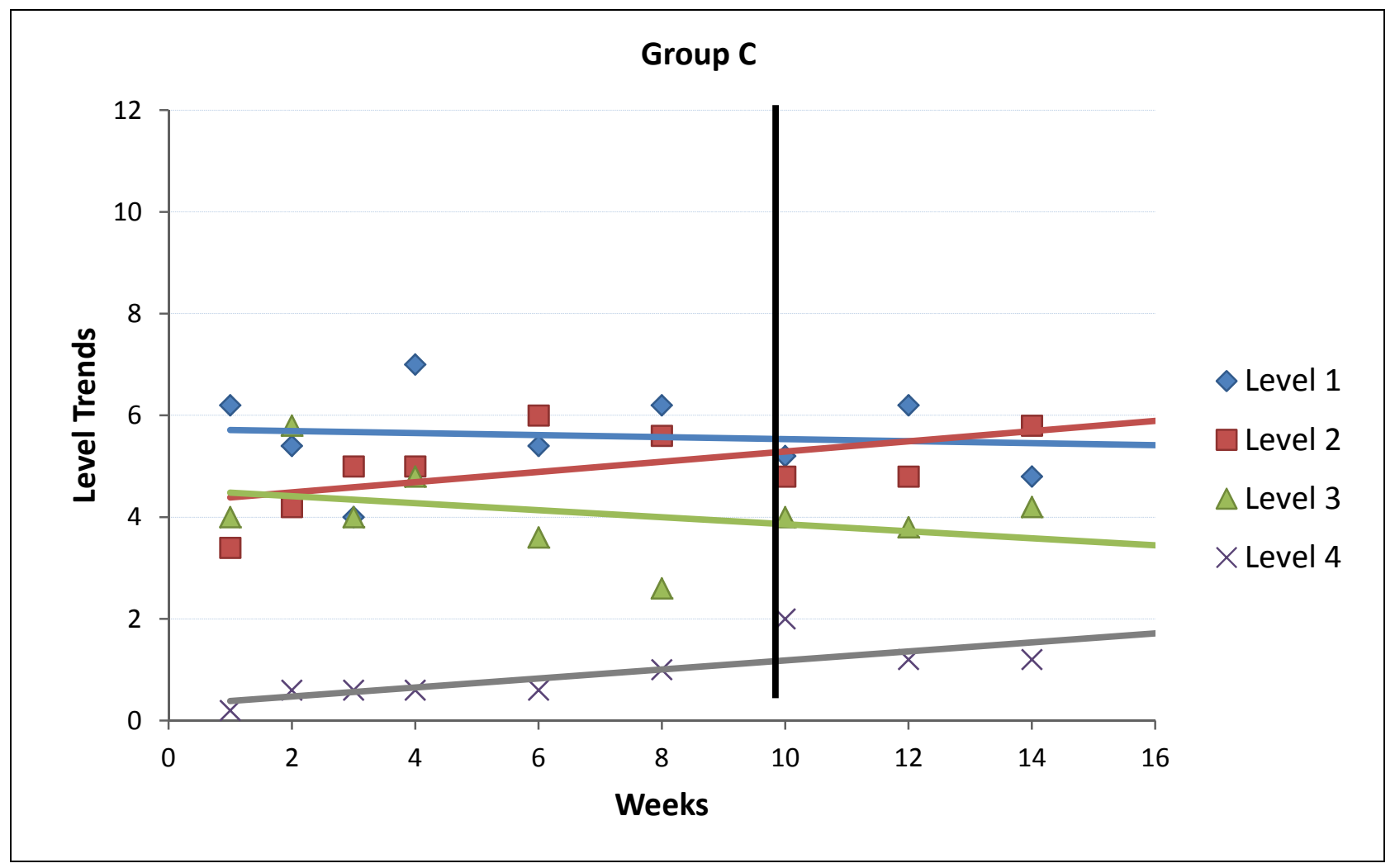

Figure 19. Group C’s overall reflective level trends in the intervention. 


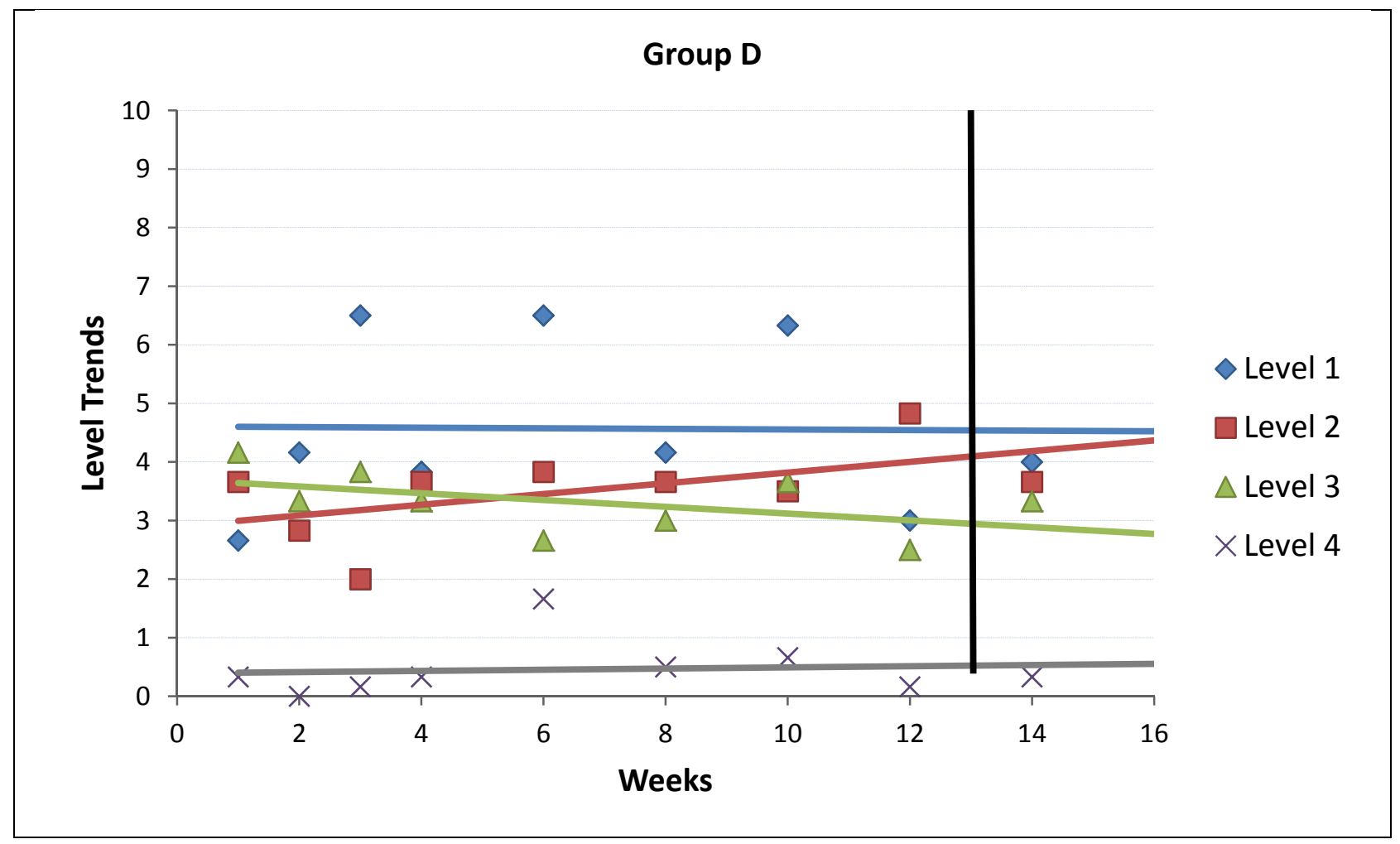

Figure 20. Group D’s overall reflective level trends in the intervention. 


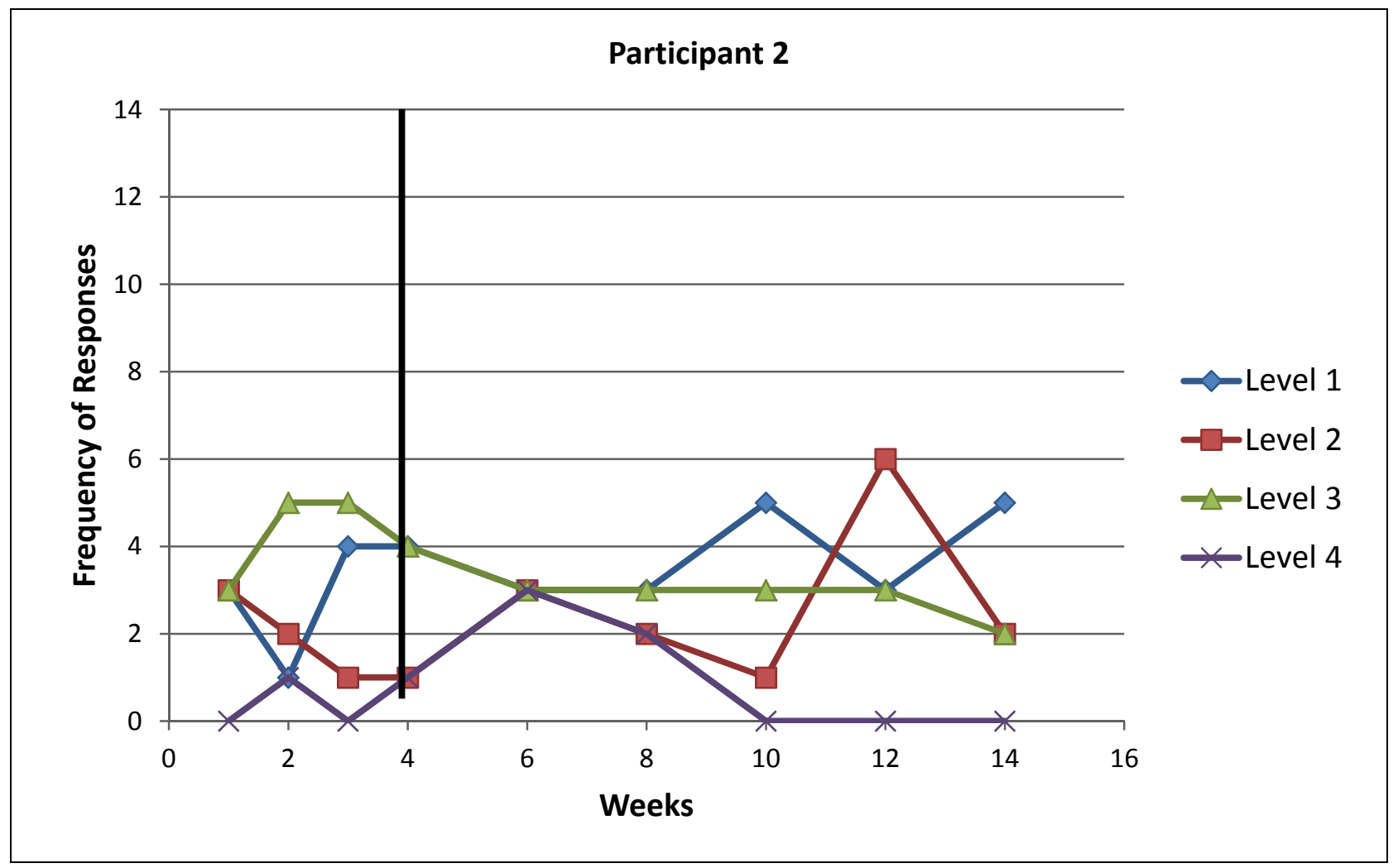

Figure 21. Participant 2’s frequencies of reflective level responses per week. 


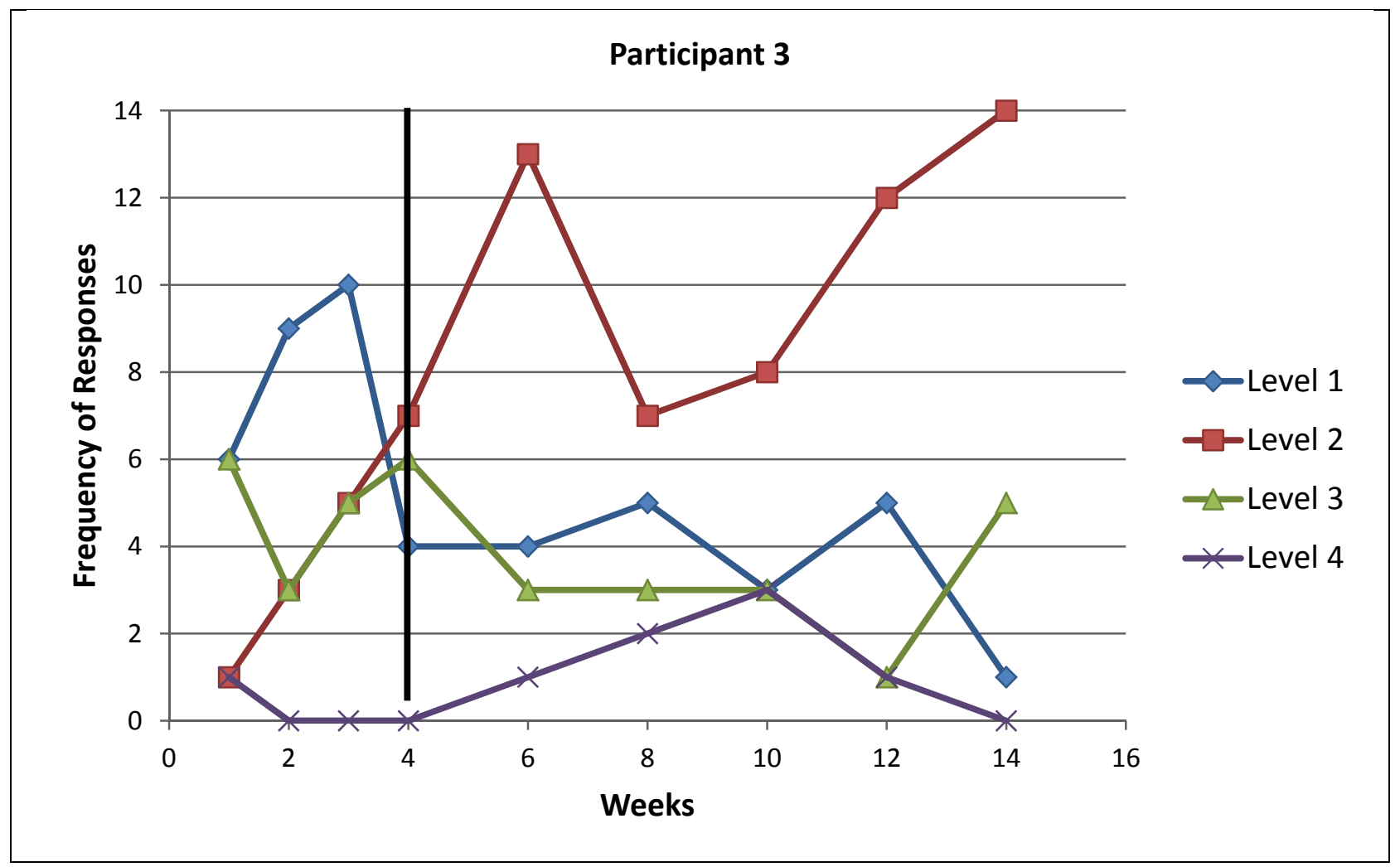

Figure 22. Participant 3’s frequencies of reflective level responses per week. 


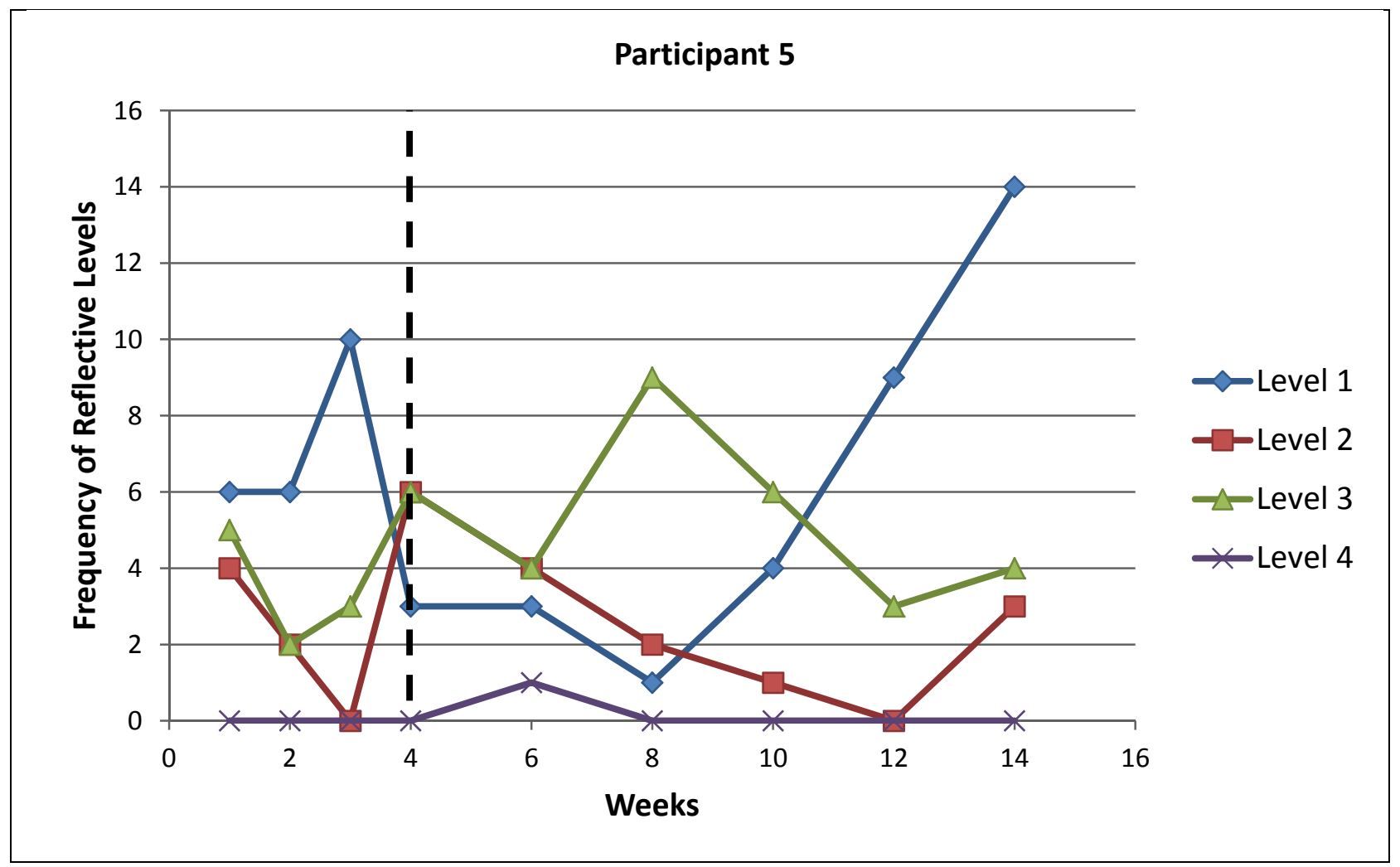

Figure 23. Participant 5’s frequencies of reflective level responses per week. 


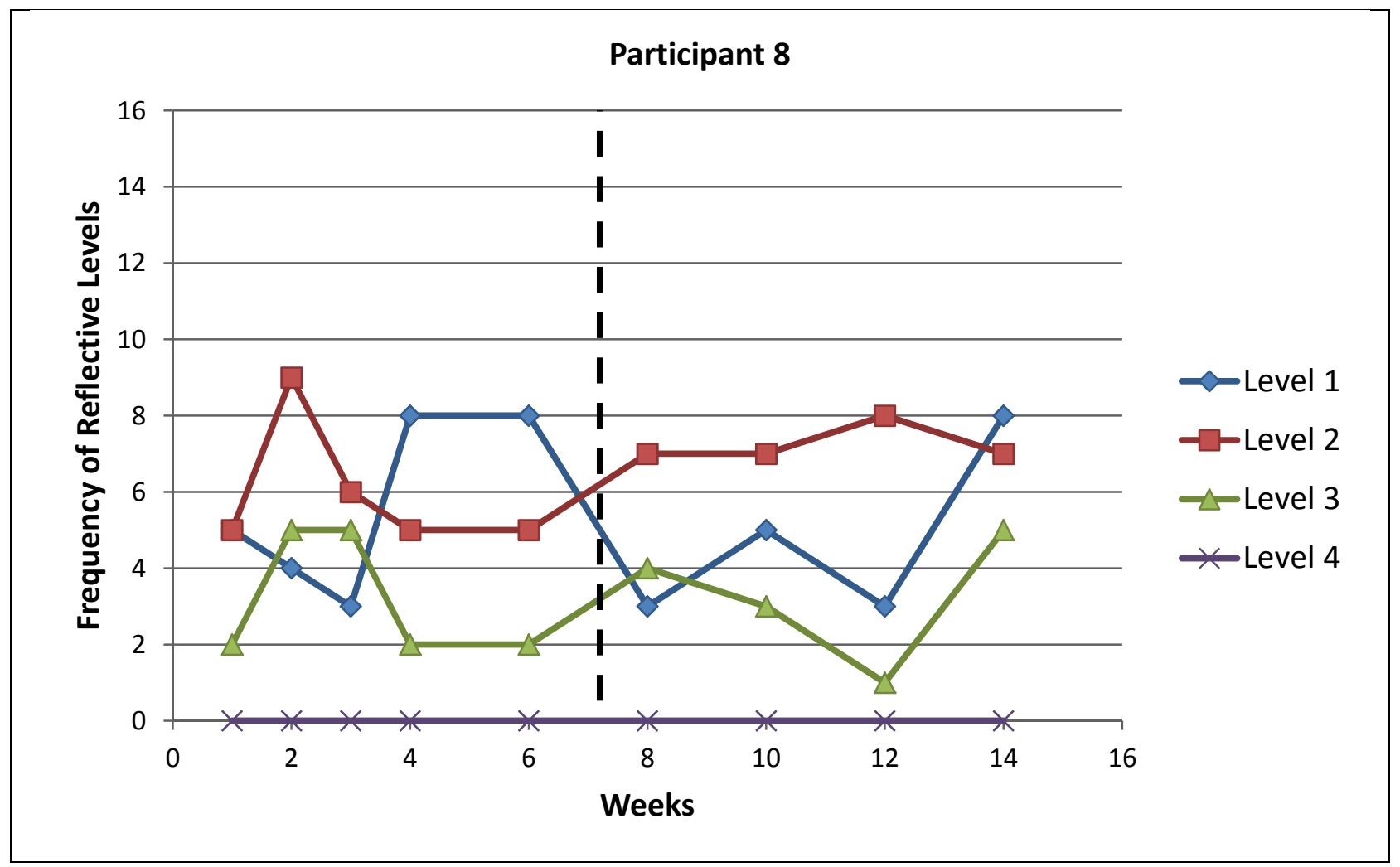

Figure 24. Participant 8’s frequencies of reflective level responses per week. 


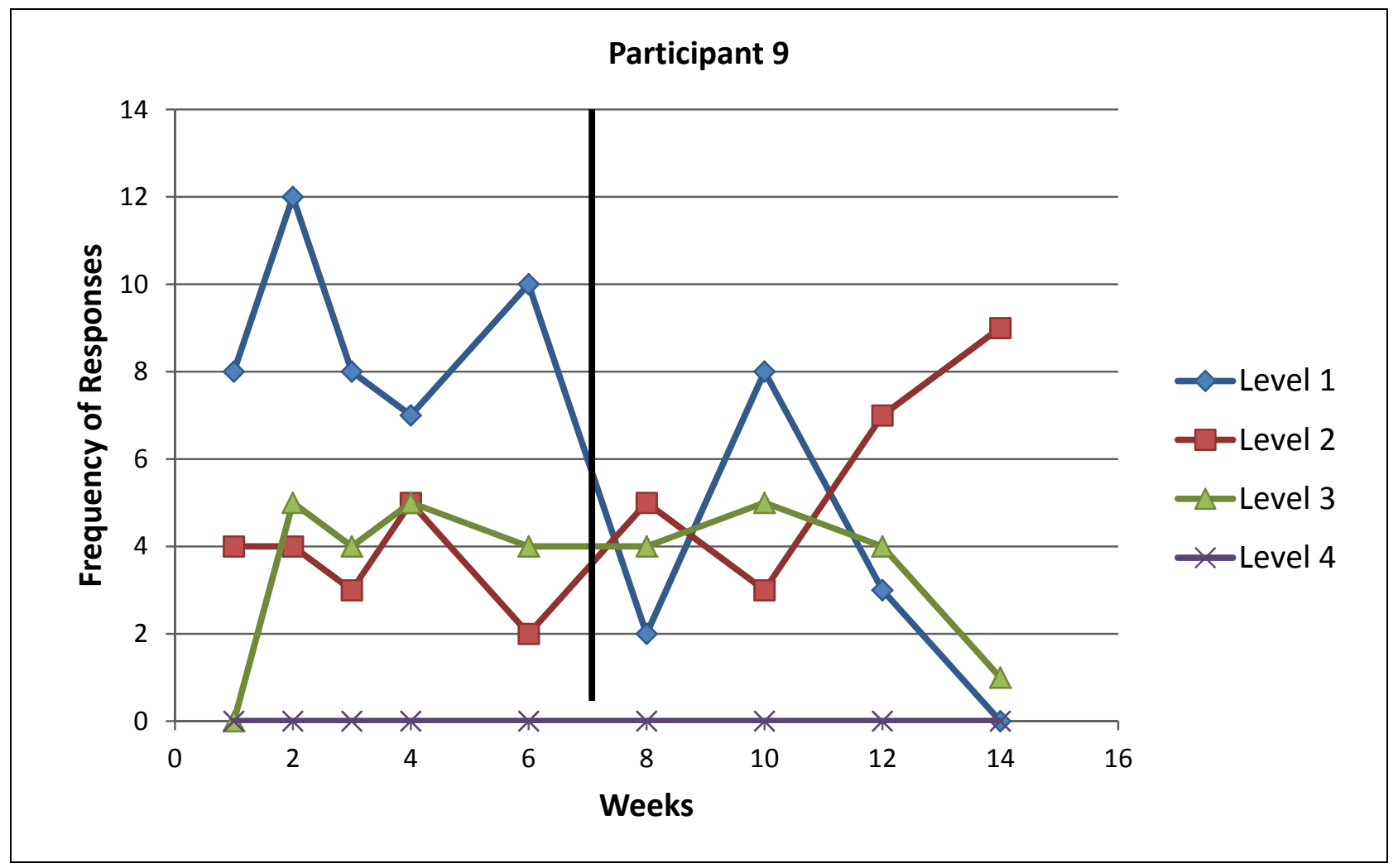

Figure 25. Participant 9's frequencies of reflective level responses per week. 


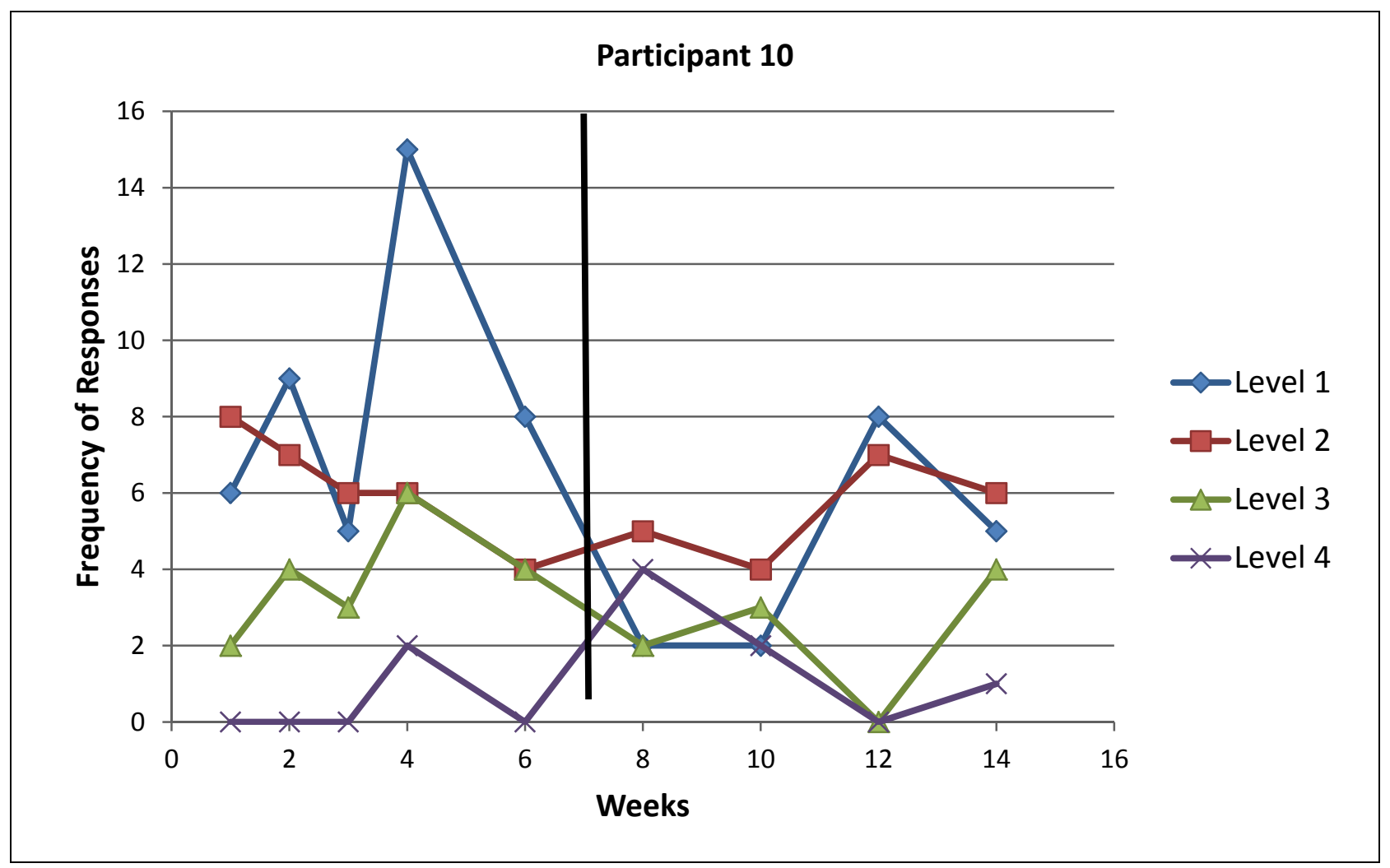

Figure 26. Participant 10’s frequencies of reflective level responses per week. 


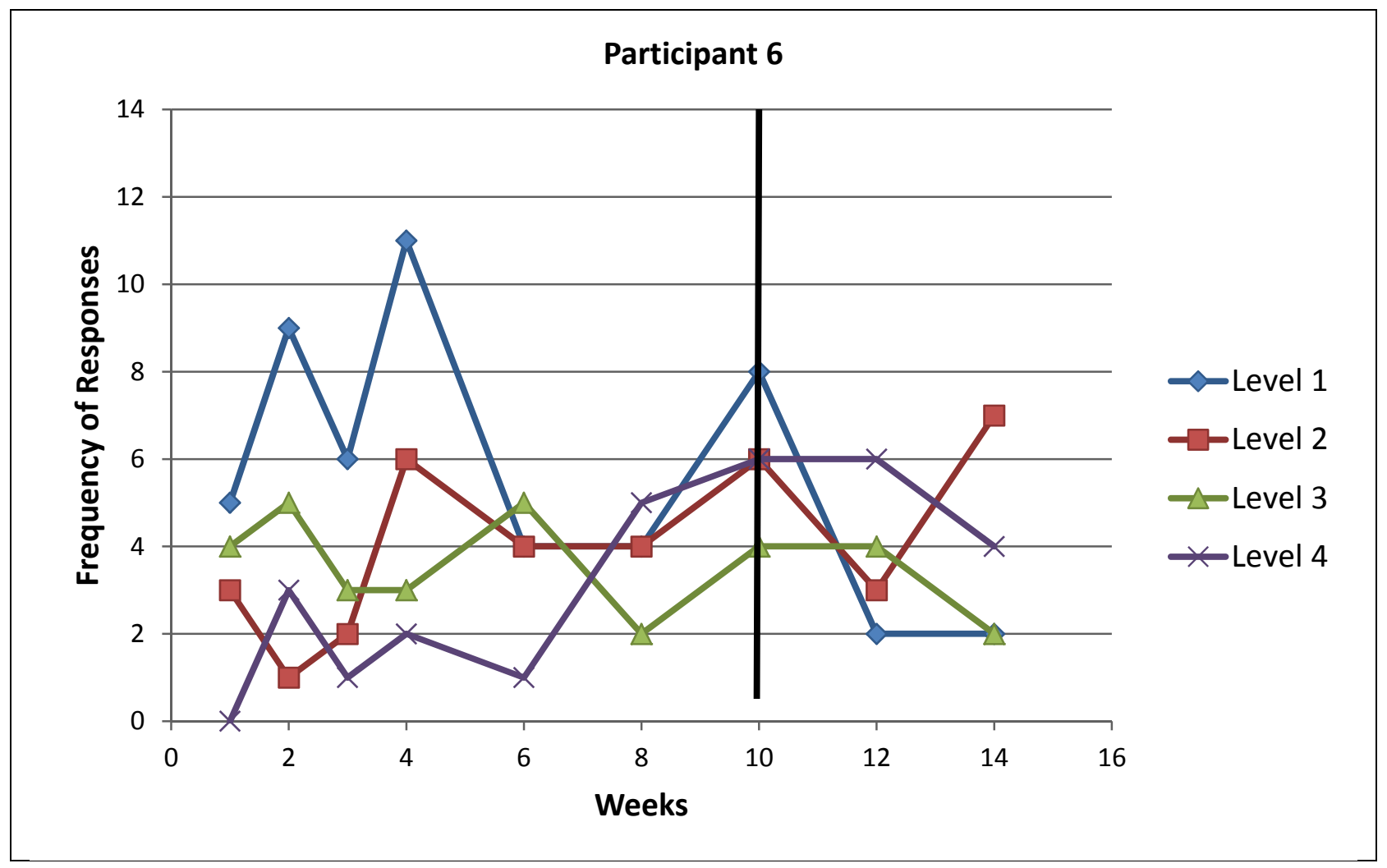

Figure 27. Participant 6’s frequencies of reflective level responses per week. 


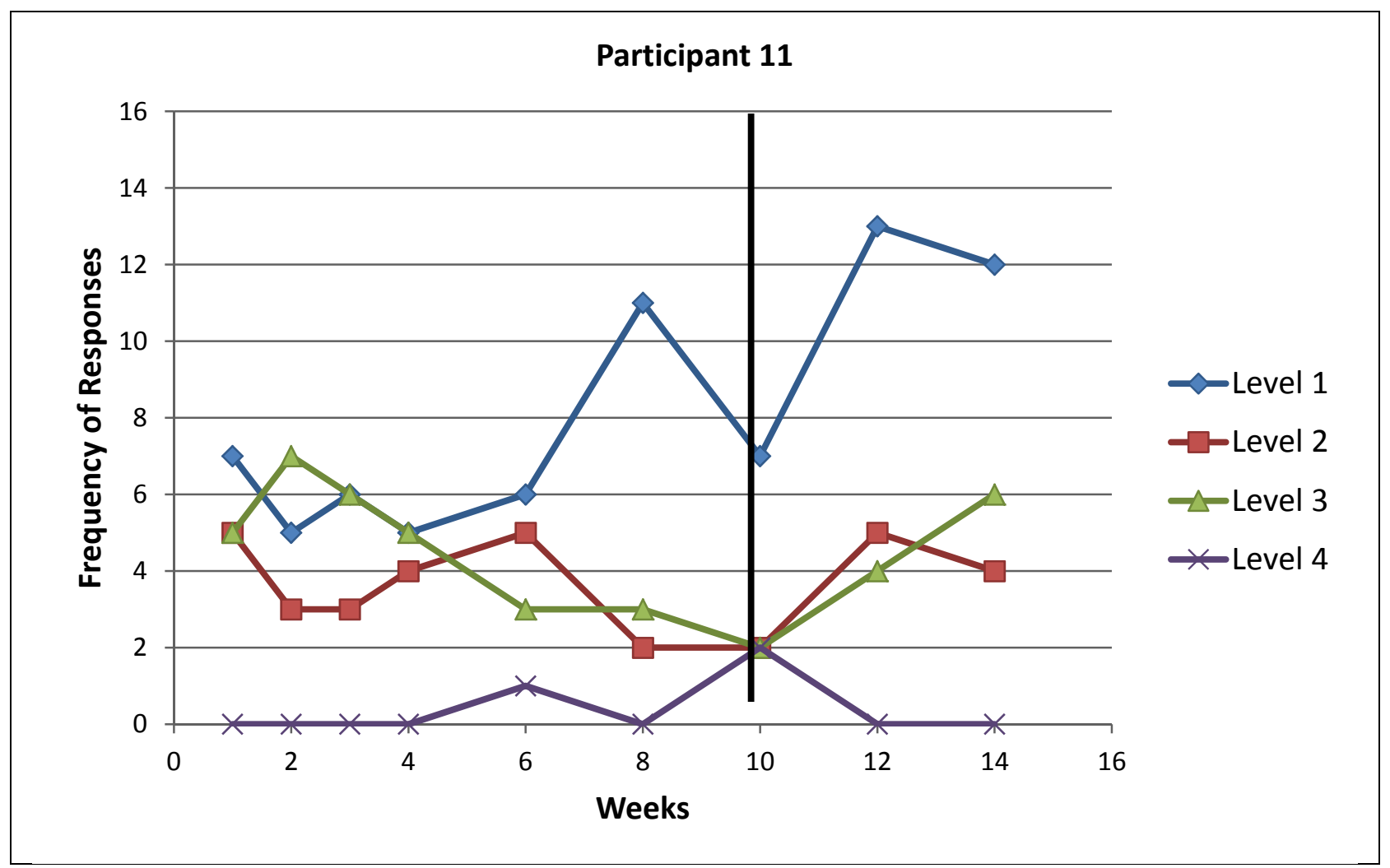

Figure 28. Participant 11's frequencies of reflective level responses per week. 


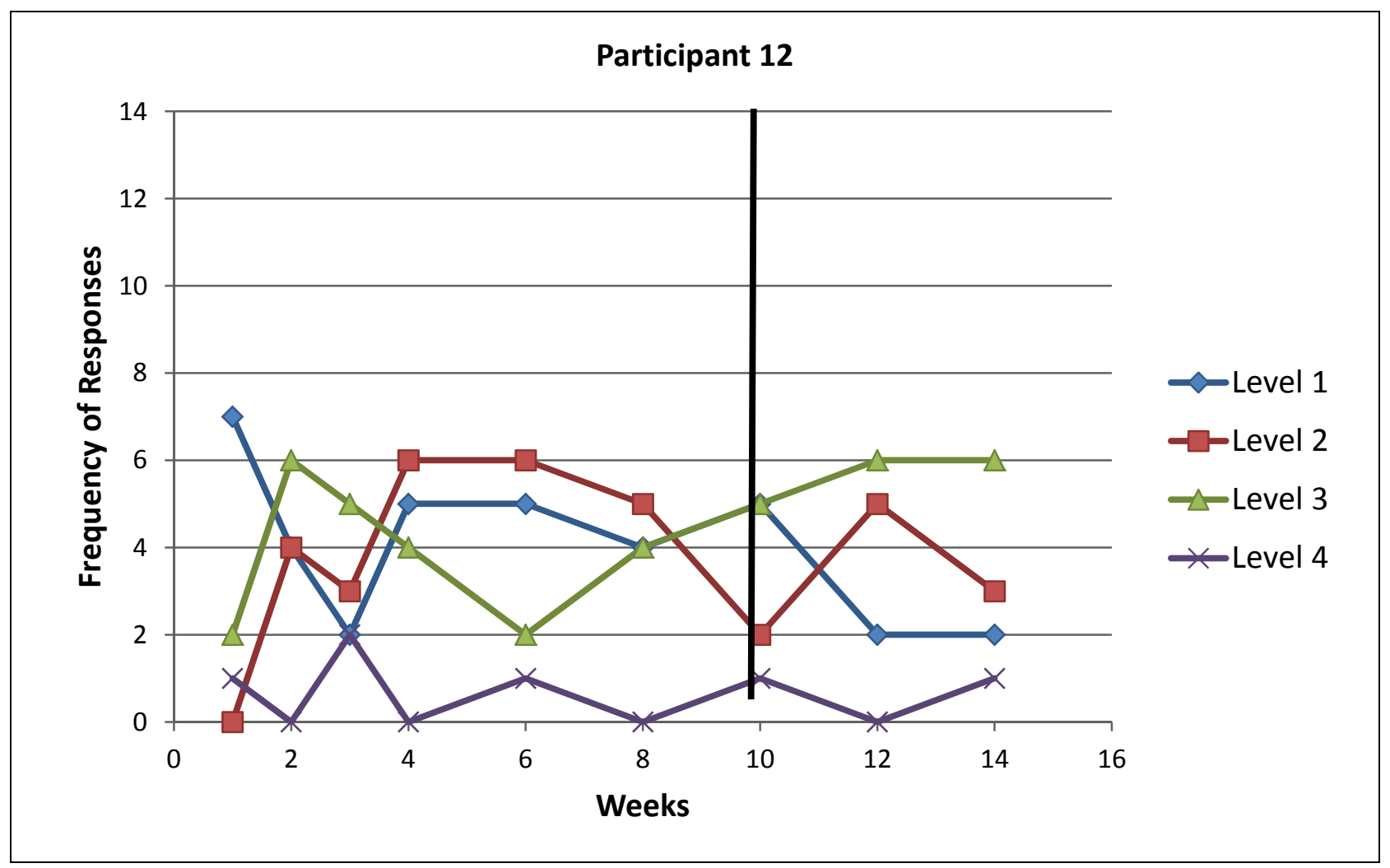

Figure 29. Participant 12’s frequencies of reflective level responses per week. 


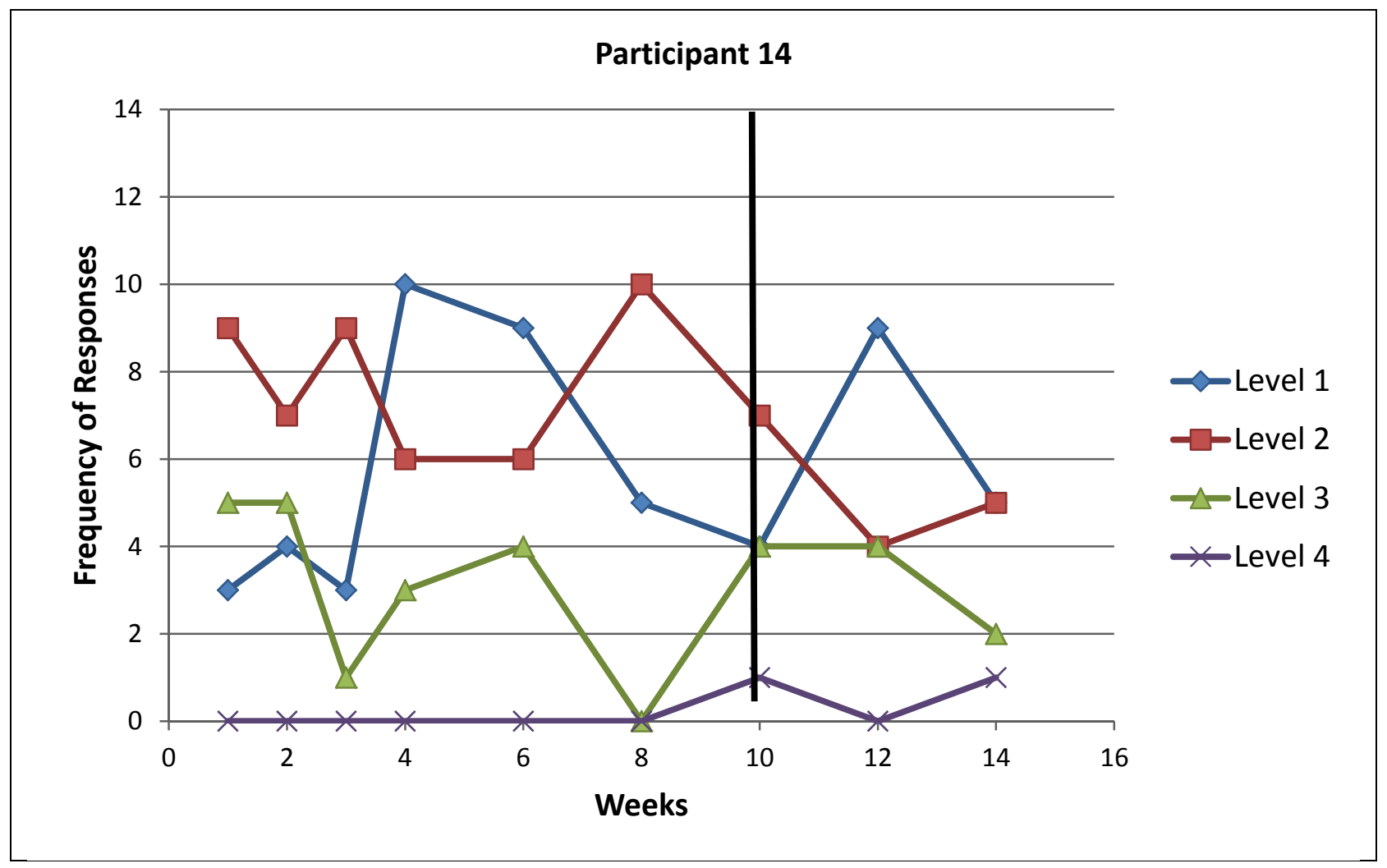

Figure 30. Participant14's frequencies of reflective level responses per week. 


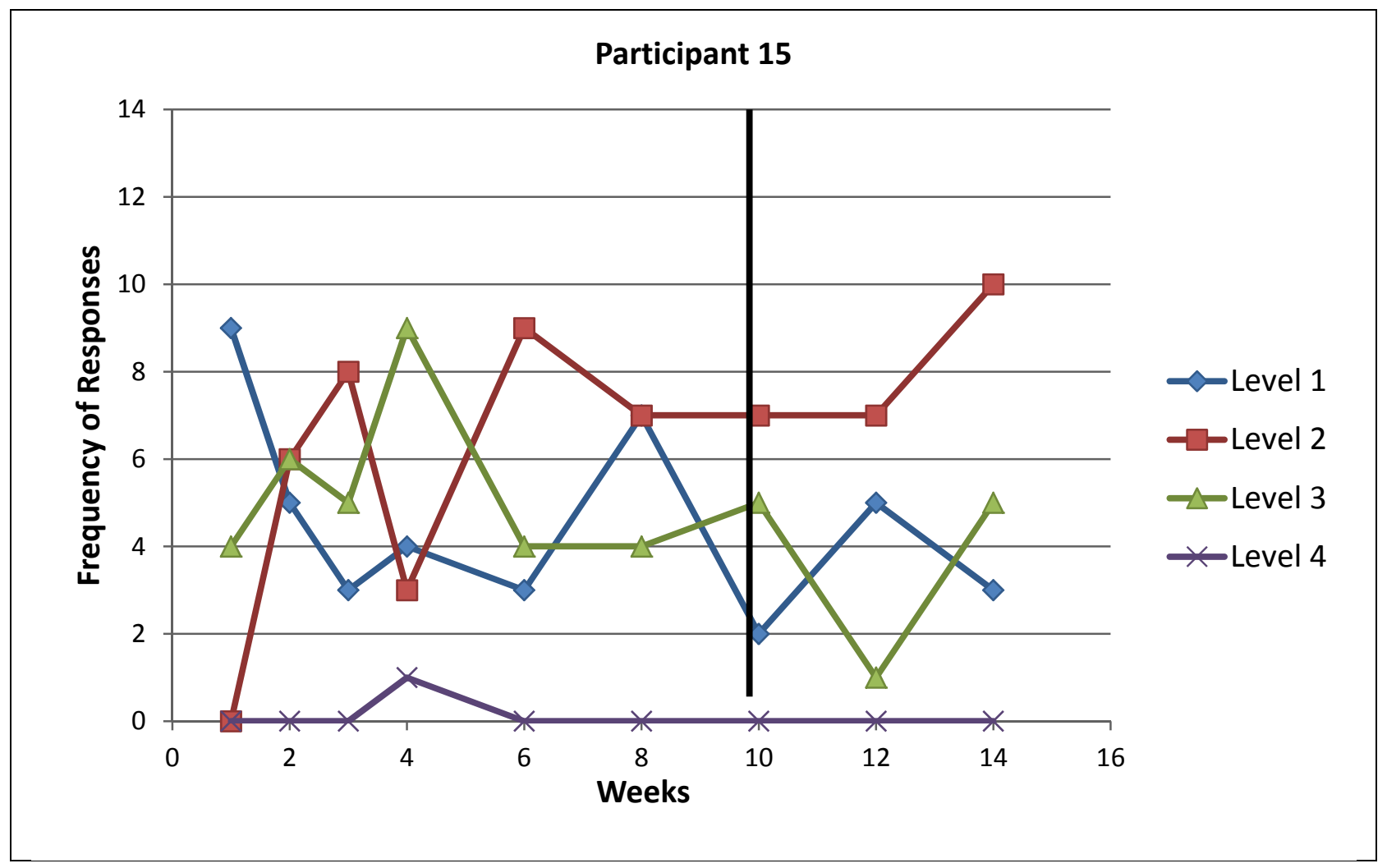

Figure 31. Participant 15's frequencies of reflective level responses per week. 


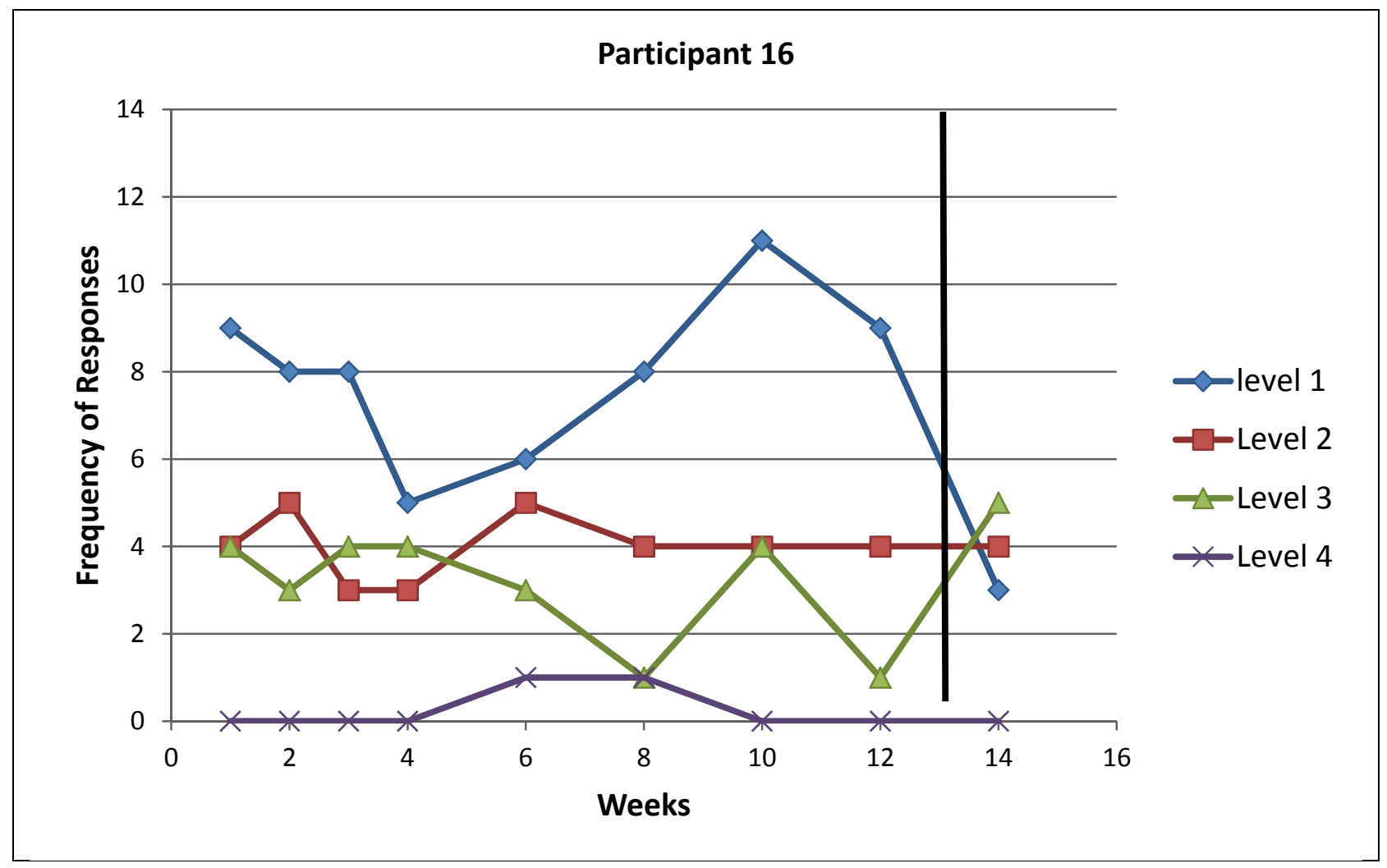

Figure 32. Participant 16’s frequencies of reflective level responses per week. 


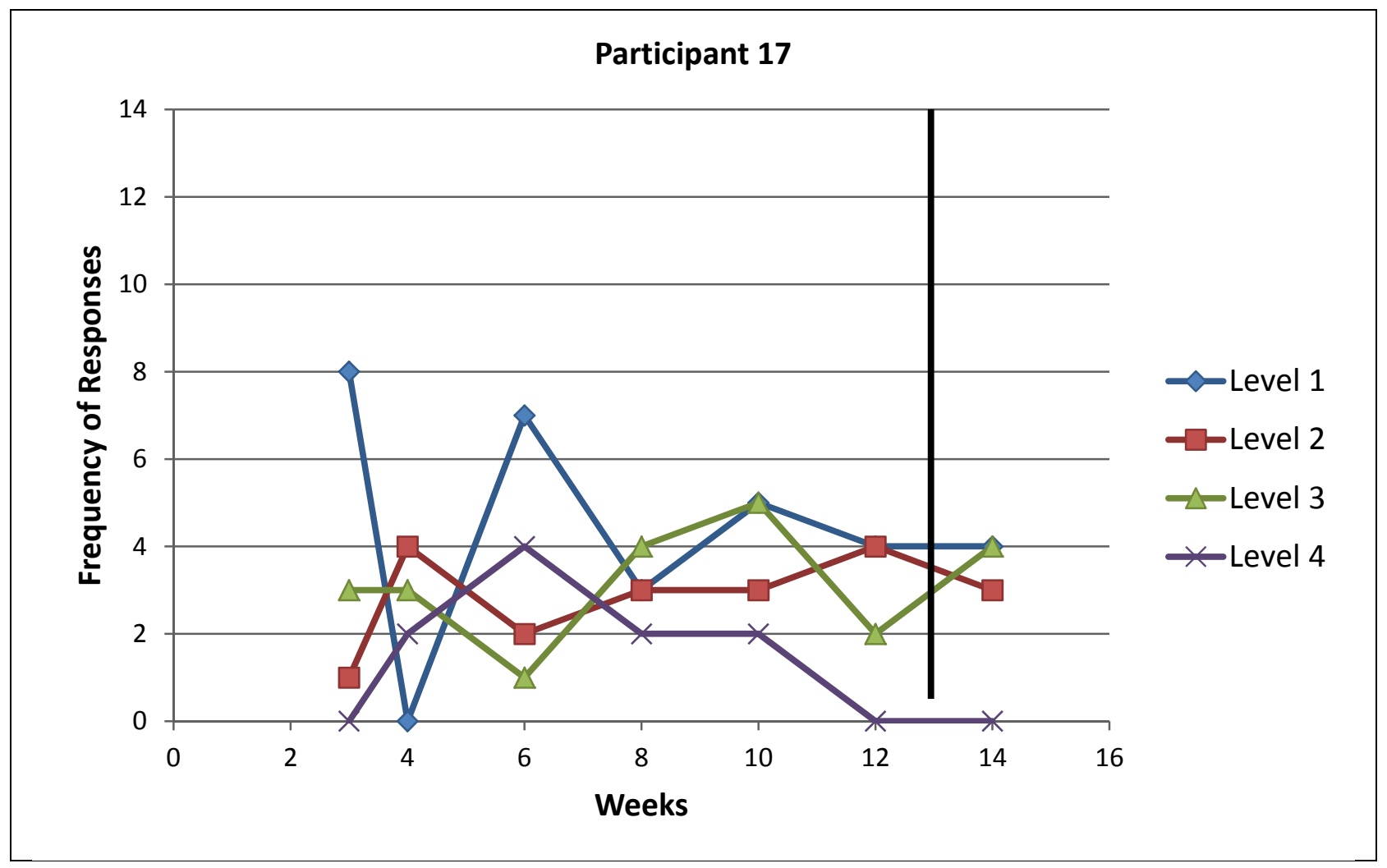

Figure 33. Participant 17’s frequencies of reflective level responses per week. 


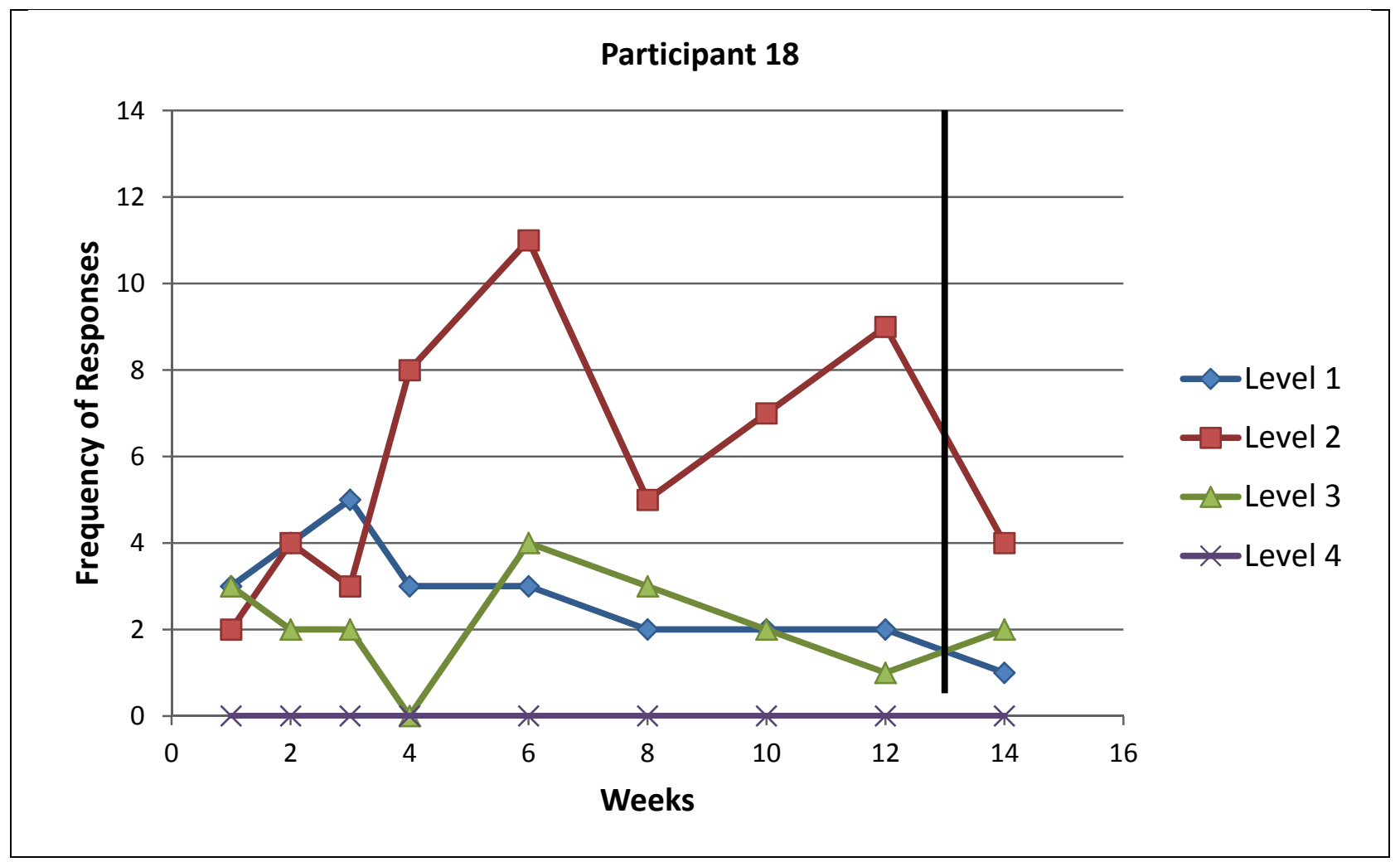

Figure 34. Participant 18’s frequencies of reflective level responses per week. 


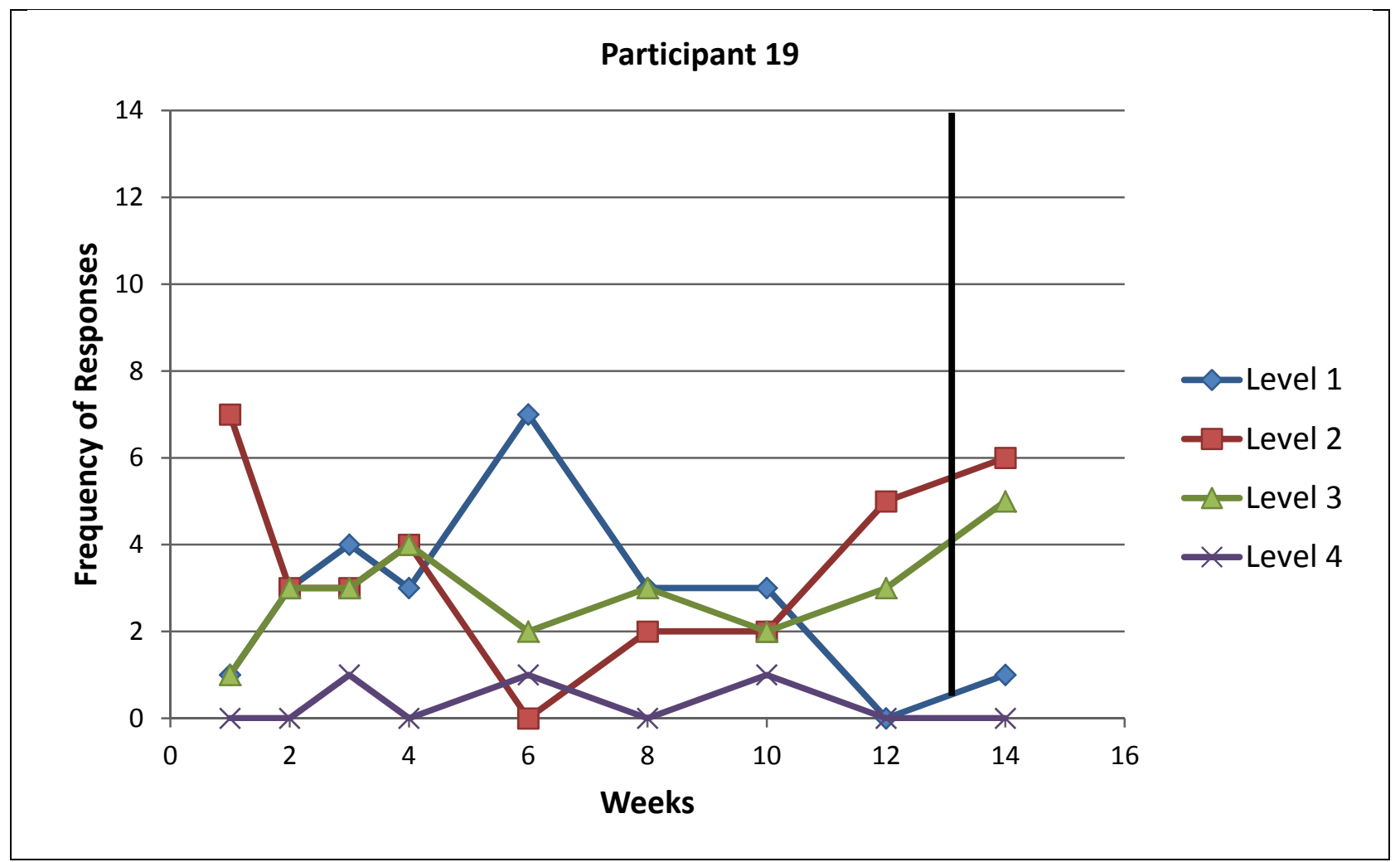

Figure 35. Participant 19’s frequencies of reflective level responses per week. 


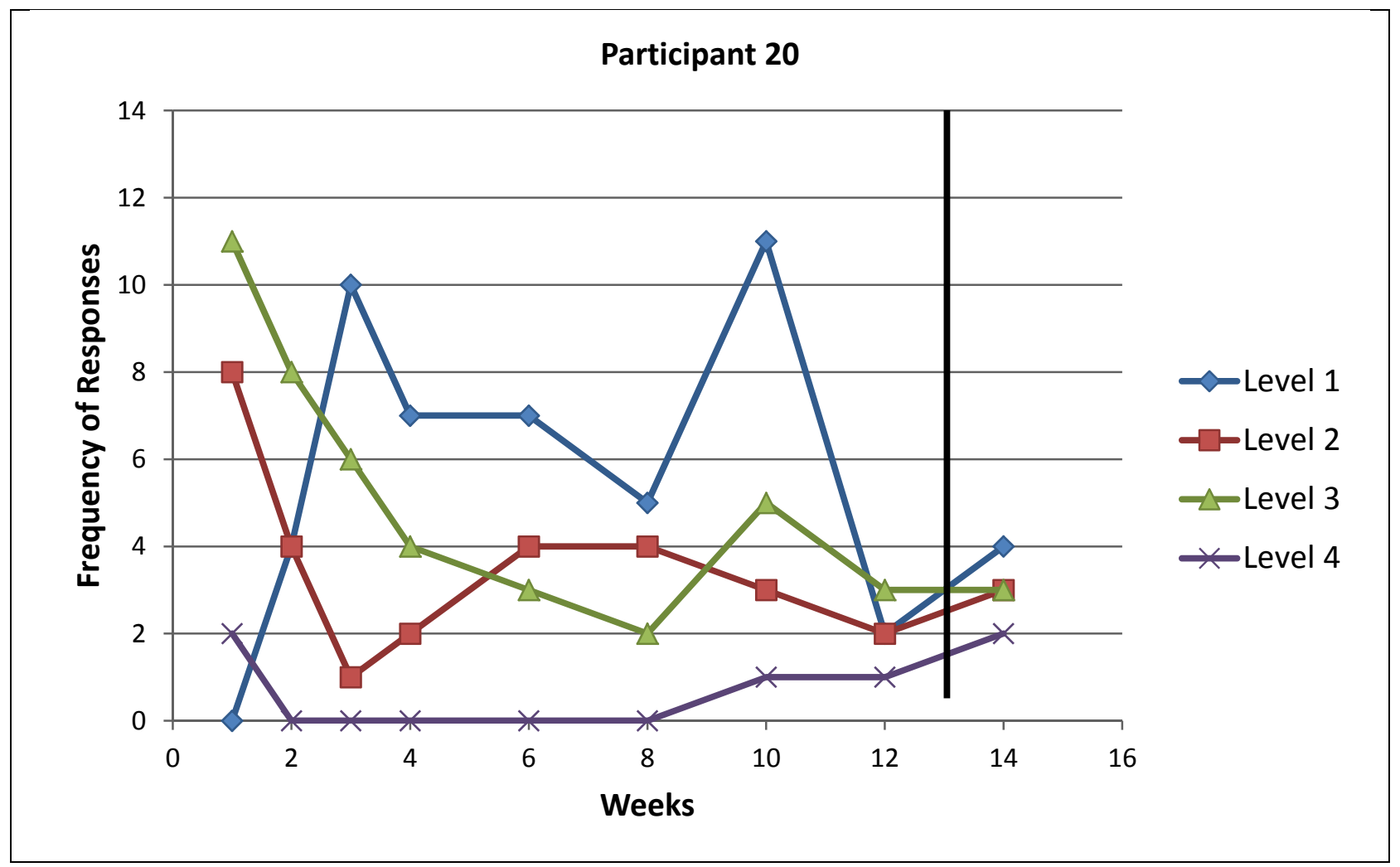

Figure 36. Participant 20’s frequencies of reflective level responses per week. 


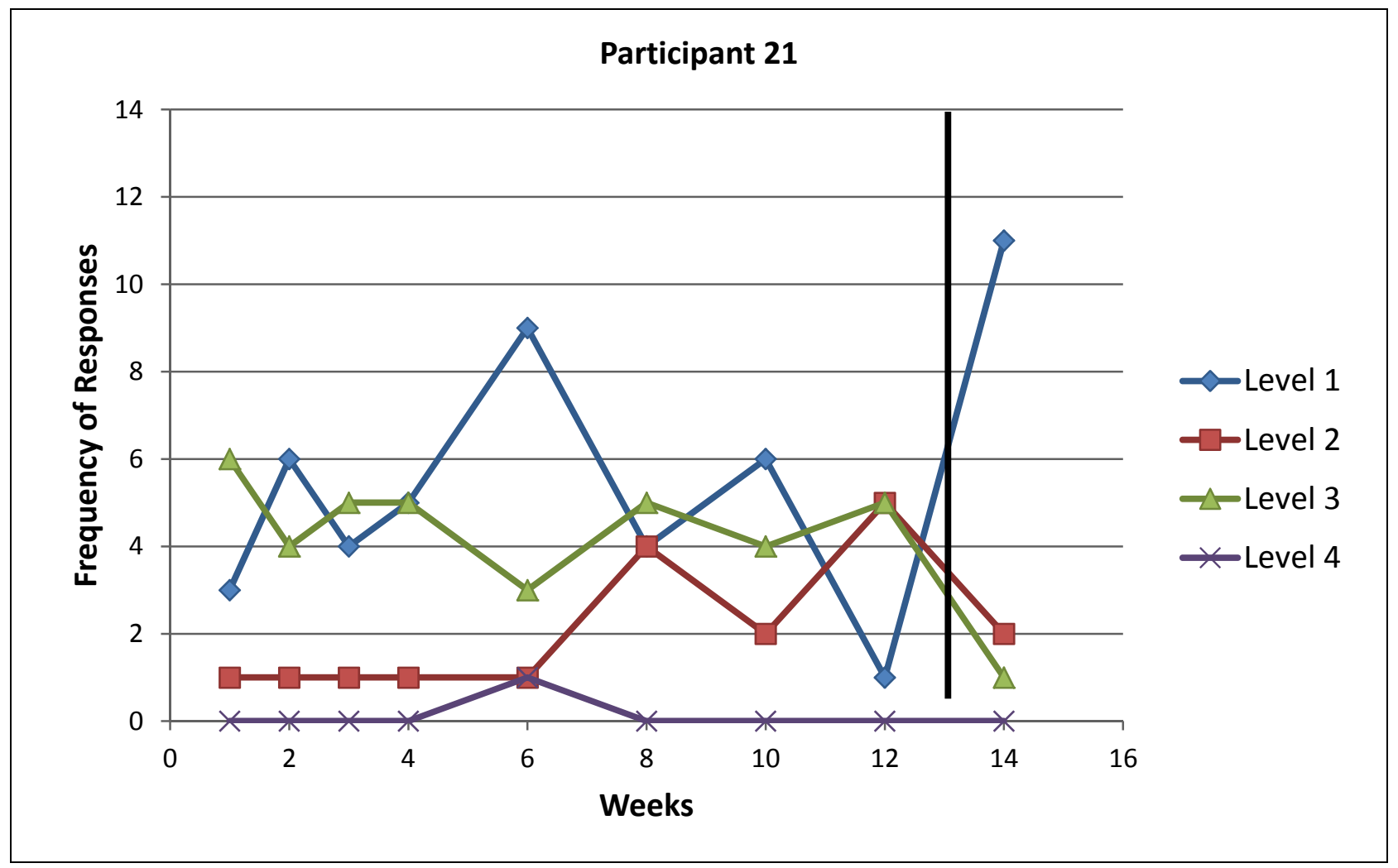

Figure 37. Participant 21's frequencies of reflective level responses per week. 